"Ya no basta con entender los fenómenos de bajo desempeño, las razones de las conductas desviantes, el estrés, la adicción al trabajo, el burnout, el tecno-estrés, el acoso psicológico, la baja motivación, entre otros. Comprender la satisfacción, compromiso, engagement, buen clima de trabajo y la felicidad laboral es una exigencia actual de la sociedad y sus empresas, consientes ahora de que la evitación y control de lo negativo tiene un impacto menor al de la gestión de lo positivo".

Esta tesis Doctoral presenta siete trabajos desarrollados por el autor alrededor de los temas de Felicidad y Optimismo en el contexto del trabajo. Los hallazgos sustentan la importancia de abordar estos temas en la organización y revelan que es posible ser más felices y optimistas.

Autor

ALEJANDRO SANÍN POSADA

Tutora

MARISA SALANOVA SORIA

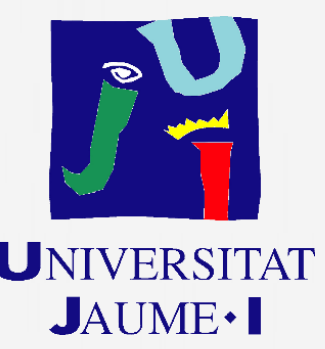


Felicidad y optimismo en el trabajo

Hallazgos de investigaciones científicas

Alejandro Sanín Posada

2017 
(C) Alejandro Sanín Posada 2017

Todos los derechos reservados. Se prohíbe la reproducción total o parcial de esta obra, por cualquier procedimiento y en cualquier medio sin la autorización expresa de su autor. 
Felicidad y optimismo en el trabajo

Hallazgos de investigaciones científicas

Alejandro Sanín Posada

Departamento de Psicología Evolutiva, Educativa, Social y Metodología

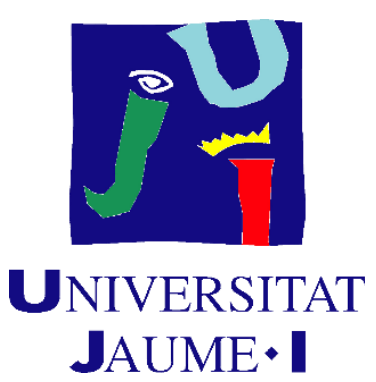

Enero de 2017

Directora

Dra. Marisa Salanova Soria 
La investigación fue financiada con recursos propios y con los aportados por el Centro de Investigación en Comportamiento Organizacional CINCEL (Colombia), la estancia doctoral con una beca ofrecida por la Agencia Chilena de Cooperación Internacional para el Desarrollo AGCID, en el marco de la Alianza de Pacifico y el trabajo cuyo producto fue el Capítulo 6 fue cofinanciado por Cincel y por la Universidad de Antioquia (Colombia). 


\section{Felicidad y optimismo en el trabajo Hallazgos de investigaciones científicas}

\section{Contenido}

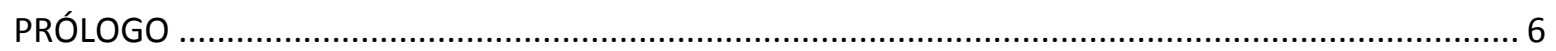

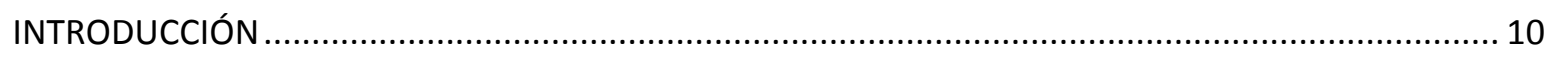

Capítulo 1. Felicidad Laboral. Reflexiones sobre la investigación en su aplicación al contexto del trabajo

Capítulo 2. Adaptación del Authentic Happiness Inventory (AHI) para población trabajadora

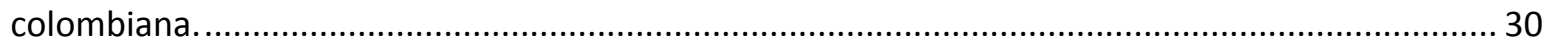

Capítulo 3. Verificación de las condiciones psicométricas del Test de Orientación en la Vida (LOT-R) sobre Optimismo Disposicional, aplicado en población trabajadora Colombiana. .......................... 38

Capítulo 4. Satisfacción laboral: el camino entre el crecimiento psicológico y el desempeño laboral en empresas colombianas industriales y de servicios............................................................. 47

Capítulo 5. Satisfacción con la Vida: El rol de la Felicidad en el Trabajo y la Vida............................ 60

Capítulo 6. Los efectos del tipo de contrato laboral sobre la felicidad en el trabajo, el optimismo y

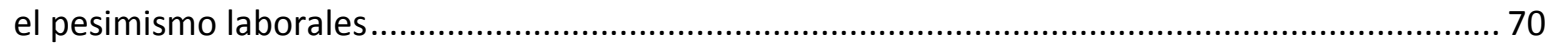

Capítulo 7. Happiness and optimism interventions at work: Gender differences........................... 84

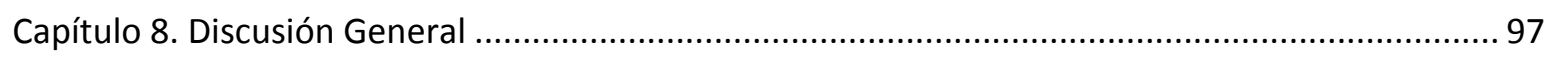

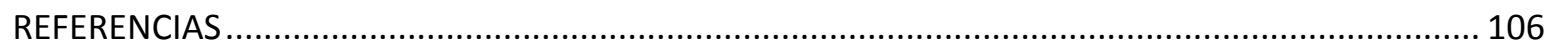

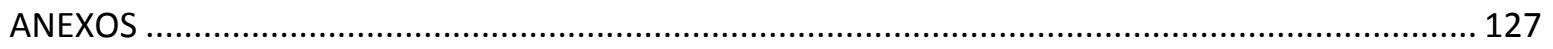

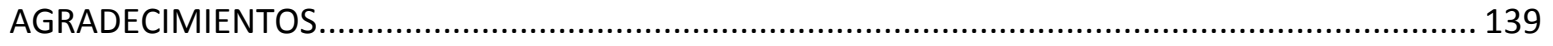




\section{PRÓLOGO}

¿Qué por qué estudié un doctorado y la felicidad en el trabajo? Son muchos años dedicados a lo mismo y tanto esmero e interés deben tener una razón. El doctorado no estaba dentro de mis planes, al menos no en los de corto plazo. Sin embargo, si está leyendo esto es porque algo cambió. Permítame contarle brevemente qué, antes de que empiece con la lectura del resto del trabajo.

En 2010 mi esposa, que en esa época era mi novia, decidió que quería estudiar una maestría. Yo había terminado una especialización hacía un año y estaba listo para sumergirme de nuevo en la academia, así que le dije que haría lo mismo. Ella buscó varias opciones; los horarios y lugares que encontró eran perfectos. Sin embargo, en su lugar de trabajo le dijeron que era difícil concederle permiso para salir más temprano. Ella solo necesitaba 30 minutos tres días a la semana, los cuáles propuso recuperar llegando más temprano o extendiendo su jornada de trabajo. La negativa se mantuvo. Así que con su característica firmeza dijo "Renuncio a mi trabajo. Y ya que no tengo ataduras, aprovecho y me voy a estudiar a otro país" por supuesto ella sabía que si elegía bien podía resultarle más barato.

Yo, por mi parte, estaba feliz con mi trabajo. Tenía autonomía, le encontraba sentido a lo que hacía, podía aplicar mis fortalezas características. Disfrutaba de la cotidianidad y retos que me ofrecía. Por eso su decisión casi me cuesta una arteria. Sabía que solo bastaba con que ella lo hubiera verbalizado para que su deseo se convertía en un hecho. Me vi entonces ante la triste perspectiva de mantener una relación a larga distancia. Seguir en mi país y en mi trabajo era muy importante para mí, y estaba dispuesto a llevar con valentía y esfuerzo el peso de una relación con esas características.

Cuando ya en mi mente tenía todo organizado para sobrellevar el asunto, se lo presenté. Le comenté los principales aspectos que debíamos tener claros para que una relación así se mantuviera. Sin embargo, más tardé yo en presentar mis ideas que ella en rechazarlas. -Las relaciones de lejos no funcionan- me dijo - Yo no creo en eso. Su panorama estaba claro. Si me iba con ella la relación continuaba, si se iba sola terminábamos. Y había algo más: ella iba a presentarse a varias universidades. Se iría a cualquiera que la aceptara. Así las cosas, yo tenía un margen de decisión muy pequeño. Quedarme en el trabajo que me hacía feliz o con la mujer que me hacía feliz. Si la conocieran entenderían porque no dude ni un instante en empezar a buscar dónde iba a estudiar por fuera de Colombia.

Pero el problema no se solucionaba con eso. Yo no iba a estudiar en cualquier lugar. Para seguir juntos necesitábamos un poco de suerte. Por fortuna ambos habíamos decidido que queríamos estudiar en España. Mi esperanza era que estando en el mismo país ella no considerara que la relación era de larga distancia. Empezamos entonces a enviar solicitudes: A Madrid, a Barcelona, a Valencia y al País Vasco. Yo quería ser aceptado en la Universidad de Valencia o en la que trabajaba Marisa. A mi esposa le llamaba mucho la atención una Universidad en Barcelona o la Politécnica de Valencia. 
Su respuesta llegó primero. La Politécnica la había aceptado. Mientras tanto yo estaba en la fase final de un proceso de selección para ser becado en una universidad del País Vasco. De miles de estudiantes seleccionaban dos. Por fortuna quedé de tercero, pues un par de semanas después me informaron que era aceptado en la UJI. Revisé rápidamente un mapa. Nos iban a distanciar unos 80 kilómetros. Era mucho <<Unas 3 o 4 horas de viaje>> pensé. Aun así no me desanimé pues podría haber sido más lejos. Luego aprendí que $80 \mathrm{Km}$ no son lo mismo en todas partes. Allí no había montañas como en mi ciudad. Busqué más información y encontré que había un tren que viajaba todos los días y tenía muchos horarios y solo tardaba 1 hora. Eso era lo mismo que yo invertía en llegar a mi trabajo. Era un poco menos de lo que tardaba en llegar a la casa de mi esposa cuando iba a visitarla en nuestra época de novios. Al final no estaba lejos. Pensé entonces que yo viviría en Castellón y ella en Valencia y la visitaría cada vez que pudiera.

Presenté mi carta de renuncia al trabajo. Ese mismo día me llamaron de la Universidad de Valencia para decirme que había sido aceptado. Sin embargo, ya me había entusiasmado con la idea de estudiar en la UJI y de conocer a las famosas Marisa, Susana, Eva e Isabel. Fue así como llegué a la UJI a estudiar la maestría. Mi esposa y yo estaríamos un año en España, cada uno haría lo suyo y luego regresaríamos a Colombia. Todo perfecto. Pero había más esperando en el camino.

Cuando yo renuncié a mi trabajo, me despedí, recogí mis cosas y agradecí por todo lo que sentí había recibido. Pero un par de días después me llamaron para proponerme ser el primer Teletrabajador de la empresa. Solo trabajaría medio tiempo. De esa manera ellos mantendrían contacto conmigo y más tarde yo podría regresar. Acepté con el compromiso de hacerlo un año después. No contaba con que la maestría y España me iban a enamorar.

Cuando estaba por finalizar mi maestría recuerdo que Marisa me mencionó que esta daba acceso al doctorado. Pensé en lo mucho que me había gustado el estudio, así que no tuve que meditarlo mucho tiempo. Mi idea fue entonces quedarme. Pero ahora el problema era qué iba a hacer mi novia ese año ¿Se devolvería para Colombia? ¿Se quedaría conmigo? ¿Y mi trabajo y mi compromiso de volver?

Pues bien. Todo se solucionó. Por un error en cuanto a la cantidad de créditos en la Maestría de mi novia y la convalidación de algunas materias, debió ver algunas adicionales en el segundo año. En mi trabajo vieron con buenos ojos la posibilidad de tener un PhD, así que aceptaron que me quedara. Fue así como llegue al doctorado. Pero aún no he contado como decidí estudiar la felicidad.

Por razón de mi trabajo, varias veces me tocó revisar artículos que mostraban que la satisfacción laboral no era un buen predictor del desempeño. Yo me preguntaba ¿cómo es que la gente más contenta con su trabajo no necesariamente lo hace mejor? - Debe haber un error- me decía. Y es que en esa época aún no sabía distinguir muy bien el concepto de satisfacción, el de bienestar y el de felicidad. Esa curiosidad se mantuvo latente durante mucho tiempo. 
Cuando llegué a la Universidad por primera vez, Valeria estaba esperándome para explicarme el funcionamiento de todo. Fue quien me dio la bienvenida y me hizo sentir que tenía un espacio para aprender. Rápidamente me adapté a la vida universitaria. Disfrutaba mucho mi retorno a clases y los aprendizajes que esta me dejaba. Obviamente hubo clases que disfruté más que otras. Cuando llegó el primer reporte de calificaciones descubrí que no necesariamente las clases en las que más a gusto me había sentido eran en las que había obtenido el mejor rendimiento. Si bien entiendo que hay muchas variables, además de mi desempeño, que pueden afectar la nota, esperaba encontrar una correlación mayor entre las notas y mi satisfacción con las materias. Pero no fue así. De nuevo mi inquietud latente se manifestó ¿Por qué mi rendimiento no está asociado con mi satisfacción?

Las clases hicieron que olvidara mi duda, me dedique de nuevo a mis actividades académicas. Hasta que llegó la clase donde nos dijeron: Tienen que pensar en un tema para su trabajo de fin de master. Piensen qué quieren hacer y presenten el proyecto.

Me fui entusiasmado para mi piso. Hice una lista de temas que me llamaban la atención. Casualmente en esa lista, que aún conservo, no aparecía por ningún lado la satisfacción y el desempeño. Busqué información sobre los temas que más me llamaron la atención, pero luego recordé algo. Hacía poco en mi trabajo se había recogido una cantidad importante de datos en un estudio conducente a la validación de una batería de instrumentos que miden factores de riesgo y protectores psicosociales. Pedí que me la enviaran Quería ver si alguno de los temas que tenía a la mano coincidía con los datos ya recopilados. Efectivamente fue así. Se había medido el crecimiento psicológico. Un concepto que tiene un buen sustento teórico pero que no ha llamado la atención de la investigación internacional. Aun así coincidía con mis gustos y, además, ya tenía datos. Pensé entonces en aprovecharlos. Revisé los propósitos de la investigación y uno de ellos era validar el modelo, el cual hipotetizaba que el crecimiento psicológico era una variable individual que podía tener efectos en la salud, el desempeño, y el desarrollo de las personas. Cuando vi el concepto de desempeño sentí que había encontrado lo que quería. Así que revisaría qué tanto el crecimiento psicológico predecía el desempeño. Lo mejor era que el desempeño había sido medido por los jefes de las personas, lo que dotaba la investigación de información robusta.

Mientras todo eso sucedía, y aclaraba qué era lo que iba a hacer, dos acontecimientos me llevaron al que finalmente fue mi trabajo de fin de master. Por una parte Marisa nos había dado una clase y en un momento hizo una pregunta que me marcó ¿Cuál es el proceso psicológico que explica eso? Hizo tanto énfasis en su pregunta y su explicación fue tan clara que me di cuenta que yo había sido un psicólogo de datos, pero no un psicólogo de explicaciones. Podía definir con acierto muchos conceptos, podía mencionar hallazgos de investigación, podía convencer sobre la importancia de la gestión humana en las organizaciones, pero no era muy bueno desentrañando el proceso psicológico que explica nuestros comportamientos y decisiones. Por otra parte, como si se tratara de un acuerdo entre ellos, Jesús nos explicó cómo probar mediación entre dos variables. Finalizó la explicación con un ejemplo en el que dijo que la variable mediadora explicaba la relación entre las otras dos. Até cabos y me di cuenta que mi trabajo de grado no tenía ninguna 
variable que me permitiera explicar el proceso psicológico que unía el crecimiento psicológico con el desempeño.

Revisé de nuevo, busqué literatura y me encontré con un meta análisis que señalaba que el crecimiento psicológico podía llevar a buen desempeño porque las personas que "crecen psicológicamente" suelen estar más satisfechas con su entorno, en la medida que se hacen expectativas realistas, se adaptan con más facilidad y pueden manejar mejor la incertidumbre. Y ahí estaba de nuevo: La Satisfacción Laboral. Pero esta vez le habían dado un rol determinante. Aquí se sugería que afectaba el desempeño. Por fortuna en los datos recopilados también se había medido esta realidad. El modelo estaba completo. Entonces me sentí muy feliz, no solo podría por fin vérmelas con mi inquietud latente, sino que, además, podía ayudar a mi empresa a validar una parte del modelo. Así que me puse manos a la obra.

Los hallazgos, que son uno de los capítulos de esta tesis, fueron los que en definitiva me Ilevaron a estudiar la felicidad. Encontré que la Satisfacción no era un buen predictor del desempeño. Lo que me desanimó. Pero un debate con Marisa me abrió los ojos. Recuerdo lo que le dije

- Efectivamente encontré lo que tantos autores han señalado, la satisfacción no afecta el desempeño, al menos no el de rol, lo que quiere decir que no necesariamente las personas más contentas con su trabajo lo hacen mejor. Entonces todo eso del disfrute, de encontrarle sentido al trabajo y de hacer lo que nos gusta, de estar felices en y con el trabajo ¿Dónde queda?

- Es que estás confundido Alejandro -dijo ella - Una cosa es el disfrute, el sentido del trabajo y la felicidad en el trabajo y otra diferente la satisfacción laboral.

Y empecé a leer. ¡Efectivamente había una diferencia! Efectivamente la Felicidad era una cosa y la satisfacción otra. Y cuando exploré la felicidad me di cuenta que había encontrado mi tema. Quería saber más, tenía muchas preguntas y la literatura no me las respondía todas. Lo mejor de todo era que en esa época aún no era moda. Así que me encontraba ante mucho terreno sin explorar. Ahí empezó todo.

Por mi esposa llegué a España. La calidad del master y sus docentes me invitó a continuar con el doctorado y la Felicidad me encontró mientras la buscaba. Luego descubrí que esa es la forma de ser feliz. 


\section{INTRODUCCIÓN}

Un marcado acento en la investigación de la enfermedad física y mental es paradójico. En lugar de estudiar lo común hemos estado estudiando durante años lo atípico (Seligman, 2011). Y eso no ha estado mal. La investigación focalizada en esto ha contribuido enormemente al aumento de la expectativa y calidad de vida de las personas y ha salvado a millones. Sin embargo, el bienestar y la salud no son opuestos del malestar y la enfermedad. La simple ausencia de estados patológicos, físicos o mentales, no es sinónimo de bienestar y salud (Organización Mundial de la Salud - OMS, 2006).

Entender la salud de las personas y su bienestar a partir de los hallazgos de las investigaciones focalizadas en la patología puede ser, cuando no arriesgado, al menos sí limitado, en tanto los procesos físicos y psicológicos que explican lo positivo y lo negativo no son necesariamente los mismos. Por ello la OMS (2006) insiste en que la salud y el bienestar son más que la simple ausencia de enfermedad. Entender esto sirvió para abrir una nueva línea de investigación en psicología focalizada en entender el funcionamiento óptimo de las personas (Seligman, Steen, Park, \& Peterson, 2005), lo cual se hace con más frecuencia cada vez (Avia \& Vázquez, 2011). Arraiga entonces en la psicología una visión más holística en la que se quiere entender, no solo las razones de lo que está mal sino, también, de lo que está bien. Por fortuna todas las áreas de la psicología se han visto permeadas por esta nueva visión (Seligman \& Csikszentmihalyi, 2000), incluyendo la organizacional y del trabajo.

Ya no basta con entender los fenómenos de bajo desempeño, las razones de las conductas desviantes, el estrés, la adicción al trabajo, el burnout, el tecno-estrés, el acoso psicológico, la baja motivación, entre otros. Comprender la satisfacción, compromiso, engagement, buen clima de trabajo y la felicidad laboral es una exigencia actual de la sociedad y sus empresas, consientes ahora de que la evitación y control de lo negativo tiene un impacto menor al de la gestión de lo positivo.

Este enfoque con el que se quiere abordar y explicar los antecedentes, consecuencias y relaciones existentes entre aspectos psicológicos positivos, ha venido a complementar con acierto la comprensión del ser humano. Se trata aún de un campo de investigación es sus primeros estadios pero con un potencial enorme de ayudar en la difícil tarea de comprender la complejidad humana (Seligman et al., 2005).

El tema central de esta tesis doctoral es la Felicidad y el Optimismo en el Trabajo. Conceptos que se han explorado ya en otros contextos de la vida de las personas, y que demandan la atención de los psicólogos del trabajo y las organizaciones, encargados de investigar las relaciones persona/trabajo y persona/organización. 


\section{La importancia de la felicidad, el optimismo y el desempeño en la vida de las personas}

Meta por excelencia del hombre la primera. Creencia inherentemente humana la segunda. Ambas juegan en la vida de las personas un rol regulador y vinculante. Nos definen como especie y sustentan muchas de las decisiones que tomamos (Dolan, 2015) y acciones que emprendemos. Ser feliz es un propósito cuya justificación es innecesaria. No es un medio para lograr algo más. Al contrario, se trata del fin último. Muchos países han entendido esto. De ahí el giro que están dando muchos gobiernos hacia la gestión y medición de la felicidad como forma de evaluar el éxito de sus políticas públicas (Vázquez, 2012).

Las empresas también han incursionado en este movimiento. Es posible que en poco tiempo las Gerencias de la Felicidad vengan, sino a remplazar, si a complementar las áreas de recursos humanos o de gestión humana (Fernandez, 2015). Cada vez más empresas comprenden que favorecer la calidad de vida de las personas aumenta sus activos intangibles, ayuda a la productividad y representa una forma de responder socialmente a la comunidad. Todo en uno. Eso claro, cuando se trabaja realmente en la gestión de la felicidad a conciencia y no como una moda más (Sanín-Posada, 2016). Los seres humanos buscamos ser felices, al menos la gran mayoría. Los gobiernos y empresas que sean contrarios a eso están destinamos a fracasar, pues nadan contra corriente.

El Optimismo, por su parte, es un recurso invaluable con el que contamos los seres humanos (Vera-Villarroel, Córdova-Rubio, \& Celis-Atenas, 2009). Nos permite lidiar con la incertidumbre del futuro. Sin optimismo no emprenderíamos proyectos ni actividad alguna. Necesitamos creer que lo que hacemos tendrá el efecto deseado (Avia \& Vázquez, 2011), de lo contrario no valdría la pena. De ahí que se piense que incluso los pesimistas más enconados no son otra cosa que optimistas camuflados. Sabemos de ellos y sus ideas porque las expresan con el optimismo de ser escuchados.

Las empresas se muestran ahora interesadas en saber sobre esto, producto de estudios que demuestran que las personas más optimistas suelen ser también más productivas, felices y eficientes y tener menos estrés (Bailey, Eng, Frisch, \& Snyder, 2007; Pedrosa, Celis-Atenas, Suárez-Álvarez, García-Cueto, \& Muñiz, 2015; Pérez, 2009). Cosas buenas les esperan a las empresas que favorecen y gestionan el optimismo de sus colaboradores.

Por su parte el desempeño es importante porque la productividad de las empresas depende de ello. Mientras no se automatice la creatividad y otras habilidades humanas el éxito de las organizaciones seguirá dependiendo en una proporción importante de la actuación de las personas (Rifkin, 2014). El logro de resultados de las organizaciones está supeditado al desempeño de las personas y a la forma como manejen los recursos (Toro, 2002). Pero el buen desempeño no es algo que solo le resulta conveniente a la organización. A la propia persona le conviene, pues favorece su autoestima, reduce posibles conflictos con otros y la ayudan a mantenerse activa y desarrollarse (Toro, 2002). La productividad de las organizaciones, por su parte, mejora la economía de los países y favorece su desarrollo, impactando con esto la calidad de vida. Si bien el aumento de la productividad correlaciona 
negativamente con la generación de más empleo (Rifkin, 2014), su impacto en la sociedad, la educación y la salud contribuye a un desarrollo sostenible, generando un entorno en el que se facilita que las personas puedan dedicar sus vidas a actividades gratificantes, placenteras y con sentido.

\section{Definición de Felicidad (y su diferencia con Satisfacción), Optimismo y Desempeño}

Científicamente se define la Felicidad como bienestar subjetivo (Diener, 2000; Fernandez, 2015). Ha sido una de las conceptualizaciones más aceptadas y divulgadas por la ciencia y con base en la cual se ha acumulado evidencia científica. Sin embargo algunos autores sugieren que está visión puede ser limitada, pues refleja solo una dimensión del constructo, la relativa a qué tan bien se siente y percibe la persona (Alarcón, 2006). Se considera que deja de lado el bien-hacer (Quick \& Quick, 2004) y el componente cognitivo que le permite a la persona juzgar su nivel de felicidad (Sheldon \& Lyubomirsky, 2006).

La felicidad no puede limitarse a la simple sensación de estar bien (bien-estar). La posibilidad de ser o no ser feliz, que se sustentada en su componente genético (Lyubomirsky, Dickerhoof, Boehm, \& Sheldon, 2011) y epigenético (ver capítulo 5) hace que el sufijo "estar" sea insuficiente para hablar de una realidad que puede ser considerada también un rasgo (ver capítulo 1). De ahí que se pueda decir que se es o no feliz y también que se está o no feliz. Las definiciones más recientes del constructo consideran el bienestar solo como una dimensión de la Felicidad (Fernandez, 2015). Cuenta con dos dimensiones más, a saber, el sentido de lo que se hace y la gratificación (Seligman, 2011). La primera de estas se refiere a la comprensión del propósito de lo que se hace. La segunda a la posibilidad de sentir que eso resulta enriquecedor, formativo y da identidad, por cuanto implica que se han utilizado las fortalezas características del ser humano. Las actividades gratificantes podrían no estar relacionadas necesariamente con el bienestar, pues no todas son placenteras, como por ejemplo ayudar en el cuidado de personas con enfermedades terminales. De ahí la importancia de separar el bien estar del bien hacer. También es posible desarrollar actividades placenteras que hacen sentir bien a quien las ejecuta, pero que podrían carecer de sentido (Dolan, 2015).

En este trabajo se aborda la felicidad desde esta perspectiva multidimensional. Se la define como característica personal estable que lleva a las personas a tener un estado de ánimo predominantemente positivo, a vivir experiencias gratificantes y articular lo que hace a un propósito que da sentido a su vida.

Por su parte, la satisfacción es una reacción afectiva de agrado en relación con una realidad determinada, tiene que ver principalmente con lo que se siente y menos con lo que se piensa (Wright \& Cropanzano, 2000). Surge de un juicio evaluativo en el que se considera que la realidad concuerda con las expectativas que se tienen o tenían de ella. Cuando la realidad está por debajo de la expectativa se genera insatisfacción. Cuando la supera puede aparecer sorpresa, asombro o fenómenos de disonancia cognitiva. La satisfacción ha sido 
utilizada como sinónimo felicidad en diversas investigaciones (Zelenski, Murphy, \& Jenkins, 2008). Sin embargo, se trata de realidades diferentes. Si se elaborará una jerarquía de conceptos, la satisfacción estaría en un nivel inferior, más básico, pues se produce como reacción. El bienestar estaría en un segundo nivel ya que para experimentarlo se requiere sentir y considerar que se han vivido experiencias satisfactorias. El concepto de mayor nivel sería la felicidad, el cual, además de integrar el bienestar, englobaría la gratificación y el sentido.

Por su parte, el optimismo, desde su consideración como una característica disposicional, se entiende como un sistema de creencias que nos ayuda a ver favorablemente el mundo (Marshall, Wortman, Kusulas, Hervig, \& Vickers, 1992). Su orientación temporal puede ser hacia el pasado, el presente y el futuro. Los optimistas ven el pasado como fuente de aprendizaje (ver capítulo 4), el presente como una oportunidad (Avia \& Vázquez, 2011) y el futuro con esperanza. Este sistema de creencias es aprendido y se constituye en una característica de las personas (Vera-Villarroel et al., 2009), permitiendo que estas puedan ser definidas como optimistas o pesimistas (Marshall et al., 1992). Esta aproximación difiere de la que entiende el optimismo como un estilo atribucional, relacionado con la forma como las personas interpretan lo que les sucede, más que como una característica personal (Scheier, et al. 1994).

El optimismo tiene la capacidad de afectar las emociones y las actuaciones de las personas. Su relación con el concepto de felicidad parece ser circular. Aunque genéticamente las personas nacen predispuestas a ciertos niveles de felicidad, el optimismo opera como activador genético (ver capítulo 5). A su vez el incremento de la felicidad favorece una visión más positiva del mundo. La circularidad puede generar espirales positivas o negativas según la persona sea optimista o pesimista. No es claro cuál de los dos es el antecedente y cual la consecuencia. Se podría argumentar que la felicidad es antecedente por su condición genética o que lo es el optimismo por operar como activador. Pero, más allá de su lugar, ambos conceptos son relevantes en esta investigación por sus interacciones y por considerarse como posibles antecedentes del desempeño de las personas.

Finalmente, en esta investigación incluimos también el Desempeño, que se trabajó entendiéndolo como la conducta consiente e intencionada orientada al logro de un objetivo (Toro, 2002). Aunque también se le ha definido como resultado (Rothwell, Hohne, \& King, 2000), se consideró que dicha aproximación es errada, pues el resultado es el efecto de la conducta, no su sinónimo (Arias \& Heredia, 2006; Muchinsky, 2002). En el campo laboral está enmarcado por una serie de realidades que constituyen su contexto, tales como las normas, los principios, los valores, entre otros. Todas estas realidades tienen la función de regular el comportamiento de forma tal que este se encamine, efectivamente, hacia el logro de objetivos laborales (Toro, 2002).

Conocer las variables que influyen en el desempeño es una ventaja para las organizaciones. Hacerlo permite una gestión exitosa e impactar con ello la productividad. Se ha hipotetizado 
mucho sobre la capacidad de la felicidad para incrementar el desempeño (Zelenski et al., 2008). De ahí el interés en este trabajo de aportar a ese conocimiento.

\section{Preguntas de Investigación}

En la exploración de los conceptos de felicidad y optimismo y de las bases teóricas que sustentan todo este trabajo, noté que se habla mucho de felicidad. Se le utiliza, a veces de forma indiscriminada, para sustentar decisiones y actuaciones. Se le considera escurridiza, momentánea, indefinible. También supremamente subjetiva pues, como dicen algunos, la felicidad la define cada quién. Sin embargo, los investigadores insisten en que el concepto también puede ser tratado como un constructo teórico susceptible de ser sometido a la exploración científica (Norrish \& Vella-Brodrick, 2008). Gracias a esta revisión me surgieron algunas preguntas ¿Qué es la felicidad? ¿Se puede separar la felicidad en la vida de la felicidad en el trabajo? ¿Es esta última un constructo teórico robusto?

Para responderlas explore la literatura, lo que me ayudó a tener algo de claridad sobre el concepto, también contribuyó a ello el discutirlo con varias personas. Me sorprendió ver que muchas coincidían en que, una cosa era definirla y otra medirla. Argumentaban que la medición de esta realidad no es posible, que nunca sabremos qué tan feliz es alguien, en tanto lo que esa persona define como felicidad no es igual a lo que definen otros (Atherton, Graham, \& Steedman, 2010). Me pregunté entonces ¿Es medible? ¿Se puede llegar a saber qué tan feliz es una persona? ¿Se pueden comparar los resultados de un test de una persona con los de otra? Y ya que estaba también interesado en el concepto del optimismo, me pregunté lo mismo en relación con él. Responder esta pregunta me pareció fundamental pues es común encontrar resistencias en las organizaciones en relación con la posibilidad de medir variables psicosociales (Fernandez, 2015).

Luego emergieron nuevas preguntas. Estas ahora estaban relacionadas con el comportamiento de las variables que me interesaban. En mi primer trabajo ya había avanzado en revisar si la satisfacción laboral era un mediador de la relación entre el crecimiento psicológico y el desempeño laboral. Luego, teniendo en cuenta que era común que en las lecturas se hablara de la satisfacción con la vida, en ocasiones como sinónimo de felicidad y en otras como indicador de la misma, quise saber cómo interactuaban estas dos realidades y si dicha interacción era diferente en la vida en general y en la vida en el trabajo.

Luego de resolver algunas de estas inquietudes, me interesé en saber si el tipo de contrato podía tener efectos en los niveles de felicidad en el trabajo de las personas. Me lo pregunté debido a que esta condición ha sido señalada con insistencia por su capacidad para afectar el bienestar y la calidad de vida de las personas (Chambel, Alcover, \& Martínez, 2012; Rodríguez-Gutiérrez \& Canal-Domínguez, 2012; Santos, Guillén, \& Montalbán, 2012; Solanes \& Zaragoza, 2010; Uribe-Rodríguez, Garrido-Pinzón, \& Rodríguez, 2011; Vesga Rodríguez, 2011). 
Finalmente me cuestioné acerca de si era posible intervenir la felicidad y el optimismo en el trabajo, dadas las condiciones especiales que dicho contexto ofrece. También quería saber si los efectos de la intervención sobre la felicidad impactaban el desempeño. La revisión teoría me mostró que sobre intervención de la felicidad había ya varios trabajos (Seligman et al., 2005; Sheldon \& Lyubomirsky, 2006), pero aplicados en el contexto de trabajo muy pocos. Me pregunté ¿Son aplicables esas estrategias en este tipo de contexto? ¿Difieren los efectos según se tratara de hombres o de mujeres? ¿El incremento en los niveles de felicidad y optimismo - si se daban- traería consigo mejoras en el desempeño de los colaboradores calificado por sus jefes? Todas estas preguntas surgieron en ese proceso de revisión. Obviamente debía centrarme, así que hice una revisión de todo lo que quería saber y me formulé las preguntas que guiaron mi trabajo. Estas son

1. ¿Qué es la felicidad y la felicidad en el trabajo?

2. ¿Cómo se puede medir la felicidad y el optimismo en el trabajo?

3. ¿Qué rol juega la satisfacción laboral en función del desempeño laboral?

4. ¿Cuál es el rol de la felicidad y de la satisfacción con la vida en función del trabajo?

5. ¿Afecta el tipo de contrato la felicidad y el optimismo de las personas?

6. ¿Se puede intervenir la felicidad y el optimismo en contextos de trabajo?

7. ¿Es diferente el efecto de la intervención de la felicidad y el optimismo en función del género?

El capítulo 1 de esta tesis doctoral consiste en una revisión teórica del concepto de felicidad y de felicidad en el trabajo. Se constituye en la respuesta a la primera pregunta. En este capítulo se diferencia la felicidad de otros conceptos similares y se especifica su importancia en el mundo del trabajo. Lo cual se sustenta a partir de múltiples estudios que revelan sus efectos positivos sobre las personas y las organizaciones. Es un recorrido por conceptos asociados y una propuesta de definición de felicidad en el trabajo.

Los capítulos 2 y 3 responden a la segunda pregunta de investigación. El 2 es el reporte de un proceso de verificación psicométrica de un instrumento diseñado para medir felicidad en población colombiana trabajadora. Ya que se identificó en la literatura que efectivamente existían varias escalas para medirla, se decidió hacer la verificación de las condiciones del instrumento en la población en la que posteriormente se desarrollarían los demás estudios. Con base en la teoría psicométrica clásica se revisaron las propiedades del Authentic Happiness Inventory (Seligman et al., 2005) una herramienta usada en otras latitudes. En este capítulo se revisa también si el instrumento puede ser adaptado para medir felicidad en el trabajo. Un aporte importante de este artículo es el inventario de diversos instrumentos que afirman medir la felicidad.

El capítulo 3, al igual que el anterior, es un proceso de verificación psicométrica. En este caso se verifican las condiciones del Life Orientation Test- Revisado (Scheier \& Carver, 1985) una de las herramientas más usadas para medir optimismo a nivel mundial. En el capítulo, además, se verifica qué sucede con el instrumento cuando se le pide a las personas responderlo pensando solo en su organización o solo en su trabajo. De esta forma se verifica 
si existe un optimismo asociado con contextos particulares (estado) y no solo un optimismo rasgo.

El capítulo 4 consistió en la verificación de un modelo de mediación en el que se hipotetizó que la Satisfacción Laboral media la relación entre el Crecimiento Psicológico y el Desempeño Laboral de las personas. Si bien por temporalidad debería aparecer primero, he decido ubicarlo como el 4 ya que a partir de este trabajo se empieza a comprender la interacción que hay entre variables de corte positivo (Satisfacción y Crecimiento Psicológico) con el desempeño. Con este capítulo se dio respuesta a la pregunta 3.

El capítulo 5, que responde a la pregunta 4, muestra el resultado de un proceso de verificación del rol de la Felicidad en el Trabajo como variable que explica la relación entre el Optimismo y la Satisfacción con la Vida. El modelo es comparado con otros dos, uno en el que el antecedente es el Optimismo en el Trabajo y otro en el que la variable que media la relación es la Felicidad en la Vida. Este capítulo nos permite explorar las diferencias entre la felicidad en la vida y en el trabajo y nos muestra cómo interactúan el optimismo, la felicidad y la satisfacción con la vida.

En el capítulo 6 se explora un tema de interés para la psicología organizacional, relacionado con los efectos de prácticas laborales que han sido consideradas como precarias. En este caso la de vincular a las personas con contratos que ofrecen condiciones por debajo de lo que se considera adecuado y saludable. En el capítulo, que responde a la pregunta 5, se presenta la exploración de si el tipo de contrato genera o no diferencias en la felicidad y el optimismo de las personas.

El capítulo 7, que da respuesta a las preguntas 6 y 7, muestra la revisión del efecto de la intervención de la felicidad y el optimismo en contextos de trabajo, controlando el género. Se pone al final para enfatizar que la felicidad y el optimismo son gestionables y que existen una serie de acciones que las personas pueden desarrollar, con o sin el auspicio de la organización, para incrementarlas.

En el último capítulo se presentan las principales conclusiones de esta tesis, se revisan las implicaciones teóricas y prácticas de la mismas, así como futuros estudios derivados de las mismas.

Aunque la tesis se presenta en este orden vale la pena comentar que, cronológicamente, el capítulo 4 se desarrolló primero (año 2011). Eso debido a que fue el trabajo de la tesis de maestría, el cual ayudó a generar las demás preguntas de investigación. Luego de eso, en el 2012 se empezó por donde se debía, por entender los constructos (Capítulo 1). Luego se pasó a asegurar que se podían medir de manera válida y fiable (Capítulo 2 y 3). Esa parte del trabajo se desarrolló entre 2013 y 2014 . Más adelante se pasó a entender la relación de las variables con otras de interés para lo cual se dedicó el 2015 (Capítulo 5) y el 2016 (capítulo 6). Por la envergadura y dificultades del último trabajo, el proceso de conseguir 
apoyo en las empresas empezó en 2014. Finalizando 2015 inició el proceso y ya en 2016 se pudo terminar con la redacción del reporte de investigación (capítulo 7). ${ }^{1}$

${ }^{1}$ En el anexo B se encuentran los cuestionarios de Felicidad Autentica, Optimismo y Satisfacción con la Vida utilizados en los diversos estudios. La Escalas de Desarrollo Psicológico, Evaluación del Desempeño y Satisfacción con la Vida no se adjuntan pues hace parte de la propiedad intelectual del Centro de Investigación en Comportamiento Organizacional Cincel. Dicho centro presta los instrumentos para investigaciones previa revisión de los proyectos de investigación. 


\section{Capítulo 1. Felicidad Laboral. Reflexiones sobre la investigación en su aplicación al} contexto del trabajo

\section{Resumen $^{2}$}

Se presenta una aproximación teórica relacionada con medidas, estrategias de intervención y estudios longitudinales sobre la felicidad, con el ánimo de reflexionar acerca de su aplicabilidad en el contexto del trabajo. Para ello se exponen brevemente los conceptos, algunos de los instrumentos de medida más usados, estrategias de intervención que han sido verificadas científicamente y estudios que permiten una comprensión del concepto de felicidad en el largo plazo. Al final se presenta una reflexión sobre la aplicabilidad de este concepto en el contexto organizacional y del trabajo.

\section{Introducción}

Felicidad es un concepto de uso común, cotidiano, pero operacionaliza también, como constructo teórico, una realidad que ha recibido atención académica, especialmente desde el surgimiento de la psicología positiva. Desde esta perspectiva se le define como la experimentación o vivencia de emociones positivas, carencia de negativas y satisfacción con la vida (Diener, 2000).

La felicidad puede ser concebida como rasgo o como estado (Moyano, Flores y Soromaa, 2011). La primera aproximación se fundamenta en estudios que sugieren que esta es un afecto positivo relativamente estable y en hallazgos que indican que un $50 \%$ de la misma se explicaría genéticamente (Lyubomirsky, 2008). La segunda se sustenta en su naturaleza cambiante y susceptible de modificación dependiendo de eventos y situaciones particulares. No obstante, esta última visión ha perdido fuerza en la medida que se ha demostrado que la felicidad, a diferencia de la satisfacción, no está necesariamente asociada con circunstancias particulares (Littlewood, 2008). Cuando lo hace, los efectos de tales circunstancias suelen ser pasajeros. La felicidad se explica más por los recuerdos, la trayectoria de vida y la consecución de metas valiosas (Avia y Vásquez, 2011), que por asuntos circunstanciales.

Aunque en algunos estudios se trata la felicidad como sinónimo de bienestar subjetivo, y se considera, este último, un concepto más adecuado desde lo técnico (Diener, 2000; Diener, Suh, Lucas y Smith 1999), algunos autores afirman que el bienestar es solo una parte de la

\footnotetext{
2 Este trabajo fue publicado íntegramente como capítulo de libro. Para la tesis se ha cambiado el título y se han actualizado algunas referencias: Sanín-Posada, A. (2016). Felicidad Laboral: Reflexiones sobre su aplicación al contexto del trabajo. En F. Uribe (Ed.), Psicología del trabajo. Un entorno de factores psicosociales saludables para la productividad (p. 210). México: Manual Moderno y Universidad Autónoma de México.
} 
felicidad, pues para ser feliz se requiere además disfrutar y comprometerse con la propia vida (Seligman, Steen, Park y Peterson, 2005), conceptos que van más allá de sentirse bien.

Si bien recientemente el mismo Seligman (2016) insiste en que el concepto de bienestar es más adecuado que el de Felicidad desde lo científico, su definición de bienestar es, sino igual, si muy parecida a la que antes daba a la felicidad. Se trata solo de un cambio de nombre. Argumenta que el concepto de felicidad no puede incluir las dimensiones de Compromiso y Sentido, pues felicidad se limita a una emoción positiva. Sin embargo, algo similar podría decirse del concepto bienestar (well being). La palabra sugiere estado (estar bien) y por tanto no cabrían las otras dimensiones que propone el autor. Este asunto, más de forma que de contenido, nos lleva a concluir que la utilización del concepto Felicidad sigue siendo apropiada.

La felicidad es un fenómeno psicológico relativamente estable (rasgo) aunque con posibilidad de cambio (estado). Se llegaría a ella no por una reacción afectiva momentánea, sino por la acumulación de emociones positivas a lo largo del tiempo. Incluye bien-estar y algo que los autores han Ilamado bien-hacer (Quick y Quick, 2004), el cual se relaciona con la sensación de que las cosas se están haciendo bien, tienen sentido y producen disfrute. Al relacionarse con un estado emocional positivo, la felicidad representa un fenómeno multidimensional que implica estados afectivos positivos distintos de los sentimientos que son pasajeros y asociados con los sentidos (Ellis, 2001). De esta manera la felicidad caracterizaría, como rasgo, a aquellos que experimentan satisfacción, disfrute de la vida y gratificación.

La felicidad también posee un componente cognitivo. A saber, aquel que nos permite juzgarnos o no como felices y el cuál se sustenta en la creencia de que en la vida las cosas marchan bien (Avia y Vázquez, 2011). Este juicio es subjetivo y no necesariamente se corresponde con lo feliz que otros nos perciben.

Ahora bien, teniendo presente que nuestro interés es generar reflexión acerca de este concepto y su importancia en el contexto de trabajo y las organizaciones, es preciso complementar la comprensión de felicidad diciendo que la felicidad laboral requiere la existencia de emociones positivas, gratificaciones y sentido del trabajo. Es el mismo concepto que hemos definido arriba solo que asociado con un contexto particular. Su evaluación implicaría entonces examinar qué tanto la persona considera que, en su empresa o través del desarrollo de su trabajo, puede sentirse bien (bienestar), desarrollar actividades que le exigen la aplicación de sus fortalezas (gratificación) y encontrarle sentido y propósito a lo que hace.

Se trata entonces de explorar el constructo de Felicidad Laboral, concepto que nos permitimos introducir aquí para englobar lo que sería la felicidad en el trabajo y la felicidad por el trabajo. La primera hace referencia al contexto en el que se manifiesta dicha felicidad y se ciñe a la conceptualización de felicidad más como un "rasgo". La segunda habla de la felicidad como dependiente del trabajo, y está ligada a la visión de felicidad como estado. 
Cuando hablamos de Felicidad Laboral englobamos entonces estas dos aproximaciones para darle lugar al trabajo y a la organización como realidades que pueden ser determinantes de la felicidad en mayor o menor medida o contextos donde esta se concreta.

El interés de trabajar este tema en el mundo de las organizaciones y del trabajo radica en las múltiples investigaciones que sugieren que la misma tiene efectos importantes en la productividad individual y laboral. Además, representa un propósito de vida que no requiere de justificación alguna, pues se trata de una búsqueda que caracteriza a los seres humanos como especie (Seligman, 2011).

Como el concepto de felicidad suele confundirse con el de satisfacción, consideramos conveniente detenernos aquí para hacer referencia a varios asuntos que los diferencian. La satisfacción se entiende como una reacción afectiva que se produce al comparar la realidad con las expectativas e intereses propios (Wright y Cropanzano, 2000). Suele producir un sentimiento de saciedad y se expresa en una evaluación y sentimientos positivos acerca de aquello que se evalúa (Meneghel, Borgogni, Miraglia, Salanova, \& Martínez, 2016). Es una medida típica de bienestar (Littlewood, 2008), el cual, a su vez, se considera afectado por las condiciones de vida y por la experimentación de afectos positivos y placer (Littlewood, 2008). La satisfacción es un constructo menos complejo que el de felicidad. Se le considera un indicador parcial de bienestar subjetivo. El bienestar, por su parte, es un componente parcial de la felicidad, como hemos señalado.

La felicidad y la satisfacción son conceptos relacionados con la emoción y los afectos. Pero la primera está determinada por asuntos genéticos y por la acumulación de estados positivos y acciones intencionales, y además, se juzga como algo que se experimenta en el presente. Mientras tanto, la satisfacción está relacionada con circunstancias y realidades particulares que pueden o no estar alineadas con las expectativas de las personas y que suceden, típicamente, en el pasado. En un continuo temporal encontraremos, en el pasado, las causas de estar o no satisfechos, y en el presente el juicio de experimentación de felicidad (Seligman, 2011).

\section{Felicidad y trabajo}

La exploración de la felicidad puede resultar de interés para diversos investigadores de múltiples disciplinas. En nuestro caso, como hemos mencionado, queremos hacerlo en el contexto de la psicología del trabajo y las organizaciones. En los párrafos siguientes expondremos algunas ideas que argumentan su vinculación con este campo de la psicología. Por lo pronto adelantamos que la felicidad es una característica personal estable asociada con la experimentación de emociones positivas que promueve resultados más favorables en el trabajo, lo cual amplía el interés en el concepto al mundo empresarial (Norrish y VellaBrodrick, 2008). 
Pese a un buen número de investigaciones, el debate acerca de si el empleado más feliz es más productivo, parece estar aún abierto (Ayala, Peiró Silla, Tordera, Lorente, \& Yeves, 2016) y lo está desde hace mucho (Quick y Quick, 2004). Mientras unos autores argumentan y encuentran que el bienestar se relaciona con el desempeño (Fogaça \& Coelho-Junior, 2016; Wright, Larwood y Denney, 2002), otros llaman la atención sobre el hecho de que esto no siempre sucede (Youssef y Luthans, 2007). Estas contradicciones no son nuevas en la literatura, pero parecieran deberse más a discrepancias en la forma como se operacionaliza y mide el constructo que a resultados realmente contradictorios.

El debate del que hablamos ha sido intermitente. Hay épocas en las que la atención académica se centra en él y otras en las que la psicología del trabajo y las organizaciones pareciera preocupada por otros asuntos, también relevantes, pero diferentes al que nos ocupa ahora. Las nuevas conceptualizaciones del constructo de felicidad y los avances metodológicos podrían resultar útiles para dar respuesta definitiva a este debate (Seligman (2016). Sin embargo, más allá de este asunto, la felicidad resulta conveniente por otras razones. Se ha encontrado, por ejemplo, que está asociada con el cumplimiento de valores y con el incremento de conductas de ciudadanía organizacional (Rego, Ribeiro, y Cunha, 2010); se asocia negativamente con el estrés (Schiffrin, Rezendes y Nelson, 2008), que conlleva daños psicológicos que resultan costosos para las empresas tales como el ausentismo y la baja productividad. También la felicidad hace que los empleados se perciban a sí mismos como más productivos (Zelenski, Murphy y Jenkins, 2008).

Pese a estos hallazgos todavía se discute si algunos de estos efectos deben atribuirse a la satisfacción laboral o a la felicidad, en la medida en que algunos autores han definido ambos como sinónimos, cuando en realidad son diferentes (Tsou y Liu, 2001). También se muestra cierto escepticismo pues cuando se ha querido examinar su relación con el desempeño, algunas medidas de este último han sido tomadas desde el auto-reporte mientras otros se deciden por evaluaciones más robustas hechas por los jefes (Wright, Cropanzano y Bonett, 2007).

Se sabe que la satisfacción laboral tiene efectos sobre diversas realidades, tales como la reducción del ausentismo, la evitación del trabajo, las quejas, los reclamos y los comportamientos desviantes como incivilidad, poco compromiso o violencia (Littlewood, 2008), lo cual resulta sumamente costoso para cualquier organización (Toro, Londoño, Sanín y Valencia, 2010). A su vez la satisfacción laboral aumenta los comportamientos de ciudadanía organizacional y el compromiso del personal, su motivación y el deseo de permanecer en la empresa (Cheng, Mauno, \& Lee, 2014; Littlewood, 2008; Wilkin, 2012). Se trata de efectos diferentes a los que podría tener la felicidad laboral, ya que esta última es un concepto más global que el primero. No se limita a una reacción afectiva, sino que incluye, como hemos mencionado la experimentación de sentido de lo que se está haciendo, la sensación de gratificación y de disfrute.

Vemos entonces que la felicidad laboral tiene efectos que van más allá del desempeño de las personas. Todos ellos son favorables. Sin embargo, es preciso analizar estos hallazgos 
con precaución haciendo especial énfasis en la definición que han dado los autores a los conceptos, pues podríamos estar asumiendo efectos de una variable que realmente corresponden a otra. En los casos en los que la felicidad se define de la misma forma como lo hacemos acá, se han visto efectos sobre el desempeño (Seligman, 2016), las conductas de ciudadanía organizacional (Rego, et al. 2010), el compromiso del personal (Field, \& Buitendach, 2011), la percepción de mejor desempeño (Zelenski, et al., 2008) entre otros. Se trata de efectos que le resultan convenientes a la organización.

\section{Medición de la Felicidad}

Hay quienes dudan de las medidas de la felicidad por sustentarse en juicios subjetivos y por considerar que la gente tiende a calificarse como feliz porque lo quiere parecer. Sin embargo, hay investigaciones que resaltan las altas y significativas correlaciones existentes entre estados neuro-anatómicos indicadores fisiológicos de felicidad y la felicidad calificada a través de autoreportes (Avia y Vázquez, 2011). Esto nos indica que tiene sentido crear escalas, métodos e ítems que sirvan como instrumentos de medida de este fenómeno, tanto en contextos generales como en el trabajo.

La literatura es generosa en relación con los instrumentos que permiten una medida de la felicidad. Algunos son escalas tipo Likert, otros métodos cuali-cuantitativos y otros sencillamente pruebas mono-ítem. Dentro de los primeros, que son los más usuales, se encuentran algunos que permiten examinar la Felicidad Auténtica, la Felicidad General, la Satisfacción con la Vida y otros conceptos relacionados con la experimentación de emociones positivas (Positive Psychology Center, 2015). Pavot y Diener (1993) ofrecen, por ejemplo, una escala que, aunque suele usarse como medida de la felicidad, evalúa la Satisfacción con la Vida. La versión en español de este instrumento se encuentra en Arce (1994). Otros instrumentos de uso común para medir la felicidad, y destacados en la literatura, son los de Fordyce, Lyubomirsky y Lepper, y Seligman, pese a esto se considera que los tres tienen algunas limitaciones. Los dos primeros en cuanto a su variabilidad (Seligman et al, 2005) y el último frente a su validez (Schiffrin, et al., 2008).

El instrumento de Lyubormisky y Lepper (1999), el Subjective Happiness, es de uso frecuente en investigaciones. También el de Seligman et al. (2005). La escala de estos últimos, se destaca entre las demás porque favorece una aproximación precisa a las dimensiones de la felicidad (emoción positiva, engagement y significado de la vida), al no evaluarla de manera general. Este instrumento cuenta con buenas propiedades psicométricas para los contextos en los que se ha aplicado e incluso muestra correlaciones con las puntuaciones obtenidas con otras escalas como la de Lyubomirsky y Lepper (1999) y el General Happiness Scale de Fordyce (1977) (en Seligman, et al. 2005). Se trata además de un instrumento validado en otros países (Kaczmarek, Stanko-Kaczmarek y Dombrowski, 2010).

Sin embargo los autores que diseñaron la escala en mención revelaron que presenta algunos problemas relacionados con su validez. Esto los llevó a crear una nueva escala con 24 ítems, 
a la que se llamó Authentic Happiness Inventory (AHI). Pese al cambio, se reconoce que aún es importante trabajar en pro de la validez de la misma (Schiffrin, et al., 2008).

En Latinoamérica encontramos ejemplos como la escala de Alarcón (2006) en Perú y la validación y adaptación del Memorial Univertity of Newfounland Scale Happinees (MUNCH) en Chile por parte de Vera, Celis y Córdova (2011) y de Moyano, et al (2011) aunque estos últimos lo hicieron específicamente para adultos mayores.

En Colombia también se cuenta con medidas válidas y confiables de la felicidad, sin embargo, es aplicable a grupos diferentes a los trabajadores (ver por ejemplo Gómez, Villegas, Barrera, y Cruz, 2007; González y Restrepo, 2010; Liberalessso, 2002; Londoño, 2009; Velasco y Londoño, 2011). Estos autores han trabajado con estudiantes, población reinsertada (personas que pertenecían a grupos al margen de la ley), personas de la tercera edad o de bajos recursos económicos o solo con personal universitario. Se trata de muestras que impiden tener una visión generalizada de la calidad de los instrumentos en población trabajadora. Sin embargo, recientemente en ese país, se Adaptó el AHI para población trabajadora y la Escala de Satisfacción con la Vida, con muy buenos resultados psicométricos (Sanín y Salanova, 2015). Seguramente más escalas son usadas en más países latinoamericanos, no obstante, encontrar reportes de su adaptación y validación en revistas de alto impacto científico no ha resultado fácil.

Ahora bien, como se mencionó, la medición no se limita al uso de escalas, también hay procesos que mezclan medidas psicométricas y cualitativas, como por ejemplo el Ecological Momentary Assessment (EMA) y el Day Reconstruction Method (DRM). En el primero la persona es evaluada en distintos momentos durante el día. En cada uno debe mencionar cómo se siente, qué está pasando, e incluso en ocasiones se examina su frecuencia cardiaca y se le pide muestras de saliva para analizar sus niveles de cortisol. El segundo se basa en un proceso de reconstrucción del día, donde se describen tanto qué pasó como qué se sintió en los momentos definidos. Lo interesante es que con ambos métodos se reportan resultados muy similares en los niveles de felicidad (Dockray, Grant, Stone, Kahneman, Wardle y Steptoe, 2010).

El tercer grupo de instrumentos corresponde a las medidas obtenidas con pruebas monoítem. En algunas de estas se pregunta directamente qué tan feliz se siente la persona (Tsou y Liu, 2001). El problema de este tipo de medida es que no provee una visión clara sobre diferentes dimensiones que puede tener la felicidad y adicionalmente el análisis de su confiabilidad resulta más complejo. Dentro de este mismo grupo se encuentran escalas que analizan la magnitud y frecuencia de presentación de la felicidad (Yousef y Luthans 2007).

Como se vio hay un buen número de escalas y métodos para evaluar la felicidad. Sin embargo, se destaca que, algunos de ellos, requieren ajustes para mejorar la confiabilidad y validez, mientras otros, para ser adaptados a culturas específicas. 


\section{Intervención de la felicidad y sus efectos en el trabajo}

Una buena cantidad de literatura expone información importante sobre la comprensión de variables psicológicas, su sentido e implicaciones. Mucha se centra en aspectos teóricos y modelos que permiten una visión integral de las realidades psicológicas de las personas. Sin embargo, es poca cuando se trata de reportes de los efectos de procesos de intervención de esas mismas variables. Más escaso es el reporte cuando se habla de intervención psicológica positiva (Seligman, et al. 2005) y todavía más cuando la intervención se da en el contexto del trabajo.

La intervención de la felicidad en las organizaciones no ha sido documentada en abundancia. En general en Latinoamérica es bastante difícil encontrar reportes al respecto (Calderón, Álvarez y Naranjo, 2006). Esto no significa que no se realicen intervenciones positivas, o que las organizaciones no inviertan en el bienestar de su personal (Meyers, van Woerkom, \& Bakker, 2013). Muestra, realmente, que este tipo de prácticas, en ocasiones, se hacen sin una idea clara de los efectos que tendrán, positivos o negativos, o se implementan sin proceder a recopilar medidas que permitan concluir si realmente la intervención fue o no efectiva. Muchas veces esta dificultad radica en el obstáculo que supone para las organizaciones disponer del tiempo de sus trabajadores para participar en estudios de carácter longitudinal (Lyubomirsky, Dickerhoof, Boehm y Sheldon, 2011).

Pese a esta dificultad, y a no encontrar abundancia de intervenciones documentadas en las organizaciones con respecto a este tema en Latinoamérica, sí es posible hallar en la literatura el reporte de estudios que hablan sobre la efectividad de algunos ejercicios de intervención de la felicidad (Meyers, et al., 2013). Por ejemplo, Seligman et al. (2005) diseñaron cinco actividades que giraban en torno a la expresión de gratitud, la autoconcienciación sobre lo que resulta positivo para la propia persona y la identificación de fortalezas personales. Los autores encontraron que algunos de estos ejercicios tienen efectos sobre la felicidad a largo plazo, especialmente los relacionados con describir acontecimientos positivos, explorar las propias fortalezas y expresar gratitud.

Otros autores han encontrado también que este último tipo de ejercicios, que giran alrededor de lo social, la afiliación y la búsqueda de apoyo, tienen una fuerte influencia sobre el bienestar (González y Restrepo, 2010). En esta misma línea los experimentos realizados por Abbe, Tkach y Lyubomirsky (2003) demuestran que los cambios positivos producen emociones positivas que se resisten a la adaptación hedónica y favorecen, por tanto, el bienestar a lo largo del tiempo. Las estrategias más efectivas señaladas por estos autores son la expresión de gratitud y tener conductas de bondad y amabilidad.

Pero existen otras estrategias que también han sido revisadas y que han mostrado efectos sobre la felicidad. Algunas de ellas son las afiliativas y de participación, las de control mental, trabajar orientado hacia metas, aprovechar activamente el tiempo libre o sencillamente relajarse, dedicarse a actividades religiosas y en general intentos directos y consientes de obtener felicidad. 
Se encontró, por ejemplo, que el control mental tiene una fuerte relación con la felicidad pero en sentido negativo (Tkach y Lyubomirsky, 2006). Pese a esto los investigadores llaman la atención ante el hecho de que es necesario contextualizar estos hallazgos ya que algunos factores sociodemográficos como el género y la procedencia étnica podrían condicionar las relaciones mencionadas. Señalan, como ejemplo, que la autoestima afecta el bienestar de forma diferente de acuerdo con las diferencias culturales (Diener and Diener, 1995 en Tkach y Lyubomirsky, 2006).

Lo interesante es que muchas de estas estrategias pueden ser aplicadas en el contexto del trabajo (Salanova, Llorens, Acosta, \& Torrente, 2013). En general la literatura indica que son más beneficiosas aquellas relacionadas con actividades que las personas pueden hacer por sí mismas, mientras que las circunstancias de vida tienen poco poder para predecir los cambios en la felicidad. Cuando lo hacen, el efecto no suele mantenerse en el largo plazo (Sheldon y Lyubomirsky, 2006). Estudios basados en estrategias de expresión de gratitud y expresiones optimistas revelan que normalmente estas sirven más si la persona es consciente del propósito para el cual se diseñaron, es decir para mejorar la felicidad (Lyubomirsky, et al., 2011).

Estos estudios que muestran que pueden darse cambios a largo plazo en la felicidad son muy destacables en tanto replantean la idea general que existe de que esta realidad solo se puede cambiar momentáneamente, dada la adaptación hedónica típica de los seres humanos (Sheldon y Lyubomirsky, 2006). Las intervenciones en felicidad suelen sustentarse, típicamente, en un modelo teórico que muestra que esta depende de tres aspectos fundamentales: el primero apunta a lo biológico, a lo genético, lo cual se refleja en el temperamento y los rasgos de personalidad. El segundo a las circunstancias personales y contextuales, que incluye aspectos demográficos y situaciones vividas y, el tercero, a las intenciones de las personas en cuanto a la búsqueda de felicidad y bienestar (Sheldon y Lyubomirsky, 2006).

Investigaciones basadas en este modelo han encontrado que el segundo no predice cambios considerables en la felicidad, el primero lo hace en un 40 o 50\% (allí el Neuroticismo y la Extraversión son los factores que más explican la varianza de la felicidad, mostrando que las personas emocionalmente estables y más extravertidas suelen estar más felices que los neuróticos y los introvertidos) y la tercera es un fuerte predictor (Tkach y Lyubomirsky, 2006).

Pese a estas investigaciones, en las que se muestra la eficacia de diferentes estrategias para mejorar la felicidad, no se analiza si estos efectos repercuten sobre el desempeño y la productividad de las personas en el trabajo. Esto solo se menciona someramente como una posibilidad que se sustenta, no obstante, en un aspecto muy debatido de la psicología de las organizaciones y del trabajo, que ya hemos mencionado, a saber, el hecho de si la felicidad efectivamente afecta o no el desempeño laboral (Fisher, 2010). 
Este debate, sobre el que volvemos aquí, se asienta en la aparición de estudios que muestran resultados contradictorios y poco concluyentes. Por ejemplo, uno buscó confirmar las relaciones entre el desempeño y el bienestar psicológico, afecto positivo / afecto negativo, agotamiento emocional, pero no obtuvo el resultado esperado (Wright, et al., 2002). Mientras tanto otro reveló hallazgos diferentes, a saber, que al combinar una perspectiva longitudinal a este tipo de análisis, las relaciones aparecían (Zelenski, et al., 2008), lo que indicaba que las personas más felices eran también más productivas. Sin embargo, se discute este hallazgo como confirmación de dicha relación ya que el desempeño se evaluó a través de auto-reporte y no con métodos más objetivos.

Pero estas contradicciones no solo se quedan en el campo de la investigación experimental, transversal o longitudinal. También algunos meta-análisis entran en contraposición mostrando conclusiones diferentes sobre la hipótesis del "happy and productive worker". Por ejemplo, Jones (2006) revisó varios meta-análisis y encontró que la satisfacción laboral se relaciona con el desempeño pero de manera pobre. Sin embargo, en un meta-análisis realizado por Whitman, Van Rooy y Viswesvaran (2010) se encontró que cuando se trabaja la satisfacción como un constructo colectivo, multinivel, los resultados sugieren una estrecha relación entre el desempeño y la felicidad (vale anotar que en esos estudios se trabajó la satisfacción laboral como sinónimo de felicidad laboral). Un resultado similar muestra que trabajar la felicidad desde el nivel de grupo y no solo desde el individual puede contribuir a la aparición de hallazgos diferentes a los reportados por la literatura previa (Taris y Schreurs, 2009). No queda entonces claro si la relación existe o no, y a qué se debe cuando se da.

Es posible que no llegar a resultados concluyentes que establezcan una relación clara entre felicidad y desempeño puede estar determinada por la existencia de variables que median dicha relación. En un estudio ya clásico desarrollado por Wright et al. (2007) se encontró, por ejemplo, que el bienestar psicológico media la relación, lo cual abre la posibilidad de que otras variables también lo hagan. También puede deberse a que el desempeño requiere motivación y la motivación es un concepto que indica activación, la satisfacción va en contra de eso pues suele generar un estado emocional diferente, de calma. Se piensa, por ello, que es la insatisfacción la que afecta el desempeño aunque de manera negativa (Crow y Hartman, 1995). Sin embargo, está no es la única explicación posible a la falta de asociación entre las variables. También puede deberse a la poca uniformidad en las medidas de ambos constructos, u obedecer a razones metodológicas, a problemas de la muestra, entre otros (Jones, 2006), como ya hemos mencionado.

Vimos entonces que la felicidad puede ser intervenida con resultados exitosos, y si bien ya hay estudios que hablan sobre sus efectos en el contexto del trabajo (Salanova, et al. 2013). Aún hay trabajos en lo que se siguen tratando la felicidad y la satisfacción como sinónimos, considerando, erróneamente, que la felicidad puede ser medida a través de la evaluación de la satisfacción con la vida (Seligman, 2016) o que han encontrado contradicciones en los hallazgos. Se trata entonces de un asunto que sigue requiriendo atención científica. 
No obstante, el mensaje que nos debe quedar es que la felicidad puede ser intervenida y, aunque no esté claro cómo se logra que la mejora se refleje en el desempeño, si sabemos de la existencia de otros efectos deseables para la organización que pueden presentarse cuando se incrementa la felicidad.

\section{Visión a largo plazo}

Las intervenciones en la organización tienen sentido si su efecto es estable y duradero. Esto implica que podamos predecir, con los cambios que realizamos, el impacto que se tendrá, bien sea en la productividad, en el desempeño de la gente o en su calidad de vida. Está capacidad de predicción debe sustentarse en estudios e investigaciones, es decir, debe estar soportada de manera tal que los efectos sean calculados y no producto del azar.

Lo anterior implica que, en el caso que estamos trabajando, nos respondamos varias preguntas ¿Cambia la felicidad? ¿Tiene la felicidad efectos en el trabajo? ¿Son estos efectos duraderos y estables? De las dos primeras preguntas nos ocupamos ya en apartados anteriores, estableciendo que hay una parte de la felicidad que es susceptible de cambio y afirmando que si bien suele haber confusión en el tratamiento de algunos conceptos, se conoce que la felicidad tiene efectos positivos en el trabajo. Sobre la tercera pregunta nos centraremos ahora.

En primer lugar conviene destacar la dificultad para hacer investigaciones longitudinales sobre la felicidad. Este tipo de estudios son la manera en la que podemos saber cómo se comporta la felicidad en el largo plazo y qué tanto el efecto de las intervenciones sobre ella permanece en el tiempo. La dificultad mencionada puede sustentarse en la metodología misma o en la idea de que no tiene sentido intervenir algo que se considera volverá al nivel anterior, por razón de la adaptación hedónica (Sheldon y Lyubomirsky, 2006).

La felicidad tiende a mantenerse en el tiempo. Cuando se producen cambios importantes en ella, estos suelen ser temporales, pasajeros (Sheldon y Lyubomirsky, 2007). Es normal que las personas, luego de cierto tiempo, recuperen sus niveles de felicidad de base, esto es producto de lo que se conoce como adaptación hedónica. La existencia de la misma desestimaría los procesos de intervención de la felicidad. Sin embargo, señalan los mismos autores, es posible que algunas estrategias logren que estos afectos positivos permanezcan en niveles superiores por más tiempo (Sheldon y Lyubomirsky, 2007).

Si los efectos de la felicidad en el trabajo fueran esporádicos, las empresas no estarían de acuerdo con aplicar estrategias de intervención que solo mejoran sus condiciones momentáneamente o de forma parcial. En el contexto del trabajo la intervención no solo está ligada a la búsqueda de bienestar, los empresarios buscan que esta se refleje en los indicadores económicos. Conocer qué estrategia permite que la felicidad permanezca en altos niveles y se mantenga en el tiempo, constituye una fuente importante de información para tomar decisiones en relación con las mejores prácticas e intervenciones que podrán 
llevarse a cabo en las empresas.

Es por esto que hay que ver si hay algo más allá de la adaptación hedónica, la cual implica que los seres humanos nos adaptamos y volvemos a la línea de base en cuanto a nuestra felicidad (Brickman y Campbell, 1971; Kahneman, 1999; Lykken y Tellegen, 1996). La esperanza está puesta en estudios en los que se señala que la felicidad pude incrementar al largo plazo (Sheldon, Abad, Ferguson, Gunz, Houser-marko, Nichols y Lyubomirsky, 2010). En otras palabras, los niveles de felicidad pueden cambiar (Lyubomirsky et al., 2011) y hacerlo a lo largo del tiempo si la persona tiene una vida activa y trabaja para tener experiencias positivas (Sheldon, et al. 2010). Este incremento y mantenimiento depende también de cómo las personas interpretan sus experiencias de vida, lo cual es más crítico que la experiencia misma (Lyubomirsky y Tucker, 1998).

Otro argumento que nos permite justificar la gestión de la felicidad dentro de las empresas, por sus efectos duraderos, y el cual supera el obstáculo de la adaptación hedónica, es que siempre se tendrá la posibilidad de trabajar en pro de la propia felicidad (Seligman, et al., 2005). Cuando las personas no trabajan duro para mantener su felicidad se puede volver a su nivel de base, pero si se trabaja con insistencia pueden seguir aumentando los niveles de felicidad $y$ entonces se incrementan también las experiencias que nos hacen sentir permanentemente felices (Seidlitz et al., 1997). Trabajar en pro de la propia felicidad ayuda a pensar positivamente sobre nosotros mismos, lo que a su turno aumenta la felicidad (Campbell, 1981), y la sensación de control personal (Larson, 1989).

Los cambios duraderos y aplicables al mundo del trabajo (Fisher, 2010) no se producen ni por el dinero ni por otros asuntos circunstanciales (Avia y Vázquez, 2011). Mantener e incrementar en el largo plazo la felicidad depende de seguir trabajando para que estos niveles sean elevados, y elegir las estrategias adecuadas. Se trata básicamente, de convertir en hábitos, conductas que favorecen la felicidad, tales como la búsqueda de apoyo social, practicar el optimismo e interesarse por la propia felicidad (Tkach y Lyubomirsky, 2006). La idea es mantener la atención en la mejora de la felicidad de manera que se venza el obstáculo de la adaptación hedónica.

Conviene mencionar acá que, algunos autores señalan que la adaptación hedónica es aplicable a contextos "normales", algunos eventos cruciales pueden cambiar la vida y por tanto el nivel de base de la felicidad (Easterlin, 2006). Si bien este punto de vista es interesante, lo desestimamos como aplicable a nuestro contexto, en la medida que estamos contemplando la intervención de la felicidad en el trabajo como algo que queremos incrementar a través de prácticas organizacionales, las cuales no suelen hacer parte del conjunto de circunstancias de gran impacto que podrían cambiarle la vida a las personas, tales como perder un ser querido, casarse, sufrir un accidente o tener un hijo. Nos interesan por tanto, las acciones que puedan afectar la felicidad en el trabajo y que pueden hacerlo a largo plazo, tales como crear ambientes saludables, de respeto y donde haya apoyo organizacional (Fisher, 2010). 
Se trata entonces de pensar la felicidad como algo que puede tener efectos duraderos, estables y predecibles sobre el desempeño y la productividad. Como una característica personal que podemos gestionar para favorecer la calidad de vida laboral de las personas y al mismo tiempo, como una condición que, si está presente en las personas, aporta positivamente al logro de los objetivos y metas organizacionales.

La visión a largo plazo implica entonces la posibilidad de predecir si la felicidad tendrá cambios estables y duraderos, en razón de que se espera que su incremento redunde en la mejora de indicadores de éxito organizacionales y de las buenas prácticas de gestión humana. Saber que efectivamente la felicidad puede tener cambios duraderos y superar la adaptación hedónica indica que tiene sentido que las organizaciones inviertan en la gestión de la misma.

\section{Reflexiones finales}

Aunque hay mucho por investigar y por conocer todavía en relación con la felicidad, los estudios señalan que se trata de un concepto que describe una característica personal que puede ser medida de manera confiable y válida, cuyos efectos conocidos sobre el trabajo y la empresa son positivos, y que puede ser contemplada dentro de los procesos de intervención y mejora organizacional, pues existen estrategias que desafían la adaptación hedónica, y pueden asegurar que los efectos de la felicidad en el trabajo sean estables y duraderos.

No se trata de una moda empresarial, tampoco de una visión romántica carente de sentido y sustento. Por el contrario, se basa en hallazgos de investigación que sugieren que las inversiones sobre la felicidad, redundan, sí o sí, en los resultados económicos de la empresa.

La felicidad en el trabajo es entonces un constructo teórico multidimensional que merece la atención de las organizaciones y que exige a los psicólogos del trabajo y la organización una comprensión clara del mismo, de sus diferencias y similitudes con otros conceptos. Demanda además conocimiento sobre sus efectos en el mundo del trabajo, de la forma como debemos medirlo e intervenirlo. La felicidad puede tenerse en cuenta desde el punto de vista estratégico por parte de las empresas, con la enorme ganancia de que al trabajarla se apunta también al bienestar y a la calidad de vida laboral de las personas. 
Capítulo 2. Adaptación del Authentic Happiness Inventory (AHI) para población trabajadora colombiana.

\section{Resumen $^{3}$}

La Felicidad es un estado afectivo positivo caracterizado por el disfrute, la gratificación y el encuentro de sentido en la vida. El Authentic Happiness Inventory (AHI) es un instrumento diseñado para medir estas tres dimensiones. En este estudio se evalúan sus propiedades psicométricas con una muestra de 802 trabajadores colombianos. El objetivo es verificar si la escala permite medir, además de la Felicidad en la Vida, la Felicidad en el Trabajo. Para ello se pidió a los participantes responder cada ítem dos veces, primero pensando en su vida en general y luego en su trabajo. Se revisó la validez convergente utilizando la Subjective With Life Scale (SWLS). La confiabilidad se estimó con el Alpha de Cronbach y se hizo un análisis factorial confirmatorio para apreciar la estructura de la escala. Estas condiciones se verificaron en las dos versiones de la prueba. Las correlaciones altas y positivas entre Satisfacción con la Vida y Felicidad (en el Trabajo y en la Vida) ofrecieron evidencia de validez convergente. El Análisis Factorial confirmatorio reveló ajuste de los datos a la estructura tridimensional propuesta y se encontró una adecuada consistencia interna. Las propiedades del instrumento indican que se trata de una escala apta para la evaluación de la Felicidad en la Vida y en el Trabajo en población colombiana trabajadora.

\section{Introducción}

La psicología positiva pone acento en el funcionamiento óptimo y el bienestar de las personas y en investigar las razones por las cuáles estas son saludables y se adaptan adecuadamente a los diferentes entornos (Seligman, Steen, Park, \& Peterson, 2005). Dentro de los muchos constructos que se abordan desde esta visión, el de Felicidad es central por tratarse de una meta humana por excelencia (Fernandez, 2016).

En la literatura científica el concepto de felicidad suele considerarse sinónimo de Bienestar Subjetivo (Diener, Suh, Lucas, \& Smith, 1999; Zelenski, Murphy, \& Jenkins, 2008). Felicidad sería la forma no técnica de referirse al constructo. Desde este punto de vista el concepto se define como la experiencia de emociones positivas, ausencia de negativas y satisfacción con la vida (Diener, 2000). Sin embargo hay autores que consideran que estos dos conceptos son diferentes, siendo el de felicidad más amplio y complejo (Alarcón, 2006). Por ejemplo Quick y Quick (2004) la definen como un estado holístico de bien-estar y bien-hacer. Así, la felicidad surgiría no solo de la experimentación de bienestar sino también de la idea de estar

\footnotetext{
${ }^{3}$ Este capítulo fue publicado íntegramente como: Sanín-Posada, A. y Salanova, M. (2015). Adaptación del Authentic Happiness Inventory (AHI) para población trabajadora Colombiana. Revista Interamericana de Psicología Ocupacional. 34 (2). 76-83
} 
haciendo bien las cosas (Seligman, 2011).

Aunque en ocasiones se le experimenta como estado, la felicidad es esencialmente un rasgo afectivo (Moyano, Flores, \& Soromaa, 2011) que caracteriza a la personas que experimentan una vida placentera (pleasent life), gratificante (engagement life) y con sentido (meaninful life) (Seligman et al., 2005). Con esta definición se trabajará en esta investigación. Es decir, no se asumirá que Felicidad es sinónimo de bienestar subjetivo.

Proponemos que está misma definición puede ser adaptada al contexto laboral, pues se trata de un entorno en el que también puede haber disfrute, sentido y gratificación (Seligman, 2011). La Felicidad en el Trabajo se definiría entonces como un estado afectivo positivo caracterizado por la presencia de emociones positivas, gratificación y sentido en el trabajo.

\section{Instrumentos para medir la felicidad}

Hay una gran variedad de instrumentos que la miden. Se debe a que también hay diferencias en la forma de comprender el concepto en la literatura (Schiffrin \& Nelson, 2010). Dentro de los más usados en la actualidad y que son recurrentes en la literatura están: La Subjetive Happiness Scale (SHS) (Lyubomirsky \& Lepper, 1999), la cual ha sido traducida a varios idiomas (Extremera \& Fernández-Berrocal, 2013; Moghnie \& Kazarian, 2012; Spagnoli, Caetano, \& Silva, 2012). La Satisfaction With Life Scale (SWLS), desarrollada por Diener, Emmons, Larsen y Griffin (1985) y revisada por Pavot y Diener (1993), la cual cuenta con una versión en español (Arce, 2010) y suele utilizarse para revisar la validez convergente de otros instrumentos que miden felicidad (Extremera \& Fernández-Berrocal, 2013; Kaczmarek, Stanko-Kaczmarek, \& Dombrowski, 2011; Moghnie \& Kazarian, 2012; Shepherd, Oliver, \& Schofield, 2014). El Steen Happiness Index (SHI) (Seligman et al., 2005), el cual luego de algunas revisiones se denominó el Autentic Happiness Inventory (AHI).

También están el Ecological Momentary Assessment (EMA), que consiste en monitorear permanente la experimentación de afectos positivos o negativos de las personas durante el día (Dockray et al., 2010); y el Day Recontruction Method (DRM), técnica similar a la anterior pero en la que se pide al individuo recordar sus sentimientos ligados a los acontecimientos que los propiciaron durante el día (Dockray et al., 2010); la Orientation to Happiness Scale (Alper Köse, 2015); el Pemberton Happiness Index (PHI), el cual examina el bienestar general y la felicidad desde el punto de vista hedónico y eudaimonico (Hervás \& Vázquez, 2013); la Escala de Felicidad desarrollada en Perú, que se basa en una conceptualización de Felicidad separada de bienestar subjetivo (Alarcón, 2006); el MUNSH que fue validado en Chile (Moyano et al., 2011), y el PANAS (Watson, Clark, \& Tellegen, 1988), uno de los más usados cuando la investigación en felicidad empezó a incrementarse (Seligman et al., 2005). También se encontró que la felicidad se ha medido con pruebas mono ítem. En ellas se pregunta directamente a las personas qué tan felices se sienten (Pei-shan, 2014; Tsou \& Liu, 2001). No se encontraron escalas para medir la felicidad en el Trabajo. 
De todas estas escalas se descartan las últimas por haber encontrado poca evidencia en la literatura de su uso y sus condiciones psicométricas. Además arrojan información genérica sobre la felicidad y concuerdan poco con la definición del concepto con la que se trabaja en esta investigación. De las tres que se señalan como las más usadas: la SHS (Lyubomirsky \& Lepper, 1999), la SWLS ( Diener et al., 1985) y el AHI se decide utilizar la última pues su estructura y dimensiones concuerdan con el concepto de felicidad desde el que se está trabajando.

En la revisión de la literatura científica que se hizo para verificar si dicho instrumento había sido adaptado ya a población colombiana trabajadora, no se encontró ninguna. Esto muestra un vacío importante por cuanto no se cuenta con instrumentos válidos y confiables para medir la felicidad en población trabajadora colombiana. La importancia de hacerlo radica en que dichas medidas facilitarían la implementación de estrategias y actividades tendientes a favorecerla y garantizarla. Esto es relevante por cuanto la felicidad tiene efectos positivos en el desempeño (Quick \& Quick, 2004; Wright, Larwood, \& Denney, 2002) y en la autopercepción de productividad (Zelenski et al., 2008), ésta relacionada favorablemente con el cumplimiento de valores y con la ciudadanía organizacional (Rego, Ribeiro, \& Cunha, 2010) y se asocia negativamente con el estrés (Schiffrin \& Nelson, 2010), el cual es un daño psicológico que resulta costoso para las personas, las empresas y los países (Ortega \& Salanova, 2016).

Los objetivos del presente estudio son verificar las condiciones psicométricas del $\mathrm{AHI}$ en población Colombiana Trabajadora y revisar si se mantienen cuando se les pide a las personas responder los mismos ítems pero pensando solamente en su trabajo. El instrumento ha sido diseñado para medir "the pleasent life", de "engagement life" y "the meaninful life" como dimensiones de la felicidad (Seligman et al., 2005).

Se hipotetiza que la felicidad en el trabajo y en la vida correlacionarán alta, positiva y significativamente, dado el influjo que tiene el trabajo en la vida de las personas (Atherton, Graham, \& Steedman, 2010). Sin embargo, se trata de dos constructos diferentes cuyas medidas separadas aportarán información interesante. También se espera un funcionamiento psicométrico adecuado del instrumento en ambos contextos (Trabajo y Vida en General).

\section{Método}

\section{Procedimiento y participantes}

La recolección de datos estuvo a cargo de investigadores de apoyo de la Facultad de Ciencias Económicas y Administrativas de la Universidad de Antioquia. Estos fueron capacitados para la administración estandarizada del instrumento en lápiz y papel. También hubo aplicaciones Online (7.6 \%). En ambos casos se pidió el consentimiento firmado de los participantes. Cada uno dedico aproximadamente una hora. La aplicación de lápiz y papel 
se hizo en grupos o de forma individual, siempre con la presencia del investigador de apoyo. Se procedió cumpliendo las leyes que regulan el ejercicio de la psicología en Colombia (Congreso de la República de Colombia, 2006).

La fusión de los datos virtuales con los de lápiz y papel dio como resultado 802 datos válidos. Por razón de displicencia, baja o nula comprensión del propósito del estudio o de la forma de calificación e intentos de manipulación hubo datos que no fueron incluidos dentro de la tabulación. Se dejó constancia de esto en actas.

La muestra, correspondiente a personas de 181 empresas, tiene las siguientes características: Sector Económico (servicios 31.1 \% educativo 22.6 \%, comercial 21.3 \%, industrial $14.5 \%$, otro $5.4 \%$, salud $2.4 \%$, financiero $1.9 \%$ y agroindustrial .9\%), tamaño (más de 300 empleados $41.7 \%$, de 11 a 50 21.2\%, menos de $1014.0 \%$, de 101 a 30010.9 \%, de 51 a $1009.3 \%$ y unipersonal 2.9\%), tipo de empleo (formal $89.5 \%$ ) , tipo de contrato (término indefinido $49.9 \%$, término fijo $28.7 \%$, prestación de servicios $14.9 \%$ y temporal $6.5 \%$ ), estado civil (soltero $57.6 \%$, casado $25.1 \%$, unión libre $10.3 \%$, separado $3.9 \%$, divorciado $1.9 \%$ y viudo $1.3 \%$ ), nivel educativo (técnico/tecnológico $28.8 \%$, bachillerato $28.6 \%$, profesional $22.6 \%$, posgrado $17.7 \%$ y primaria $2.3 \%$ ), edad ( 21 a 25 años $25.5 \%$, de 26 a $3018.0 \%$, de 31 a $3514.0 \%$, de 41 a $4510.1 \%$, de 36 a 40 8.5\%, de 46 a $507.4 \%$, de 51 a $557.1 \%$, de menos de 20 años $6.0 \%$, de 56 a $602.6 \%$ y de más de 61 años .9 \%), género (femenino $54.9 \%$ ), estrato socioeconómico (3 49.1 \%, 2 24.9 \%, 4 14.2 \%, 57.8 \%, 1 $2.9 \%$ y 6 1.1\%). En algunas de las empresas la muestra que participó fue representativa. En esos casos se envió informe de sus resultados.

\section{Instrumentos}

Versión en español del AHI ("Questionnaire Center | Authentic Happiness," 2016). $\alpha=.82$ reportado en Schiffrin y Nelson (2010). Examina el grado en el que la persona posee un estado de ánimo positivo, considera que obtiene logros importantes y gratificantes y le encuentra sentido a su vida. Consta de 24 grupos de cinco afirmaciones cada uno. Van de lo negativo (v.g. rara vez consigo lo que quiero) a lo positivo (v.g. siempre consigo lo que quiero). La persona debe elegir la afirmación de cada grupo con la que más se identifique. AHI en el Trabajo. Para ver si se podía adaptar la escala para que resultara una medida de felicidad en el trabajo, se les pidió a los participantes cumplimentar el mismo cuestionario pero pensando específicamente en su trabajo.

Satisfaction With Life Scale (SWLS). $\alpha=.86$ reportado en Schiffrin y Nelson (2010). Evalúa la Satisfacción con la vida en general. Consta de cinco ítems que se responden con base en una escala tipo Likert con extremos 1 (Completamente en desacuerdo) a 6 (completamente de acuerdo) (v.g. mi vida está cerca de mi ideal). A esta escala se le eliminó el punto central por los problemas psicométricos que eso implica (Hodge \& Gillespie, 2003; Raaijmakers, Hoof, Hart, Verbogt, \& Vollebergh, 2000).

Análisis de datos 
Con SPSS (v.17) se calculó la correlación entre los resultados del SWLS con los del AHI para revisar la validez convergente. Luego se calculó el Alpha de Cronbach como indicador de su consistencia interna. Finalmente con el Stata (v.12) se realizó un Análisis Factorial Confirmatorio (AFC) para verificar la estructura de la escala. Este procedimiento de verificación psicométrica es similar al seguido por otros investigadores que han verificado las condiciones de instrumentos que miden felicidad o bienestar subjetivo (Extremera \& Fernández-Berrocal, 2013; Moghnie \& Kazarian, 2012; Shepherd et al., 2014).

\section{Resultados}

En la Tabla 1 se muestran las medias, desviaciones estándar y correlaciones entre las variables del estudio.

Tabla 1. Medias (M), Desviaciones Estándar (DE) y Correlaciones entre las variables del estudio

\begin{tabular}{|c|c|c|c|c|c|c|c|c|c|c|}
\hline & M & $\mathrm{DE}$ & 1 & 2 & 3 & 4 & 5 & 6 & 7 & 8 \\
\hline 1. AHI TRABAJO & 3,56 & 0,54 & - & & & & & & & \\
\hline 2. Pleasent Life Trabajo & 3,57 & 0,68 &, $919^{* *}$ & - & & & & & & \\
\hline 3. Engagement Life Trabajo & 3,39 & 0,54 &, $907^{* *}$ &, $758^{* *}$ & - & & & & & \\
\hline 4. Meaninful Life Trabajo & 3,72 & 0,56 &, $891^{* *}$ &, $712^{* *}$ &, $748^{* *}$ & - & & & & \\
\hline 5. AHI VIDA & 3,72 & 0,54 &, $614^{* *}$ &, $565^{* *}$ &, $538^{* *}$ &, $565^{* *}$ & - & & & \\
\hline 6. Pleasent Life Vida & 3,76 & 0,67 &, $572^{* *}$ &, $602^{* *}$ &, $465^{* *}$ &, $473^{* *}$ &, $906^{* *}$ & - & & \\
\hline 7. Engagement Life Vida & 3,54 & 0,51 &, $551^{* *}$ & $468^{* *}$ &, $576^{* *}$ & $477^{* *}$ & $889^{* *}$ &, $718^{* *}$ & - & \\
\hline 8. Meaninful Life Vida & 3,86 & 0,59 &, $535^{* *}$ & $447^{* *}$ & $436^{* *}$ &, $587^{* *}$ & $897^{* *}$ &, $709^{* *}$ &, $728^{* *}$ & - \\
\hline 9. SWLS & 4,49 & 0,90 & $425^{* *}$ &, $396^{* *}$ &, $373^{* *}$ &, $395^{* *}$ & $460^{* *}$ & $428^{* *}$ &, $397^{* *}$ & $421^{* *}$ \\
\hline
\end{tabular}

Nota. Correlaciones: ${ }^{* *} \mathrm{p}<.000$.

Las correlaciones más altas se dan entre el total cada escala ( $\mathrm{AHI}$ en el Trabajo y $\mathrm{AHI}$ en la Vida) y sus respectivas dimensiones. Las que se dan entre AHI en el Trabajo y AHI en la Vida son también altas, pero no tanto como para considerar que se trata del mismo constructo. Esto se sustenta en el comportamiento de las correlaciones entre sus respectivas dimensiones.

También se observa que ambas escalas presentan correlaciones altas y significativas con SWLS, lo que aporta evidencia de validez convergente y es similar a lo encontrado en otros estudios (Kaczmarek, Bujacz, \& Eid, 2014; Shepherd et al., 2014).

El Cálculo del Alpha de Cronbach como medida de consistencia interna reveló índices superiores a lo indicado como conveniente en la literatura (.70) (Kaplan \& Saccuzzo, 2006; Nunnally \& Berstein, 1999). Para la escala de Felicidad en la Vida $(\alpha=.921)$ y sus dimensiones: Pleasent Life $(\alpha=.854)$, Engagement Life $(\alpha=.803)$ y Meaninful Life $(\alpha=.749)$. 
Lo mismo sucedió con Felicidad en el Trabajo $(\alpha=.922)$ y sus dimensiones Pleasent Life ( $\alpha$ $=.856)$, Engagement Life $(\alpha=.820)$ y Meaninful Life $(\alpha=.740)$.

Para el AFC se revisó el ajuste del modelo de tres factores usando la Estimación de Máxima Verosimilitud. La bondad de ajuste se verificó con el Root Mean Square Error of Approximation (RMSEA) y con los índices relativos Tucker Lewis Index (TLI) y Comparative Fit Index (CFI). En el RMSEA los valores inferiores a .070 y con probabilidad superior a .050 se consideran aceptables, los otros dos índices lo son si sus valores son superiores a .90 (Jöreskog \& Sörbom, 1986).

Los análisis se replicaron limitando la ecuación a un solo factor. Se hizo para ver revisar el efecto del sesgo que puede producirse por la varianza común derivada de la aplicación del mismo método (Podsakoff, MacKenzie, \& Podsakoff, 2011).

Tabla 2. AFC y bondad de ajuste

\begin{tabular}{|c|c|c|c|c|c|c|c|c|c|}
\hline \multirow[b]{2}{*}{ Contexto } & \multirow[b]{2}{*}{ Modelo } & \multicolumn{2}{|l|}{$\chi^{2}$} & \multirow[b]{2}{*}{ gl } & \multicolumn{2}{|c|}{ RMSEA } & \multirow[b]{2}{*}{ AIC } & \multirow[b]{2}{*}{$\mathrm{CFI}$} & \multirow[b]{2}{*}{ TLI } \\
\hline & & valor & $p$ & & valor & $p$ & & & \\
\hline \multirow[t]{3}{*}{ Trabajo } & AHI tres factores & 807,682 & ,000 & 75 &, 053 & 1 & 43296.019 & 918 & 0,909 \\
\hline & $\mathrm{AHI}$ un factor & 892,218 & ,000 & 72 & ,056 & 1 & 43374.555 & ,906 & 0,897 \\
\hline & Diferencia & -84.536 & - & 3 &,- 003 & - & -78.536 & ,012 & ,012 \\
\hline \multirow[t]{3}{*}{ Vida } & $\mathrm{AHI}$ tres factores & 792,971 & ,000 & 75 & ,052 & 1 & 43183.660 & ,916 & 0,907 \\
\hline & $\mathrm{AHI}$ un factor & 878,149 & ,000 & 72 & ,056 & 1 & 43262.838 & 904 & 0,894 \\
\hline & Diferencia & -85.178 & - & 3 &,- 004 & - & -79.178 & ,012 & ,013 \\
\hline
\end{tabular}

Nota: $\chi^{2}=\mathrm{Ji}$ Cuadrado; gl= Grados de Libertad; RMSEA: Root Mean Square Error of Approximation; AIC = Akaike's Information Criterion; CFI =Comparative Fit Index; TLI = Tucker Lewis Index

En la Tabla 2 se observa que todos los modelos ajustan a los datos (RMSEA <.070, $p>0.05$; CFI y $\mathrm{TLI}>$.90). Sin embargo, los de tres factores muestran un ajuste significativamente mejor que los de un factor, tanto para la Escala de Felicidad en el Trabajo (Delta $\chi^{2}=84.536$, $p<0.001$ ) como para la de Felicidad en la Vida (Delta $\chi^{2}=85.178, p<0.001$ ).

\section{Discusión}

El propósito de este estudio fue verificar las condiciones psicométricas de un instrumento que mida felicidad en población colombiana trabajadora y revisar si estas se mantenían cuando se les pedía a las personas responder a los mismos ítems pensando en su trabajo. Como se esperaba se encontraron correlaciones significativas y positivas entre AHI y SWLS (Avia \& Vázquez, 2011; Kaczmarek et al., 2011; Seligman, 2011). Esto constituye evidencia de validez convergente. También se encontró una relación alta y significativa entre AHI en el Trabajo y AHI Vida, lo cual también se esperaba por el alto impacto que tiene el trabajo 
en la vida de las personas (Aguilar \& Rentería, 2009). Sin embargo, las correlaciones entre las dimensiones de estas subescalas fueron más bajas, lo que permite hablar de constructos relacionados pero diferentes.

También se encontró un nivel de consistencia interna alto. Esta es similar a la reportada en otros estudios (Seligman et al., 2005).

Los AFC mostraron que los modelos de tres factores ajustan mejor a los datos que los de un solo factor. Se confirma que el instrumento mide con precisión las tres dimensiones de felicidad contempladas. Esto se da tanto en el en la medición de la Felicidad en la Vida como en la medición de Felicidad en el Trabajo.

Estos hallazgos son importantes pues la posibilidad de medir la felicidad de manera válida y confiable da un impulso a la psicología positiva en la medida que se puede tener una aproximación científica a conceptos relevantes para la investigación(Alarcón, 2006; Avia \& Vázquez, 2011; Diener et al., 1999; Lyubomirsky \& Lepper, 1999).

Lo anterior señala que la investigación ha sido exitosa. Se cuenta entonces con instrumentos con condiciones psicométricas adecuadas que permiten la medición de los atributos señalados y por tanto su monitoreo. Esto es positivo por cuanto las medidas psicológicas son un soporte a la investigación y a la intervención psicológica, permiten ver cambios y, de esta manera, favorecen la comprensión de los procesos psicológicos y el desarrollo de técnicas de intervención.

\section{Conclusiones y limitaciones}

Los análisis nos permitieron no solo conocer las propiedades psicométricas de los instrumentos, las cuales son adecuadas, sino apreciar su estructura interna. Se pudo constatar que además de medir la felicidad de manera general, también se puede conocer el nivel de algunas de sus dimensiones como el estado de ánimo positivo (pleasent life), el compromiso positivo con la vida (engagement life) y el sentido de vida (meaninful life). Esto favorece una mira holística del constructo.

Pese a lo anterior se señalan algunas limitaciones del presente estudio. En primer lugar la muestra pudo haber sido más amplia. La mayoría de los casos son solo de una de las ciudades del país (Medellín) por lo que se podría pensar que el instrumento sería solo aplicable allí. Pese a esto varias de las personas que participaron provienen de otras regiones de Colombia. Además, se trató de una muestra suficientemente heterogénea según se pudo constatar en los datos sociodemográficos reportados.

Futuros estudios deberán indagar por la invarianza factorial del instrumento, la cual permitirá ver si efectivamente estamos hablando de medidas con aplicabilidad transcultural (Bieda et al., 2016). 
También es una limitación el hecho de que las medidas posean sesgo, lo que podría estar asociado con la idea de que las personas se quieren mostrar como más felices y de lo que en verdad son. Sin embargo, esta limitación es típica en la medida de estos atributos (Avia \& Vázquez, 2011) y no puede ser adjudicada solo a Colombia pues ha sido identificada en muchos otros países. Además, no puede ser tampoco adjudicada a la homogeneidad de la muestra pues, como se mencionó, esta es altamente heterogénea.

Este trabajo es entonces un aporte importante al desarrollo de la psicología positiva en entornos laborales. Se trata de un avance relevante pues permite contar con un instrumento adecuado y adaptado para población Colombiana Trabajadora pudiendo medir no solo la Felicidad en la Vida sino también la Felicidad en el Trabajo. 
Capítulo 3. Verificación de las condiciones psicométricas del Test de Orientación en la Vida (LOT-R) sobre Optimismo Disposicional, aplicado en población trabajadora Colombiana.

\section{Resumen $^{4}$}

El optimismo/pesimismo disposicional es un sistema de creencias positivas/negativas acerca de los eventos. El Test de Orientación en la Vida es un instrumento diseñado para medirlo. En este estudio se evalúan sus propiedades psicométricas con una muestra de 791 trabajadores colombianos. El objetivo es verificar si la escala permite medir, además del Optimismo/Pesimismo en la Vida, el relativo a la Organización y al Trabajo de forma válida y confiable. Para ello se pidió a los participantes responder cada ítem tres veces, primero pensando en su vida en general, luego en su empresa y finalmente en su trabajo. Se revisó la validez convergente utilizando la Subjective Whit Life Scale (SWLS). La consistencia interna se estimó con la fórmula de la Confiabilidad Compuesta y con el Alpha de Cronbach. Finalmente se hizo un análisis factorial confirmatorio para apreciar la estructura de la escala. Estas condiciones se verificaron en las tres versiones de la prueba. Hubo correlaciones altas, significativas y positivas entre Satisfacción con la Vida y Optimismo (en los tres enfoques) y negativas con Pesimismo (en los tres enfoques), lo que es evidencia de validez convergente. El Análisis Factorial Confirmatorio mostró ajuste de los datos a la estructura bidimensional en todos los casos. Finalmente se encontró una adecuada consistencia interna. Lo hallazgos indican que esta es una escala idónea para la evaluación del Optimismo/Pesimismo en la Vida, la Empresa y el Trabajo en la población objetivo.

\section{Introducción}

La Psicología Positiva se ocupa de estudiar el funcionamiento óptimo de las personas (Seligman, Steen, Park, \& Peterson, 2005). Esto implica comprender e investigar las variables que pueden favorecerlo. Dentro de las muchas existentes está el optimismo, el cual se ha encontrado afecta positivamente el bienestar y la salud (Augusto-Landa, Pulido-Martos, \& Lopez-Zafra, 2011; Londoño-Pérez \& Velasco-Salamanca, 2015; Scheier, Carver, \& Bridges, 1994).

El optimismo es la "inclinación a esperar resultados favorables" (Marshall, Wortman, Kusulas, Hervig, \& Vickers, 1992, p. 1067). Es una sistema de creencias aprendidas en relación con los eventos próximos, los cuales se considera serán beneficiosos (Carver \& Scheier, 2014). Puede estar más o menos sustentado y ser más o menos persistente dependiendo de la información con que se cuente (Avia \& Vázquez, 2011; Vera-Villarroel, Córdova-Rubio, \& Celis-Atenas, 2009) y puede basarse en información objetiva o subjetiva (Scheier et al., 1994).

\footnotetext{
${ }^{4}$ Este capítulo fue sometido para su publicación en la Revista Iberoamericana de Diagnóstico y Evaluación Psicológica.
} 
Se le ha definido como rasgo, lo que significa que caracteriza a las personas (Bérdi \& Köteles, 2010; Burke, Joyner, Czech, \& Wilson, 2000; Carver \& Scheier, 2014; García-Naveira, RuizBarquín, \& Ortín, 2015; Steca, Monzani, Greco, Chiesi, \& Primi, 2015), lo cual, no obstante, está supeditado a procesos meta-cognitivos. No basta entonces con la expectativa positiva sino que se requiere saber qué tanto las personas creen en ellas (Briñol, Gandarillas, Horcajo, \& Becerra, 2010).

Por su parte, el pesimismo se define de manera antagónica al optimismo. Sin embargo no se trata de polos opuestos (Avia \& Vázquez, 2011; Herzberg, Glaesmer, \& Hoyer, 2006; Segerstrom, Evans, \& Eisenlohr-Moul, 2011) sino de variables que correlacionan negativamente y que tienen diferentes efectos (Marshall, et al, 1992).

Proponemos que las definiciones de optimismo y pesimismo se pueden adaptar al contexto laboral, pues se trata de un entorno en el que también puede haber creencias positivas frente a lo que uno logrará y a lo que logrará la empresa. En este contexto el optimismo no sería un rasgo y estaría afectado por las condiciones particulares del entorno del trabajo (Aguilar \& Rentería, 2009).

El optimismo laboral lo entenderíamos como la creencia en que se obtendrán buenos resultados en el trabajo. Esto puede tomar dos vertientes. Por una parte, la creencia sobre lo que uno mismo podrá lograr (Optimismo en el Trabajo). Por otra parte, la creencia sobre lo que podrá lograr el equipo o la empresa (Optimismo en la Empresa). Ambas creencias estarían determinadas por el optimismo como rasgo.

Tenemos entonces tres tipos de optimismo. Uno general visto como independiente del contexto y dos asociados con el mundo laboral.

\section{Instrumentos para medir el Optimismo}

La medición de los aspectos positivos es relativamente nueva si se compara con el tiempo que llevan explorándose los negativos (Seligman et al., 2005). Sin embargo, la medición del optimismo tiene ya más de 30 años de historia. En la literatura se encuentran herramientas como el Cuestionario de Optimismo (Pedrosa, Celis-Atenas, Suárez-Álvarez, García-Cueto, \& Muñiz, 2015), el Optimism-Pessimism Scale (Burke et al., 2000), el Life Orientaton Test LOT- (Scheier \& Carver, 1985) y su versión revisada el -LOT-R- (Scheier et al., 1994).

Por mucho, el LOT-R ha sido el instrumento más usado. Este permite medir optimismo y pesimismo como dos dimensiones relacionadas y muestra, en estudios de su calidad psicométrica, una adecuada validez predictiva y discriminante. Se han verificado sus condiciones psicométricas en países como Canadá (Trottier, Trudel, Mageau, \& Halliwell, 2008), China (Li, 2012; Xia, Wu, Zhang, Xu, \& Xu, 2016), Portugal (Laranjeira, 2008), Chile (Vera-Villarroel et al., 2009), Alemania (Glaesmer, Hoyer, Klotsche, \& Herzberg, 2008; 
Herzberg et al., 2006), Brasil (Bandeira, Bekou, Lott, Teixeira, \& Rocha, 2002; Bastianello, Pacico, \& Hutz, 2014), Eslovaquia (Köverová \& Ferjenčik, 2013), Hungría (Bérdi \& Köteles, 2010), Holanda (ten Klooster et al., 2010), Grecia, (Lyrakos, Damigos, Mavreas, Georgia, \& Dimoliatis, 2010), Italia (Giannini, Schuldberg, Di Fabio, \& Gargaro, 2008; Steca et al., 2015) Serbia (Jovanović \& Gavrilov-Jerković, 2013), Hong Kong (Lai, Cheung, Lee, \& Yu, 1998), Japón (Sakamoto \& Tanaka, 2002) y España (Otero, Luengo, Romero, Gómez, \& Castro, 1998).

La versión en castellano ha sido validada por otros autores en diferentes muestras de habla hispana reportando también condiciones adecuadas (Ferrando, Chico, \& Tous, 2002; García-Naveira et al., 2015; Landero Hernández \& González Ramirez, 2009; Rondón-Bernard \& Angelucci-Bastidas, 2016).

En Colombia se hizo también una verificación de su condiciones psicométricas con una población que incluyó, entre otras personas, a un grupo de 730 trabajadores de distintas ciudades del país (Zenger et al., 2013). También se ha utilizado el LOT-R en el país en otros trabajos (Londoño-Pérez, 2009; Londoño-Pérez \& Velasco-Salamanca, 2015; Salamanca \& Pérez, 2011).De estas muestras Colombianas solo la primera incluyó población trabajadora. Sin embargo, allí no se midió el optimismo con el referente que nos interesa en esta investigación (empresa y trabajo).

A pesar de las críticas que ha recibido el instrumento (Pedrosa et al., 2015), su buen funcionamiento psicométrico verificado con métodos robustos y rigurosos como Análisis Factoriales Confirmatorios (Glaesmer et al., 2012) y revisión desde la Teoría de Respuesta al Ítem (Chiesi, Galli, Primi, Innocenti Borgi, \& Bonacchi, 2013; Steca et al., 2015) nos Ilevan a elegirlo para el presente estudio.

El interés de verificar sus condiciones en la población objetivo está asociado con poder contar con una herramienta válida y confiable que permita monitorear este atributo en el trabajo, contexto en el que este constructo es de especial interés (Norrish \& Vella-Brodrick, 2008). Esto se debe a resultados de investigación que muestran, entre otros hallazgos, que los optimistas mantienen sus niveles de desempeño cuando las empresa tienen resultados negativos pero no los pesimistas (Avia \& Vázquez, 2011). Los optimistas suelen reportar menos síntomas físicos (Figueras, 2012; Martínez-Correa, Reyes, García-León, \& Isabel, 2006), están más satisfechos y felices en el trabajo (Youssef \& Luthans, 2007), se desempeñan mejor (Andersson, 2004; Youssef \& Luthans, 2007), y reportan niveles más bajos de depresión y ansiedad (Seligman \& Csikszentmihalyi, 2006).

Aunque también se han encontrado algunos beneficios de ser pesimista (Avia \& Vázquez, 2011), la investigación ha encontrado que es mucho más benéfico para el organismo tener una actitud positiva (Figueras, 2012). 
Pese a todos estos hallazgos aún se sabe poco del optimismo en contextos de trabajo y si este se ve o no afectado por ese entorno particular, en cuyo caso se requeriría de medidas específicas de optimismo relacionado con la empresa y con el trabajo.

Son objetivos del presente estudio revisar las condiciones psicométricas del LOT-R en población colombiana trabajadora y verificar si estas se mantienen al pedirle a las personas cumplimentar el cuestionario pensando primero en su vida, luego en su empresa y luego en el trabajo.

Se hipotetiza que habrá una correlación significativa entre los tres tipos de optimismo que se revisarán y entre los tres de pesimismo. Además, estos correlacionarán negativamente entre sí. Por su parte la Satisfacción con la Vida, medida que se usará para ver la validez convergente, correlacionará positiva y significativamente con las tres dimensiones de optimismo y negativamente con las tres de pesimismo. Esto debido al influjo que tiene el trabajo en la vida de las personas (Atherton, Graham, \& Steedman, 2010). También se espera que el funcionamiento psicométrico del instrumento sea adecuado en los tres contextos (Vida, Empresa y Trabajo).

\section{Método}

\section{Procedimiento y participantes}

Investigadores de apoyo de la Facultad de Ciencias Económicas y Administrativas de la Universidad de Antioquia fueron capacitados para la administración estandarizada del instrumento en lápiz y papel. Se pidió el consentimiento firmado de los participantes. Cada uno dedico aproximadamente 30 minutos a la aplicación, la cual se hizo en grupos o de forma individual. Se procedió cumpliendo las leyes que regulan el ejercicio de la psicología en Colombia (Congreso de la República de Colombia, 2006).

Se trabajó con 791 casos. Se excluyeron los datos de personas con displicencia, baja o nula comprensión del propósito del estudio o de la forma de calificación e intentos de manipulación. Se dejó constancia de esto en actas.

La muestra tiene las siguientes características: Sector Económico (Servicios 30,9\%, Educativo 22,8 \%, Comercial 21,6, Industrial 14,2 \%, Otro 5,4\%, Salud 2,4, Financiero 1,9\% y Agroindustrial ,9\%), tamaño (más de 300 41,4\%, de 11 a 50 21,4\%, menos de 10 empleados 14,0 \%, de 101 a 300 10,8 \%, de 51 a 100 9,4 \% y Unipersonal 3,0 \%), tipo de empleo (formal $89.5 \%$ ) , tipo de contrato (Término Indefinido 49,7\%, Término Fijo 28,9\%, Prestación de Servicios 14,8 \% y Temporal 6,6 \%) estado civil (Soltero 57,7 \%, Casado 24,8 $\%$, Unión libre 10,5 \%, Separado 3,8 \%, Divorciado 1,9 \% y Viudo 1,3 \%), nivel educativo (Bachillerato 28,7 \%, Técnico/Tecnológico 28,4 \%, Profesional 23,0 \%, Posgrado 17,6 \% y Primaria 2,3\%) edad (entre 21 y 25 años 25,6\%, de 26 a 30 17,8\%, de 31 a $3514,1 \%$, de 41 a $4510,0 \%$, de 36 a 40 8,5\%, de 46 a 50 7,5\%, de 51 a 55 7,1\%, con menos de 20 años 6,1 \%, de 56 a 60 2,5 \% y Más de 61 años .9 \%) género (femenino $62.1 \%$ ), estrato 
socioeconómico (3 49,5 \%, 2 24,6 \%, 4 14,3 \%, 5 7,7 \%, 12,9 \% y 6 1,0 \%). A las empresas en las que la muestra fue representativa se les envió informe de sus resultados.

Instrumentos

Versión en castellano del Life Orientation Test-Revisado (LOT-R) (Otero et al., 1998). Consistencia en población colombiana (Optimismo $\alpha=.72$; Pesimismo $\alpha=.57$ ) reportada en Zenger (2013). Cuenta con 10 reactivos que se cumplimentan con base en una escala tipo Likert con extremos 4 "Totalmente de acuerdo" y 1 "Totalmente en desacuerdo" (v.g. En tiempos difíciles, suelo esperar lo mejor). Tres de sus ítems miden optimismo, tres pesimismo y los demás son distractores.

Optimismo en la Empresa y en el Trabajo. Para verificar si se podía adaptar la escala para que resultara una medida de optimismo en la empresa y en el trabajo, se solicitó a cada participante responder el mismo cuestionario anterior pensando primero en su vida en general, segundo en su empresa (para ver el grado en el que cree que en esta se obtendrán resultados positivos/negativos) y tercero en su trabajo (para ver el grado en el que cree que obtendrá resultados positivos/negativos en su trabajo).

Satisfaction With Life Scale (SWLS). Consistencia interna $(\alpha=.86)$ reportada en Schiffrin y Nelson (2010). Mide el nivel de Satisfacción con la Vida. Cuenta con cinco afirmaciones que se responden con una escala tipo Likert. Sus extremos son 6 (completamente de acuerdo) y 1 (Completamente en desacuerdo) (v.g. mi vida está cerca de mi ideal).

A ambas escalas se les eliminó el punto central por los inconvenientes psicométricos que puede representar su conservación (Hodge \& Gillespie, 2003; Raaijmakers, Hoof, Hart, Verbogt, \& Vollebergh, 2000).

Análisis de datos

Se verificó la validez convergente calculando con SPSS (v.17) la correlación entre los resultados del SWLS con los del LOT-R. Se utilizó el cálculo de la confiabilidad compuesta ya que al ser esta una escala con pocos ítems se requiere de un indicador que no se vea afectado por esta condición (Fornell \& Larcker, 1981; Valdunciel, Flórez, \& Davila, 2007). También se calculó el Alpha de Cronbach por ser usado en general en este tipo de análisis. Por último, con Stata (v.12.) se hicieron Análisis Factoriales Confirmatorios (AFC) para verificar cuál estructura (unidimensional o bidimensional) ajustaba mejor a los datos. Esto se replicó en los tres contextos (Vida, Empresa, Trabajo). Este procedimiento de verificación psicométrica es similar al seguido por la mayoría de los autores revisados.

\section{Resultados}

En la Tabla 1 se muestran las medias, desviaciones estándar y correlaciones entres las variables del estudio. 
Tabla 1. Medias (M), Desviaciones Estándar (DE) y Correlaciones entre las variables del estudio

\begin{tabular}{lllllllll} 
& $\mathrm{M}$ & $\mathrm{DE}$ & 1 & 2 & 3 & 4 & 5 & 6 \\
\hline 1. Optimismo en la Vida & 3,57 & 0,53 & - & & & & & \\
2. Pesimismo en la Vida & 1,95 & 0,77 &,$- 147^{* *}$ & - & & & & \\
3. Optimismo en la Empresa & 3,44 & 0,56 &, $613^{* *}$ &,$- 126^{* *}$ & - & & & \\
4. Pesimismo en la Empresa & 1,95 & 0,74 &,$- 170^{* *}$ &, $755^{* *}$ &,$- 199^{* *}$ & - & & \\
5. Optimismo en el Trabajo & 3,45 & 0,56 &, $698^{* *}$ &,$- 155^{* *}$ &, $811^{* *}$ &,$- 200^{* *}$ & - & \\
6. Pesimismo en el Trabajo & 1,95 & 0,73 &,$- 161^{* *}$ &, $805^{* *}$ &,$- 171^{* *}$ &, $873^{* *}$ &,$- 191^{* *}$ & - \\
7. SWLS & 4,49 & 0,90 &, $278^{* *}$ &,$- 109^{* *}$ &, $242^{* *}$ &,$- 159^{* *}$ &, $261^{* *}$ &,$- 145^{* *}$ \\
\hline
\end{tabular}

Nota. Correlaciones: ${ }^{* *} \mathrm{p}<.000$.

Todas las correlaciones son significativas. Las más altas se dan entre las medidas de optimismo entre sí (Vida, Empresa, Trabajo) y las de pesimismo entre sí (Vida, Empresa, Trabajo). Por su parte todas las variables de optimismo correlacionan negativamente con las de pesimismo, sin embargo, son bajas, lo que sugiere que se trata de constructos diferentes.

Se observa que el resultado en SWLS correlaciona positivamente con las medidas de optimismo y negativamente con las de pesimismo, esto es evidencia de validez convergente.

Tabla 2. Consistencia Interna de las escalas con Alpha de Cronbach $(\alpha)$ y Coeficiente de fiabilidad compuesta $(\rho)$

\begin{tabular}{lll} 
& $\alpha$ & $\rho$ \\
\hline 1. Optimismo en la Vida &, 537 & 0,76 \\
2. Pesimismo en la Vida &, 477 & 0,77 \\
3. Optimismo en la Empresa &, 581 & 0,78 \\
4. Pesimismo en la Empresa &, 483 & 0,75 \\
5. Optimismo en el Trabajo &, 585 & 0,79 \\
6. Pesimismo en el Trabajo &, 483 & 0,75 \\
\hline
\end{tabular}

El resultado del Alpha de Cronbach presenta índices inferiores a los indicados en la literatura (.70) (Kaplan \& Saccuzzo, 2006; Nunnally \& Berstein, 1999). Sin embargo, lo calculados con la fórmula de confiabilidad compuesta son superiores. Se consideran estos últimos mejores indicadores de la consistencia interna de la prueba pues el método no se ve afecto por el reducido número de ítems que la integran.

En los AFC se revisó el ajuste del modelo de dos factores usando la Estimación de Máxima Verosimilitud. Se verificó la bondad de ajuste con el Root Mean Square Error of Approximation (RMSEA) y con los índices relativos Tucker Lewis Index (TLI) y Comparative 
Fit Index (CFI). EI RMSEA se considera indicador de ajustes si sus valores son inferiores a .070 y su probabilidad superior a .050 . TLI y CFI son captables si sus valores son superiores a .90 (Jöreskog \& Sörbom, 1986).

También se verificó la bondad de ajuste de la estructura unifactorial para contrastar con lo encontrado en otros estudios y revisar el efecto de la varianza común del método (Podsakoff, MacKenzie, \& Podsakoff, 2011).

Tabla 3. AFC y bondad de ajuste

\begin{tabular}{|c|c|c|c|c|c|c|c|c|c|}
\hline \multirow[b]{2}{*}{ Contexto } & \multirow[b]{2}{*}{ Modelo } & \multicolumn{2}{|l|}{$\chi^{2}$} & \multicolumn{3}{|c|}{ RMSEA } & \multirow[b]{2}{*}{ AIC } & \multirow[b]{2}{*}{$\mathrm{CFI}$} & \multirow[b]{2}{*}{ TLI } \\
\hline & & Valor & $p$ & $\mathrm{gl}$ & valor & $p$ & & & \\
\hline \multirow[t]{3}{*}{ Vida } & LOT-R dos factores & 13,543 & 0,094 & 19 & 0,030 & 0,874 & 12108.122 & 0,981 & 0,964 \\
\hline & LOT-R un factor & 83,417 & 0,000 & 18 & 0,104 & 0,000 & 12175.996 & 0,739 & 0,566 \\
\hline & Diferencia & $-69,874$ & - & 1 & $-0,074$ & - & $-67,874$ & 0,242 & 0,398 \\
\hline \multirow[t]{3}{*}{ Empresa } & LOT-R dos factores & 13,089 & 0,000 & 19 & 0,030 & 0,868 & 11364.528 & 0,982 & 0,966 \\
\hline & LOT-R un factor & 63,486 & 0,000 & 18 & 0,092 & 0,001 & 11412.925 & 0,809 & 0,681 \\
\hline & Diferencia & $-50,397$ & - & 1 & $-0,062$ & 0,867 & $-48,397$ & 0,173 & 0,285 \\
\hline \multirow[t]{3}{*}{ Trabajo } & LOT-R dos factores & 12,133 & 0,000 & 19 & 0,026 & 0,914 & 11844.328 & 0,987 & 0,976 \\
\hline & LOT-R un factor & 68,452 & 0,000 & 18 & 0,093 & 0,000 & 11898.647 & 0,817 & 0,696 \\
\hline & Diferencia & $-56,319$ & - & 1 & $-0,067$ & 0,914 & $-54,319$ & 0,170 & 0,280 \\
\hline
\end{tabular}

Nota: $\chi^{2}=\mathrm{Ji}$ Cuadrado; $g l=$ Grados de Libertad; MSEA: Root Mean Square Error of Approximation; AIC = Akaike's Information Criterion; CFI =Comparative Fit Index; TLI = Tucker Lewis Index

En la Tabla 3 se observa que todos los modelos bidimensionales ajustan mejor a los datos (RMSEA < .070, $p>0.05$; CFI y TLI > .90). La diferencia entre estos y los unidimensionales en los tres contextos son significativas (Optimismo en la Vida, Delta $\chi^{2}=69,874, p<0.001$; Optimismo en la Empresa, Delta $\chi^{2}=50,397, p<0.001$; Optimismo en el Trabajo Delta $\chi^{2}=$ $56,319, p<0.001)$.

\section{Discusión}

El propósito de este estudio fue revisar las condiciones psicométricas de la versión en castellano del LOT-R en población colombiana trabajadora y verificar si las mismas se mantenían cuando se cambiaba el contexto con base en el cual las personas respondían.

Tal y como se esperaba hubo correlaciones significativas y positivas entre LOT-R y SWLS (Bailey, Eng, Frisch, \& Snyder, 2007), lo cual es evidencia de la validez convergente de la escala.

También se encontró una relación alta y significativa entre Optimismo en la Vida, en el Trabajo y en la Empresas, lo cual se puede deber al impacto que el mundo laboral tiene en la vida en general de las personas (Aguilar \& Rentería, 2009). Como se vio las correlaciones 
entre pesimismo y optimismo fueron significativas pero bajas, lo cual es usual cuando se calculan estas medidas con este test (Herzberg et al., 2006; Marshall et al., 1992; MartínezCorrea et al., 2006; Segerstrom et al., 2011; ten Klooster et al., 2010).

El nivel de consistencia baja calculado con el Alpha de Cronbach fue imputado a la sensibilidad que tiene este indicador a la cantidad de ítems (Valdunciel et al., 2007). Cuando se calculó un índice que no se ve afectado por esta condición se encontró que tanto pesimismo como optimismo (en sus tres contextos) pueden ser medidos de forma confiable con el instrumento.

Los AFC mostraron que los modelos de dos factores ajustan a los datos. Los de un solo factor no. Esto concuerda con lo encontrado en otros estudios (Cano-García et al., 2015; Fogarty, Perera, Furst, \& Thomas, 2016; Glaesmer et al., 2008; Herzberg et al., 2006; Sakamoto \& Tanaka, 2002; Segerstrom et al., 2011) pero contrasta con los que reportan una estructura unidimensional (Bastianello et al., 2014; Giannini et al., 2008; Lai et al., 1998; Vautier, Raufaste, \& Cariou, 2003). La unidimensionalidad puede deberse a la alta deseabilidad social de la escala (Rauch, Schweizer, \& Moosbrugger, 2007), o a la forma como están redactados los ítems (Vautier \& Raufaste, 2006). Sin embargo, como se apreció en los datos, la estructura unifactorial no ajusta, por lo que resulta mejor separar las medidas en optimismo y pesimismo.

El resultado de la investigación es favorable. Pues se cuenta con escalas que permiten medir adecuadamente el optimismo y el pesimismo en el contexto general, en la empresa y aplicado al trabajo. Esto es conveniente pues los países requieren de medidas propias y ajustadas a sus realidades culturales 0 , al menos, la verificación de que la forma como se miden las variables en otras latitudes es aplicable al propio contexto (Kaplan \& Saccuzzo, 2006).

\section{Conclusiones y limitaciones}

La estructura interna bifactorial se confirma. Se encuentran niveles aceptables de consistencia y evidencia de validez convergente, todo ello indica que se cuenta con un instrumento con condiciones adecuadas.

Se pudo validar la escala en contextos específicos. El funcionamiento psicométrico de la misma nos varió cuando se pidió a las personas responder teniendo como referente contextos diferentes a la vida en general (empresa y trabajo).

Pese a lo anterior se señalan algunas limitaciones del presente estudio. Si bien el tamaño de la muestra es amplio la mayoría de las personas fueron encuestadas en la misma ciudad (Medellín). Sin embargo, aunque no quedó registrado, se tiene conocimiento de que muchas de ellas provienen de otras regiones del país. Además, se trabajó con una muestra heterogénea. 
Es importante que en futuras investigaciones se indague por la invariancia factorial del instrumento, esto para verificar si se trata de medidas con aplicabilidad transcultural (Bieda et al., 2016).

Otra limitación es el sesgo en la medida. Las puntuaciones son altas en general. Sin embargo, esta dificultad es usual en la medida de estos atributos (Avia \& Vázquez, 2011) no es algo específico de esta muestra.

Este estudio es un avance importante para la psicología positiva en entornos laborales, ya que ofrece evidencias de calidad psicométrica de instrumentos que pueden ser usados en población Colombiana Trabajadora para medir no solo el optimismo y el pesimismo en la vida, sino también referido a la empresa y al trabajo. 
Capítulo 4. Satisfacción laboral: el camino entre el crecimiento psicológico y el desempeño laboral en empresas colombianas industriales y de servicios

\section{Resumen $^{5}$}

En el presente estudio se analiza cómo la satisfacción laboral media las relaciones entre el crecimiento psicológico (apertura al cambio, manejo del fracaso y flexibilidad) y el desempeño laboral (extrarol, intrarol y cumplimiento de normas), evaluado este último por los jefes. Participaron 731 empleados y sus correspondientes jefes de cinco empresas Colombianas de los sectores industrial y de servicios. Los resultados obtenidos a través de Ecuaciones Estructurales (Structural Equation Modeling, SEM) muestran que la satisfacción laboral media parcialmente la relación entre apertura al cambio y desempeño extrarol (evaluado por el jefe). Se encontró además que la flexibilidad y la apertura al cambio se asocian positiva y directamente con la satisfacción laboral general y que esta, a su vez predice el desempeño extrarol y el cumplimiento de normas, evaluados por el jefe.

\section{Introducción}

El hecho de que el desempeño laboral afecte la productividad de las organizaciones (Toro, 2000) ha llevado a que los investigadores quieran determinar sus antecedentes y consecuencias. En la literatura se pueden hallar numerosos modelos que intentan cumplir con este propósito (Muchinsky, 2002), y que evidencian aspectos que lo afectan directa o indirectamente (Sanín y Restrepo, 2009). Recientemente se ha desarrollado en Colombia un Modelo de los factores psicosociales que permite entender la complejidad de las relaciones existentes entre las dimensiones organizacionales, las individuales, los resultados de esta interacción y sus efectos sobre la salud, el bienestar, el desarrollo y, por supuesto, el desempeño de las personas en el trabajo (Toro, Londoño, Sanín y Valencia, 2010). Dentro de las variables que integra este modelo se encuentran el Crecimiento Psicológico (en adelante CPs), la Satisfacción Laboral y el Desempeño, Allí la primera variable se muestra como una condición antecedente de las dos siguientes.

La relevancia de estos temas para la psicología organizacional y para las empresas radica en comprender que el comportamiento de las personas, es decir, su desempeño es un fenómeno psicológico que determina la productividad (Toro, 2002), por su parte, la satisfacción favorece el deseo de permanencia de las personas y se asocia con la reducción del ausentismo, la rotación y las quejas del personal (Littlewood, 2008). Se trata, por tanto, de temas de interés empresarial en tanto apuntan a la solidez, eficiencia y permanencia organizacional, lo cual es fundamental en un contexto competitivo y globalizado como el

\footnotetext{
${ }^{5}$ Capítulo publicado íntegramente como: Sanín-Posada, A. \& Salanova, M. (2014). Satisfacción Laboral: el camino entre el Crecimiento Psicológico y el Desempeño Laboral. Universitas Psychologica, 13(1), 15-27. JCR Impact Factor 2014: 0.309 (Psychology, Multidisciplinary Q4). doi:10.11144/Javeriana.UPSY13-1.slcp
} 
que enfrentan las organizaciones actuales, no estando exentas las colombianas de esta demanda global. Al tratarse de temas de carácter psicosocial, es imperativo que los investigadores de la Psicología del Trabajo y las Organizaciones asuman el reto de explorar las condiciones psicológicas y sociales que modulan o favorecen la eficiencia de las personas y por tanto la productividad de la organización.

El CPs es una variable psicológica que puede afectar el comportamiento de las personas en el trabajo y su satisfacción (Romero, 1999) de ahí el interés de analizarlo. En este trabajo nos centraremos en la exploración de las relaciones entre este constructo, la satisfacción laboral general y el desempeño laboral, siendo la satisfacción el mecanismo psicológico que explicaría la relación entre crecimiento psicológico y desempeño, esto es, que ejerce un rol mediador. Entendemos pues que la apertura al cambio, el manejo del fracaso y la flexibilidad (dimensiones de CPs) favorecen evaluaciones más positivas sobre la realidad y aportan, por ello, a la satisfacción del personal (Romero, 1994), la cual, a su vez, puede influir sobre el desempeño de las personas (Zelenski, Murphy, y Jenkins, 2008).

El Crecimiento Psicológico se ha definido como un proceso a través del cual las personas generan estructuras cognitivas que les permiten integrar su realidad exterior e interior (Romero, 1999). Se refiere a la forma como se interpreta la realidad para conseguir visiones más positivas sobre el mundo. Implica un manejo abierto y creativo de la incertidumbre, una amplia apertura al cambio, flexibilidad y manejar el fracaso desde un punto de vista positivo como una importante oportunidad de aprendizaje (Eljuri, 1994; Romero 1994). Si bien se le reconoce como proceso, la aproximación a este concepto suele hacerse a través de la exploración del nivel en el que se encuentran un conjunto de variables (dimensiones) que lo facilitan.

Inicialmente el CPs, como factor de segundo orden, se operacionalizaba a partir de cuatro dimensiones: apertura al cambio, flexibilidad, manejo de la incertidumbre y manejo del fracaso (Romero, 1994;) Sin embargo, en Colombia un estudio reciente mostró una estructura diferente, conformada por tres dimensiones en donde flexibilidad y manejo de la incertidumbre se agrupan en un mismo factor. Apertura al cambio y manejo del fracaso permanecieron como independientes (Sanín, 2010).

La apertura al cambio se entiende como la "percepción de la persona sobre su disposición para exponerse a experiencias nuevas y crecer a partir de ellas" (Sanín, 2010, p. 150). Se trata de la facilidad que ven de afrontar situaciones nuevas, de su juicio sobre la conducta que suelen mostrar ante el cambio.

La flexibilidad, por su parte, se conceptualiza como la posibilidad que tienen las personas de generar cambios que les permiten adaptarse (Kaiser y DeVries, 2010). Caracteriza a personas con iniciativa, que manejan la incertidumbre de manera adecuada y que logran juzgar su entorno desde diversos puntos de vista (Elaine, Pulakos, Arad, Donovan y Plamondon, 2000). Se operacionaliza como el "grado en que la persona se considera capaz de generar construcciones alternativas de personas o situaciones que le ayudan a crecer" 
(Sanín, 2010, p. 150). Se diferencia de la apertura al cambio en tanto implica un cambio que puede ser observado. La apertura solo habla de la disposición.

Finalmente, el manejo del fracaso es la posibilidad de ver positivamente los errores, entenderlos como oportunidades de aprendizaje (Newton, Khanna y Thompson,. 2008). Esta dimensión se operacionaliza como "el nivel en que la persona se considera capaz de utilizar información presente de las situaciones de fracaso de manera favorable para su crecimiento personal" (Sanín, 2010, p. 150). Constituye un punto fundamental del CPs en la medida que, desde una connotación positiva, permite crecer a partir del aprendizaje que se obtiene del error.

\section{Crecimiento Psicológico y Satisfacción Laboral}

La satisfacción laboral se entiende como una reacción afectiva que surge al contrastar la realidad laboral con las expectativas relacionados con esa realidad (Wright y Cropanzano, 2000). En este trabajo se operacionaliza como el nivel de complacencia o agrado que la persona experimenta en relación con su realidad laboral, y se refiere a la reacción afectiva con el trabajo visto como un todo, sin contemplar aspectos particulares de esta realidad (Wright y Cropanzano, 2000). La investigación sugiere que su relación con el CPs podría deberse a que ambas son condiciones necesarias para el bienestar (Romero, 1994) y al hecho de que el CPs está asociado con la orientación de las personas hacia metas valiosas (Romero, 1994). Si la persona le concede valor a su satisfacción dirigirá su proceso de crecimiento en esa dirección. También es posible pensar en la relación de estas dos variables cuando se analizan las dimensiones de CPs separadamente.

Se ha encontrado que bajos niveles de apertura al cambio se relacionan con insatisfacción, irritación laboral y aparición de intenciones de renuncia (Wanberg y Banas, 2000). Desde un enfoque positivo, cabe esperar que tenga una relación positiva con la satisfacción. La flexibilidad, por su parte, favorece la adaptación, lo cual puede consistir en generar cambios que permitan obtener mayor satisfacción (Bond, Flaxman y Bunce, 2008). En cuanto al manejo del fracaso se sabe que cuando se tiene una visión positiva sobre este las personas pueden sentirse más complacidas con las realidades que los rodean (Morales de Romero, 2008), adicionalmente saber manejar el fracaso se asocia con niveles más altos de autoestima (Shelley y Silvia, 2002), la cual, a su vez, se relaciona con armonía, estabilidad emocional y autoeficacia, y negativamente con desajustes emocionales, improductividad y dependencia (Judge y Bono 2001).

En conjunto la apertura al cambio permite una mayor flexibilidad en las expectativas (Wanberg y Banas, 2000). La flexibilidad facilita modificar las realidades del trabajo que resultan adversas (Bond, et al., 2008) y el manejo del fracaso contribuye a sacar provecho de las fallas y, al hacerlo, puede promover reacciones afectivas placenteras y satisfacción laboral (Shelley y Silvia, 2002). 


\section{Crecimiento Psicológico y Desempeño Laboral}

El desempeño se entiende como la acción o acciones que una persona realiza con el ánimo de obtener un resultado (Toro, 2002). En el trabajo puede incluir conductas orientadas al cumplimiento de las responsabilidades del cargo y al desarrollo de procesos inherentes a este (desempeño intrarol), la realización de actividades extras que agregan valor (desempeño extrarol) o a actuaciones coherentes con las normas y principios definidos por la organización (cumplimiento de normas) (Toro, 2010). Esas son las tres dimensiones de desempeño laboral que se analizan como variables dependientes en nuestro modelo. Su relación con el CPS puede explicarse en la medida en que la apertura al cambio, la flexibilidad y el manejo del fracaso contribuyen a la modificación de comportamientos (Romero, 1994). También porque el CPs se encuentra relacionado con el motivo de logro (Salom y Romero, 1994), el cual implica un interés permanente de las personas por alcanzar metas retadoras, las cuales favorecen la persistencia y el esfuerzo $y$, por tanto, un mejor desempeño (Sanín y Restrepo, 2009).

También es posible entender la relación entre estos constructos si se analizan por separado las dimensiones del CPs. La apertura al cambio y la flexibilidad favorecen la adaptación de la persona, lo cual puede consistir en hacer el trabajo de la mejor manera posible, cumpliendo con las normas de la organización y agregando valor a la misma. Por su parte una visión positiva del fracaso permite aprendizaje y desarrollo esto siempre y cuando se valore como algo que enseña, como parte del proceso y no como el punto final (Polivy y Herman, 2002).

De acuerdo con lo anterior y teniendo presente que se quiere probar un modelo de mediación partimos de tres supuestos necesarios para confirmar la hipótesis acerca de que la Satisfacción Laboral media la relación entre el CPs y el Desempeño Laboral: 1) las variables independientes (Dimensiones de CPs) correlacionarán con la mediadora (Satisfacción Laboral) y con las dependientes (dimensiones de Desempeño Laboral). 2). la Satisfacción Laboral y el Desempeño correlacionarán positivamente y 3) al incluir la variable mediadora en el modelo, el efecto entre las variables independientes y la dependiente dejará de ser significativo.

\section{Método}

Participantes y procedimiento

En el estudio participaron 731 empleados de las principales ciudades de Colombia (Medellín, Bogotá y Cali) de diferentes edades (entre 21 y 25 años 23,4\%, 26 a 30 años 22,6\%, 31 a 35 años 15.2\%, 36 a 40 años 12.7\%, 41 a 45 años 12.5\% 46 a 50 años 5.8\%, 51 a 55 años 3.6\%, 56 a 60 años 1.2\% y más de 61 años .1\%), áreas ocupacionales (Operario 80.7\%, Profesional 7.3\%, Empleado de Oficina 6.0\%, Técnicos y Tecnólogos 3.7\%, Directivos $1.6 \%$ y vendedores $.7 \%$ ), estratos socioeconómicos (estrato $251 \%$, estrato $325.5 \%$, estrato $115.2 \%$, Estrato $45.5 \%$, estrato $51.7 \%$ y estrato $6.7 \%$ ) niveles educativos (bachillerato 
$66.0 \%$, Técnico Tecnológico $16.6 \%$, Primaria $7.9 \%$, Profesional 7.1 y posgrado $2.3 \%$ ) y género $64.2 \%$ hombres)y sus respectivos jefes. Encuestadores profesionales estuvieron a cargo de la aplicación de las encuestas y control de la información, siguiendo procesos de recolección de la información estandarizados y normalizados. Se hizo a partir de encuestas aplicadas en grupos de entre 10 y 20 participantes. Los instrumentos se cumplimentaron en un promedio de 30 minutos. En la evaluación hecha por los jefes se les comunicó a quién o a quiénes debían evaluar. Cada persona fue identificada con un código, de tal forma que las evaluaciones hechas por sus jefes pudieran ser emparejadas con las que ellas habían hecho respetando la confidencialidad. Cada jefe tardo alrededor de 10 minutos juzgando el desempeño de cada uno de sus colaboradores. En todas las evaluaciones se pidió el consentimiento informado para la participación en el estudio.

\section{Instrumentos}

El CPs fue evaluado con la Escala de Desarrollo Psicológico (EDEPSI) (Sanín, 2010). Apertura al cambio fue medida con una subescala de cinco ítems $(\alpha=.80)$ (e.g. de ítem: "Me interesa iniciar actividades nuevas con el fin de incrementar mis conocimientos"). Manejo del fracaso con una subescala también de cinco ítems $(\alpha=.80)$ (e.g. de ítem: "Veo el fracaso como una posibilidad de desarrollar mis habilidades"). Flexibilidad se examinó con una escala de cinco ítems ( $\alpha=.70)$ (e.g. de ítem: "Enfrentar situaciones de las que no sé qué esperar me ha servido para desarrollar mis habilidades"). Los participantes respondieron con base en una escala tipo Likert de 6 opciones, siendo 6 (completamente de acuerdo) y 1 (completamente en desacuerdo).

La satisfacción laboral general se midió con la Escala General de satisfacción laboral (EGSL) (Toro, 2010). Un instrumento de siete ítems $(\alpha=.83)$ (e.g. de ítem: "en relación con las exigencias físicas de mi trabajo yo me siento..."). Los participantes respondieron con base en una escala tipo Likert de 6 opciones que van desde 6 (muy satisfecho) a 1 (muy descontento).

Las tres dimensiones de desempeño Laboral fueron evaluadas con la Escala de Evaluación el Desempeño (EED) (Toro, 2010) por parte de los jefes. Desempeño intrarol fue medido con una escala de cinco ítems ( $\alpha=.93)$ (e.g. de ítem: "Realizó todas las actividades especificadas para su cargo"). Desempeño extrarol se midió con una escala de cuatro ítems $(\alpha=.85)$ (e.g. de ítem: "Asumió riesgos sin necesidad."). Cumplimiento de normas se examinó con una escala de cuatro ítems también $(\alpha=.84)$ (e.g. de ítem: "Cumplió las normas especificadas en el reglamento interno de trabajo"). Los jefes respondieron con base en una escala de 6 opciones que evalúa con qué frecuencia el empleado realiza conductas intrarol, extrarol y asociadas al cumplimiento de normas. La escala va desde 6 (todo el tiempo lo hace) a 1 (nunca lo hace).

Tanto las dimensiones de CPs como las de desempeño corresponden a variables latentes en nuestro modelo de ecuaciones estructurales. El CPs es un factor de segundo orden, sin embargo no se trabajó con este, en tanto se consideró que trabajar con las dimensiones 
permitiría una mejor comprensión del proceso psicológico y del tipo y la intensidad de las relaciones con la variable mediadora y las dependientes.

\section{Análisis de Datos}

Se verificaron dos criterios de calidad psicométrica: la validez y confiabilidad de las escalas, la primera se examinó a través de análisis factoriales confirmatorios y la segunda con el Alfa de Cronbach. Luego, para poner a prueba el sesgo de método de la varianza común se aplicó la prueba de un solo factor de Harman (Podsakoff, Mackenzie, Lee y Podsakoff, 2003) con análisis factorial confirmatorio (CFA) para las variables de CPs y desempeño laboral (ver en la Tabla 2: M2 y M5 respectivamente). Después, se realizaron análisis de ecuaciones estructurales utilizando el programa AMOS 16.0 para poner a prueba la hipótesis. Se verificó que se cumplieran los supuestos de la mediación, a saber: que cada una de las variables independientes se relacionara significativamente con la dependiente y con la mediadora y que, a su vez, esta lo hiciera con la dependiente. Luego, que al introducir la variable mediadora en la ecuación desapareciera el efecto de las independientes sobre las dependientes (Baron y Kenny, 1986). De ser así se hablaría de mediación total. Si el efecto permanece sería mediación parcial.

Se verificó el ajuste de cada modelo a través de la Estimación de Máxima Verosimilitud. La bondad de ajuste se evaluó a través de los índices: Root Mean Square Error of Approximation (RMSEA). En este, valores inferiores a .070 se consideran aceptables en cuanto al nivel de ajuste, siempre que su probabilidad sea superior a .050. Normed Fit Index (NFI), Tucker Lewis Index (TLI) y el Comparative Fit Index (CFI) (Jöreskog y Sörbom, 1986). En estos, valores superiores a .90 son considerados aceptables. El ajuste será mejor entre más cercano a 1 sea el valor. También se utilizó el índice Chi Cuadrado.

Se calcularon además los promedios, desviaciones típicas y correlaciones entre variables. No fue posible calcular el ICC (Intraclass Correlation Coefficient), lo cual hubiera permitido ver la adecuación de la medida de cada jefe a su grupo de colaboradores (McGraw y Wong, 1996), debido a que la segmentación de los grupos de colaboradores fue en áreas mayores y no en pequeños grupos, con lo que no fue posible saber qué colaboradores compartían jefe.

\section{Resultados}

Se aprecia en la Tabla 1 las medias, desviaciones típicas y correlaciones entres las variables del estudio. Allí puede verse también el nivel de consistencia de cada escala.

Flexibilidad y manejo del fracaso mostraron correlaciones significativas entre ellas, sin embargo, sólo apertura al cambio correlacionó con una de las dimensiones de desempeño (extrarol). Satisfacción laboral correlacionó con todas las dimensiones de CPs y de desempeño. 
Tabla 1. Correlaciones entre las variables del estudio, Medias (M) y Desviaciones Estándar (SD)

\begin{tabular}{lllllllllll}
\hline & $\alpha$ & $M$ & SD & 1 & 2 & 3 & 4 & 5 & 6 & 7 \\
\hline 1. APERTURA AL CAMBIO & .80 & 3.57 & 1.34 & - & & & & & & \\
2. FLEXIBILIDAD & .70 & 4.94 & .80 & .059 & - & & & & \\
3. MANEJO DEL FRACASO & .80 & 4.74 & 1.17 & .01 & $.35^{* *}$ & - & & & \\
4. SATISFACCIÓN & .79 & 5.27 & .67 & $.10^{* *}$ & $.16^{* *}$ & $.08^{*}$ & - & & \\
5. DESEMPEÑO INTRAROL & .92 & 5.18 & .74 & .02 & -.02 & .03 & $.13^{* *}$ & - & & \\
6. DESEMPEÑO EXTRAROL & .94 & 4.20 & $1.71 .34^{* *}$ & .02 & .05 & $.12^{* *}$ & $.16^{* *}$ & - \\
7. CUMPLIMIENTO DE NORMAS & .83 & 5.35 & .66 & .06 & -.03 & .00 & $.14^{* *}$ & $.56^{* *}$ & $.22^{* *}$ \\
\hline
\end{tabular}

Nota: Correlaciones; ${ }^{* *} p<.01 ;{ }^{*} p<.05$.

A través de ecuaciones estructurales se sometió a verificación el modelo de tres factores de CPs, el de un factor de satisfacción laboral general y el de tres factores de desempeño laboral. Luego, para poner a prueba el sesgo de la varianza común del método, se aplicó la prueba de un solo factor de Harman (Podsakoff, et al., 2003), con análisis factorial confirmatorio (CFA) para las variables de CPs y desempeño laboral (ver Tabla 2). Se observa que los modelos de un solo factor de CPs (Delta $\chi^{2}=1778,57, p<.005$ ) y de desempeño laboral (Delta $\left.\chi^{2}=5046,19, p<.005\right)$ muestran un ajuste más pobre.

Tabla 2. Ajuste de la Estructura Factorial de las Escalas

\begin{tabular}{|c|c|c|c|c|c|c|c|c|c|c|c|c|}
\hline & $x^{2}$ & Df & RMSEA & $p$ & $\mathrm{NFI}$ & TLI & $\mathrm{CFI}$ & $x^{2}$ & RMSEA & NFI & TLI & $\mathrm{CFI}$ \\
\hline M1 & 194.4 & 83 & .03 & 1 & .95 & .96 & .97 & & & & & \\
\hline $\mathrm{M} 2$ & 1973.8 & 90 & .14 & .000 & .51 & .45 & .53 & & & & & \\
\hline Diferencia entre M2-M1 & & & & & & & & $=1778,57$ & .11 & .44 & .51 & .44 \\
\hline M3 & 65.75 & 28 & .05 & .385 & .96 & .96 & .97 & & & & & \\
\hline M4 & 243.2 & 58 & .05 & .205 & .97 & .98 & .98 & & & & & \\
\hline M5 & 5289.4 & 65 & .27 & .000 & .53 & .43 & .53 & & & & & \\
\hline Diferencia entre M5-M4 & & & & & & & & $=5046,19$ & .22 & .44 & .55 & .45 \\
\hline
\end{tabular}

Nota: $\chi^{2}=$ Chi-Cuadrado; $\mathrm{Df}=$ grados de libertad; RMSEA = Root Mean Square Error of Apprximation; $p=$ probabilidad de RMSEA; NFI = Normed Fit Index; TLI = Tucker Lewis Index; CFI = Comparative Fit Index. M1 = Modelo de tres factores de crecimiento psicológico, $\mathrm{M} 2=$ Modelo de un factor de crecimiento psicológico, $\mathrm{M} 3=\mathrm{Modelo}$ de un factor de satisfacción laboral, M4=Modelo de tres factores de desempeño laboral, M5 Modelo de un factor de desempeño laboral.

Luego se verificaron las asociaciones entre las variables, usando ecuaciones estructurales, para finalmente examinar el modelo de investigación. La Tabla 3 muestra los resultados.

Tabla 3. Pasos y ajuste del modelo de Investigación 


\begin{tabular}{llllllll}
\hline & $\chi^{2}$ & Df & RMSEA & $p$ & NFI & TLI & CFI \\
\hline M1 & 33.689 & 14 & .04 & .675 & .97 & .96 & .98 \\
M2 & 49.575 & 39 & .02 & 1 & .99 & .99 & .99 \\
M3 & 15.024 & 14 & .01 & .996 & .99 & .99 & 1 \\
M4 & 84.503 & 56 & .03 & 1 & .98 & .99 & .99 \\
\hline
\end{tabular}

Nota: $\chi^{2}=$ Chi-Cuadrado; $\mathrm{Df}=$ grados de libertad; RMSEA $=$ Root Mean Square Error of Apprximation; $p=$ probabilidad de RMSEA; NFI = Normed Fit Index; TLI = Tucker Lewis Index; $\mathrm{CFI}=$ Comparative Fit Index. $\mathrm{M} 1=$ Modelo de la relación entre las dimensiones de crecimiento psicológico y la satisfacción laboral, M2= Modelo de relación entre las dimensiones de crecimiento psicológico y las de desempeño laboral, M3= Modelo de relación entre Satisfacción Laboral y las Dimensiones de desempeño laboral, M4=Modelo de investigación.

Puede verse que los datos ajustaron bien en cada uno de los pasos. A continuación se presentan los estimados y sus niveles de significación, a través de diagramas de ecuaciones estructurales. Estos resumen los pasos seguidos para la verificación del modelo de investigación.

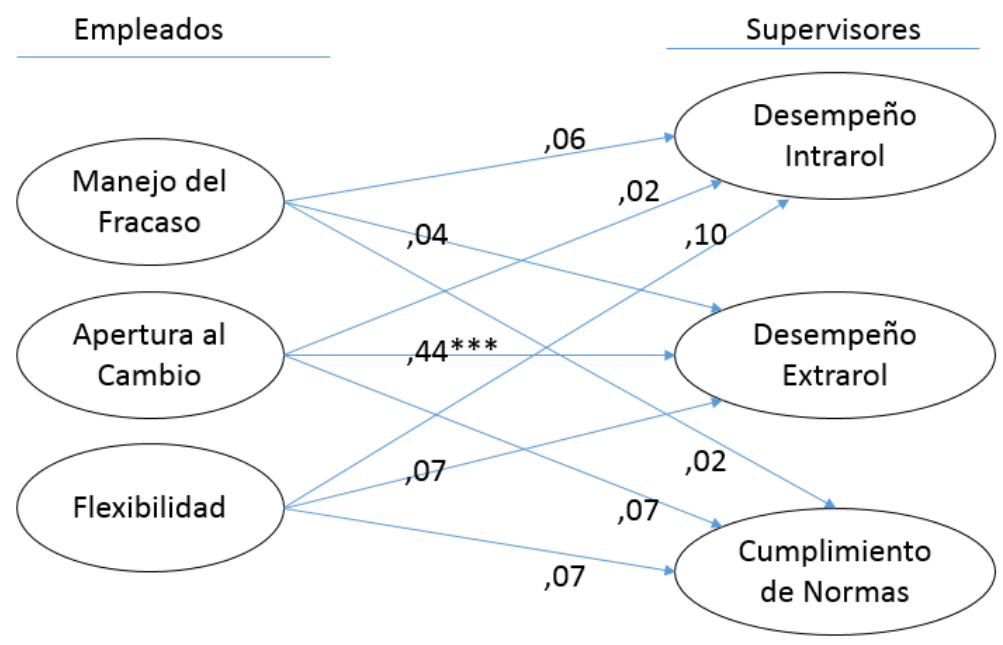

Figura 1. Significación y estimados estandarizados de las relaciones de las Dimensiones de CPs con las de desempeño laboral. ${ }^{* * *} p<.001$.

Se aprecia, primero, la relación entre las variables independientes y las dependientes (ver figura 1). Los resultados evidencian que solo apertura al cambio se relaciona con uno de los componentes del desempeño, a saber con el extrarol, lo que da soporte parcial al modelo.

Si bien esto sugiere la idea de que la satisfacción solo podría ejercer un rol mediador entre apertura al cambio y las conductas extrarol, se mantuvo el modelo completo con el ánimo de observar la intensidad de las demás relaciones. Se siguió entonces el segundo paso de verificación de la mediación, a saber, examinar si existían relaciones significativas entre las variables independientes y la mediadora (Baron y Kenny, 1986) (ver figura 2). 


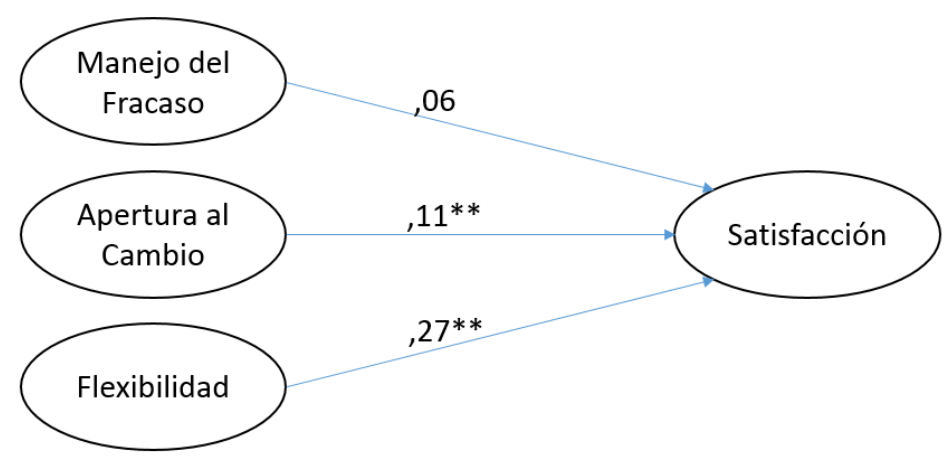

Figura 2. Significación y estimados estandarizados de las relaciones de las Dimensiones de crecimiento psicológico con la satisfacción laboral general. $* * p<.01$.

Flexibilidad y apertura al cambio mostraron una relación significativa con la satisfacción. No lo hizo el manejo del fracaso.

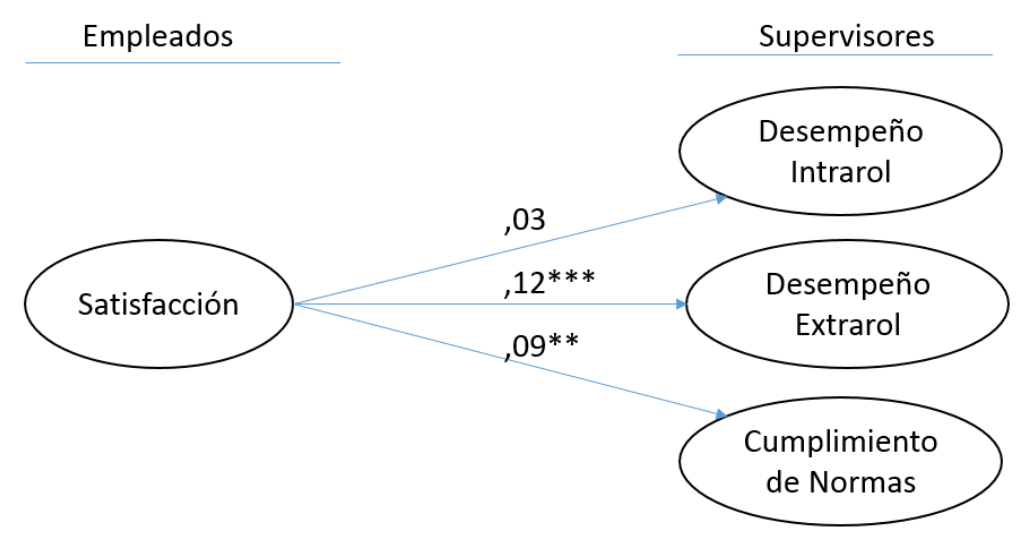

Figura 3. Significación y estimados estandarizados de las relaciones de la satisfacción laboral general con las Dimensiones de desempeño laboral. ${ }^{* *} p<.001 ; * * p<.01$.

El siguiente paso consistió en revisar que la variable mediadora se relacionara con las dependientes (ver figura 3). Los resultados revelan que la satisfacción laboral se asocia con el cumplimiento de normas y con el desempeño extrarol, no con el intrarol.

Se procedió luego a la verificación del modelo de investigación. Según los resultados previos se examinó si la satisfacción laboral general media la relación entre la apertura al cambio y el desempeño extrarol. Las demás relaciones han quedado descartadas por no cumplir los supuestos de la mediación. No se confirma la mediación total. El efecto de la apertura al 
cambio sobre el desempeño extrarol no desaparece al poner en medio la satisfacción laboral (ver figura 4). El cambio del efecto no es significativo según lo muestran los resultados del Test de Sobel (z-value=, 1.53 p>.050) (Baron y Kenny, 1986). Se encuentra entonces una mediación parcial.

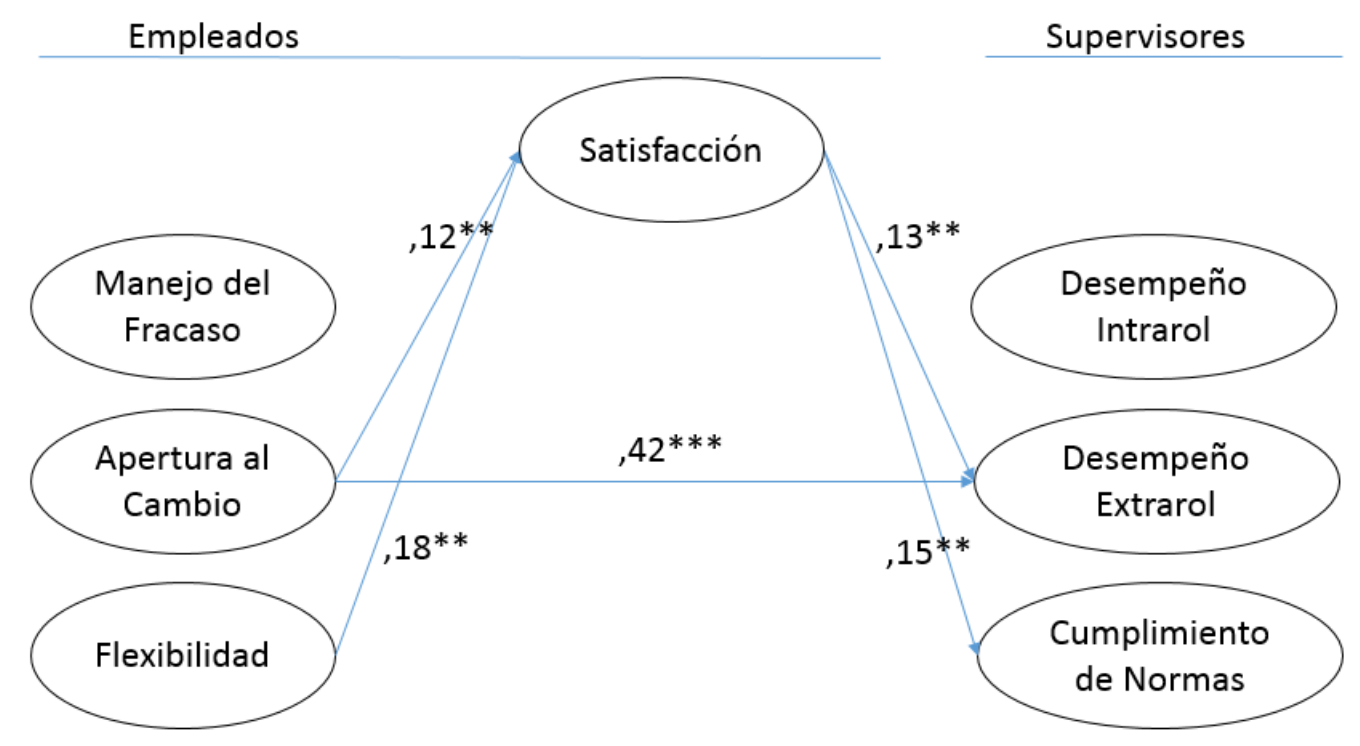

Figura 4. Significación y estimados del modelo de mediación de la satisfacción laboral. ***p $<.001{ }^{* *} p<.01$. Nota: Se conservan solo los Paths significativos con el ánimo de que el esquema resulte más claro.

\section{Discusión}

Se obtuvo confirmación parcial de la hipótesis planteada. De las tres dimensiones de CPs exploradas solo apertura al cambio mostró alguna relación con una de las dimensiones del desempeño laboral (desempeño extrarol). Por su parte, la satisfacción laboral solo reveló asociaciones significativas con el cumplimiento de normas y el desempeño extrarol. El efecto de la apertura al cambio sobre las conductas extrarol no desapareció al ubicar la satisfacción laboral como variable mediadora, lo que nos habla de una mediación parcial.

Esto sugiere que, en el contexto de la investigación, las personas abiertas, que exploran diferentes alternativas y que muestran una actitud positiva ante lo cambiante de la vida, suelen sentirse más satisfechos e involucrarse con actividades que exceden los límites de su cargo. Esto es consistente con la idea de que quienes se cierran a los cambios suelen experimentar insatisfacción laboral e irritación (Wanberg y Banas, 2000). Es posible, además, que la relación entre estas variables se deba a que los jefes consideren que los colaboradores abiertos al cambio son personas que agregan valor a su trabajo (Omar y Uribe, 2005). También es probable que se deba a que ambas son condiciones asociadas con la proactividad (Omar y Uribe, 2005). Este resultado podría explicarse también por algunas 
características de la muestra. Esta está compuesta, en su mayoría, por personas con un nivel académico de bachillerato y tecnológico y con edades inferiores a los 30 años. Se trata de un grupo de población más joven y con más posibilidades de desarrollo, lo cual los puede caracterizar como más abiertos al cambio y como personas que considera que tiene que ofrecer un plus a su organización a sus empresas (Homan, van Knippenberg, van Kleef, y de Dreu, 2007).

La relación de la flexibilidad y la apertura al cambio con la satisfacción laboral sugiere que la capacidad de adaptarse y de abrirse a nuevas experiencias puede llevar a las personas a juzgar más positivamente sus realidades del trabajo y con esto a sentirse más satisfechos, lo cual es consistente con hallazgos previos (Morales de Romero, 2008). Es posible que por tratarse de un proceso de cambio en el cual se busca integrar la realidad exterior e interior desde un punto de vista positivo, experimentado el cambio y la incertidumbre como elementos de CPs (Eljuri, 1994; Salom y Romero, 1994) se logre una alteración de las expectativas o de las condiciones del entorno haciendo que el trabajo se vuelva más satisfactorio. Es posible que de ahí se derive la relación entre esta característica y la salud mental (Bond, et al., 2008). Nuevamente las condiciones sociodemográficas de los sujetos que participaron en el estudio pueden explicar este tipo de resultado en la medida que, como se explicó, las personas más jóvenes, suelen ser más abiertos al cambio, en tanto se encuentran en un proceso de exploración que les permite cambiar más fácilmente sus expectativas (Homan et al. 2007; Lisbona, 2004).

De otra parte, aunque la literatura sugiere que una visión positiva del fracaso podía mejorar la satisfacción (Romero, 1994, 1999), los resultados no apoyan esta premisa. Esto se puede explicar en la medida que, aunque se vea el fracaso positivamente (Newton, et al., 2008) y se le considere útil para el éxito (Polivy y Herman, 2002), esta sigue siendo una experiencia que se vive como antagónica a la felicidad. Difícilmente alguien se sentirá satisfecho por fracasar, especialmente cuando se trata de personal operativo, en un país en el que los jefes poseen dificultades para ofrecer retroalimentación (Toro, 2005), logrando que los errores sean vistos solo desde la perspectiva del fracaso y no del aprendizaje. Tampoco se encontró una asociación de esta dimensión del CPs con el desempeño, lo cual puede deberse a que la sola visión positiva del fracaso no garantiza un cambio comportamental.

Por su parte aunque flexibilidad no se relacionó con ninguna de las dimensiones del desempeño, si lo hace con cumplimiento de normas de manera indirecta, vía Satisfacción. En este caso la satisfacción es un mecanismo psicológico que explica las relaciones entre otras variables.

La falta de asociación directa de la flexibilidad y el manejo del fracaso con las dimensiones de Desempeño Laboral podría explicarse porque estos atributos del CPs no producen cambios sobre condiciones antecedentes del desempeño como la motivación o las habilidades (Toro, 2002). Es posible que el manejo del fracaso afecte el desempeño hacia futuro, justo en el momento en el que el aprendizaje derivado de este se traduce a la 
práctica (Kirkpatrick, y Kirkpatrick, 2009) o cuando los jefes contribuyen a verlo así, especialmente en personas que se encuentran en los primeros años de trabajo y en niveles jerárquicos bajos como los que caracterizan a la muestra de este estudio. La cual, por lo demás, suele ser demandante de aprecio y afecto por parte de sus superiores (Toro, 1996). Por su parte la flexibilidad podría afectar el desempeño intrarol en contextos y cargos donde esta sea una característica exigida por la organización, pues se sabe que una habilidad o competencia solo se desarrolla y evidencia si el contexto lo exige (Spencer, McClelland y Spencer, 1990). Si bien son muchas las ocasiones en las que las personas deban enfrentar la incertidumbre (Taborda, 2010) y se requiere de flexibilidad por estar en un contexto de cambio permanente, se trata todavía de atributos que se demandan más en personas con responsabilidad de mando en la organización (Sanín 2007). Es decir que una persona con una flexibilidad alta y un buen manejo de la incertidumbre podría mejorar o no su desempeño dependiendo del nivel en que su tarea se lo exija. Este es un tema interesante de investigación, pero que escapa a los propósitos del presente estudio.

Otro resultado nos muestra que la satisfacción de las personas puede motivarlas a dar la milla extra (Omar y Uribe, 2005) y a mostrarse coherentes con las normas y principios definidos por la organización, pero no necesariamente a un mejor desempeño intrarol (Wright y Cropanzano, 2000). Según esto, es posible que una persona insatisfecha haga bien su trabajo y que, por el contrario, una satisfecha lo haga de manera pobre. La satisfacción podrá afectar el desempeño de rol, solo si se transforma en un elemento motivacional (Lock, y Lathan, 1990).

Los resultados de esta investigación aportan conocimiento en relación con aspectos positivos del trabajo y de la vida de las personas, y a la comprensión sobre los antecedentes y las consecuencias de factores psicosociales, además muestra algunas variables que anteceden el desempeño y la satisfacción de las personas. Otorga además, soporte a investigaciones previas que muestran los efectos de la satisfacción sobre las conductas extrarol e intrarol y revela una nueva categoría de desempeño sobre la que tiene efectos, el cumplimiento de normas.

Desde el punto de vista práctico estos hallazgos muestran que las organizaciones interesadas en mejorar la satisfacción de su personal $y$, con esto, reducir sus efectos negativos (rotación, ausentismo, quejas del personal...) deberán apuntar al desarrollo de la flexibilidad y la apertura al cambio de su personal. El hallazgo resulta fundamental para las empresas en general, y especialmente para las Colombianas, en tanto les permite entender sobré que aspectos hacer gestión para conseguir reducciones de la rotación y el ausentismo del personal, dos problemas comunes que ocasionan pérdidas económicas considerables (Littlewood, 2008). En este sentido, la comprensión de estos fenómenos aporta información que sirve de insumo para plantear políticas y estrategias que favorezcan la existencia de condiciones de trabajo saludables. Lo cual es muy necesario en el contexto actual, en los que los costos asociados con la salud en el trabajo son altísimos (Gómez, 2007). 
Resultará clave que se busque que las personas estén abiertas al cambio. Evitar el trabajo rutinario y dar participación a los colaboradores, motivarlos para encontrar nuevas y mejoradas formas de hacer las cosas. De esta investigación se deriva entonces que las dimensiones del CPs requieren ser tenidas en cuenta a la hora de diseñar estrategias de intervención de la satisfacción laboral. También cuando se quiere analizar y promover las conductas extrarol de las personas.

La investigación aporta información sobre el comportamiento de las dimensiones del CPs, el rol mediador de la satisfacción y los antecedentes del desempeño intrarol, extrarol y el cumplimiento de normas. Futuras investigaciones podrían examinar el modelo diferenciando por tipo de cargo ya que es posible que los efectos de estos atributos sobre el desempeño estén en función de esta condición. Dada la poca atención que ha recibido el CPs en la literatura científica, explorar su relación, antecedentes y consecuencias sobre otras variables individuales, sociales, organizacionales y extra laborales aportará a la comprensión del fenómeno.

Por lo pronto conviene señalar que una visión positiva del fracaso no afecta la satisfacción, pero si el aprendizaje. La flexibilidad contribuye a que las personas estén más complacidas con sus realidades de trabajo y la apertura al cambio cumple un doble papel al asociarse con la satisfacción y apuntar a su desempeño extrarol. Lo anterior indica que si las organizaciones desean personas que den la milla extra y que cumplan con las normas definidas es necesario que se preocupen por que el personal esté satisfecho y abierto al cambio. Para dimensionar este trabajo es importante preguntarse ¿Qué empresas, Colombianas o extranjeras, no están interesada en trabajadores que den más y que se adapten a las normas y políticas definidas? Este trabajo de investigación es una clave para saber cómo conseguirlo. 
Capítulo 5. Satisfacción con la Vida: El rol de la Felicidad en el Trabajo y la Vida.

\section{Resumen $^{6}$}

Con base en un modelo teórico de bienestar en el que se especifica el Optimismo como antecedente de la Satisfacción con la Vida, se quiere probar si la Felicidad en el Trabajo explica la relación entre esas variables. El modelo se contrasta con otros dos, uno en el que la relación es explicada por la Felicidad en la Vida y otro en el que el antecedente es el Optimismo en el Trabajo. La variable edad fue controlada. Los análisis se hicieron con 197 casos de empleados de ocho empresas de Medellín, Colombia. Se encontró que la Felicidad en la Vida es en un mediador total de la relación entre Optimismo y Satisfacción con la Vida, la Felicidad en el Trabajo es un mediador parcial de esa relación y total de la que se da entre Optimismo en el Trabajo y Satisfacción con la Vida. La Edad no moduló las relaciones entre las variables. Se discuten las implicaciones de este hallazgo para las organizaciones que quieren favorecer el bienestar de sus trabajadores y para los trabajadores.

\section{Introducción}

Este estudio se enmarca en un enfoque psicológico positivo. Se sustenta en el postulado de que para favorecer el bienestar y la salud de las personas es necesario conocer los antecedentes y las consecuencias de su funcionamiento óptimo en todas las esferas de su vida (Seligman, 2011). El trabajo es una de las principales áreas de actuación de las personas, no solo por la cantidad de tiempo que se invierte en él, sino también por las representaciones cognitivas que genera, por ejemplo, como forma de identidad y relacionamiento (Rentería, 2008). Independientemente de la labor que se realice, el trabajo debe favorecer la salud y bienestar de la persona (Salanova, Llorens, Cifre, \& Martínez, 2012). Ser un propiciador y no un obstáculo en la búsqueda de la felicidad, meta humana por excelencia (Fernández, 2016).

A pesar del incremento de investigación sobre la felicidad en la última década (RodríguezMuñoz, \& Sanz-Vergel, 2013), aún hay mucho por explorar sobre esta en contextos de trabajo (Sanín, Salanova y Vera-Villaroel, s.f.) y sobre el efecto del trabajo en la felicidad general de las personas. Se sabe que las personas que no están bien en su trabajo empiezan a tener problemas en otras áreas de la vida y viceversa (llies, Schwind, Wagner, Johnson, DeRue, \& Ilgen, 2007), pero se desconoce el tamaño del impacto sobre la satisfacción con la vida. Por la importancia del trabajo ha sido lícito para algunos autores plantear que puede afectarla completamente (Brief, \& Nord, 1990), lo que ha llevado a una centralidad tal vez excesiva del trabajo en la vida de las personas.

\footnotetext{
${ }^{6}$ Este capítulo está en proceso de revisión por parte de los autores (Sanín-Posada, A., Vera-Villaroel, P., \& Salanova, M.) para ser sometido.
} 
Ha habido organizaciones con esta visión que invierten en estrategias para favorecer el bienestar en el trabajo descuidando otras facetas consideradas menos relevantes. Por el contrario, hay organizaciones que ponen sus esfuerzos en prácticas de conciliación de la vida privada con la vida laboral ${ }^{7}$ partiendo de una visión más holística del ser humano (Castillo, 1998). El desconocimiento sobre si el trabajo impacta completa o parcialmente la satisfacción con la vida ha contribuido a visiones diferentes en las organizaciones sobre lo que deben hacer para favorecer el bienestar de sus trabajadores. Esto se complejiza pues la forma como las personas se relacionan con el trabajo puede ser diferente en función de la edad (Guevara, 2016; Smyer, \& Pitt-Catsouphes, 2007).

El problema entonces radica en saber si la Felicidad en el Trabajo es condición suficiente para explicar la Satisfacción con la Vida de las personas. Saberlo puede ayudar a las personas a ver su trabajo en perspectiva, valorar si el que realizan vale o no la pena. A las empresas les servirá para saber si basta con que sus estrategias apunten a mejorar las condiciones de trabajo o si conviene que existan otras que garanticen la conciliación de la vida privada con la laboral. Una forma de conocer el verdadero rol de la Felicidad Laboral es verificando si media o no completamente la relación entre el Optimismo y la Satisfacción con la Vida. Se trata de probar el rol de la variable a través de su inclusión en un modelo en el que el Optimismo se considera antecedente del Bienestar (Vera-Villarroel, Contreras, Celis-Atenas, Lillo, Urzua, \& Silva, 2016).

El optimismo es un sistema de creencias que se manifiesta en expectativas favorables acerca de la ocurrencia de eventos futuros (Carver, Sheier, \& Segerstrom, 2010). Es más o menos estable a lo largo de la vida y permite hacer frente a la incertidumbre propia de los eventos venideros (Londoño, Velasco, Alejo, Botero, \& Vanegas, 2014; Vera-Villarroel, CórdovaRubio, \& Celis-Atenas, 2009). Las creencias pueden sustentarse en información más o menos objetiva (Scheier, Carver, \& Bridges, 1994) y ser específicas de contextos particulares, como por ejemplo, el laboral (Sanín, \& Salanova, s.f.). El Optimismo se deriva de las experiencias tempranas, de la calidad y el tipo de relaciones que se hayan tenido con familiares, amigos y otras figuras importantes en la infancia (Avia, \& Vázquez, 2011) de ahí que se señale como antecedente del bienestar y la Satisfacción con la Vida (Vera-Villaroel, et al., 2016).

Por su parte la Felicidad es fenómeno positivo multidimensional que puede caracterizar a las personas que experimentan disfrute, gratificación y sentido en su vida (Seligman, 2011). Puede evaluarse de manera general o especifica según el contexto de actuación de la persona (Sanín, \& Salanova, 2015). La Felicidad en el Trabajo se define igual que la general, pero delimitando el disfrute, la gratificación y el sentido en ese contexto particular.

La conceptualización de la felicidad suele sustentarse en un modelo teórico que muestra su dependencia de tres aspectos fundamentales: el primero genético, lo cual se refleja en el

\footnotetext{
${ }^{7}$ Se prefiere el uso del concepto vida privada - vida laboral al de vida familiar - vida laboral, más usado en la literatura (Jiménez, Figueroa, A., \& Gómez Urrutia, V. (2015), pues no todas las personas tienen familia o se dedican a ella en su tiempo libre.
} 
temperamento y los rasgos de personalidad; el segundo apunta a las circunstancias personales y contextuales, incluye aspectos demográficos y situaciones vividas; el tercero está relacionado con la búsqueda de felicidad y bienestar (Sheldon, \& Lyubomirsky, 2006). Investigaciones basadas en este modelo han encontrado que lo primero predice cerca del $50 \%$ de la felicidad (allí el Neuroticismo y la Extraversión son los factores que más explican la varianza de la felicidad. Las personas emocionalmente estables y más extravertidas suelen estar más felices que los neuróticos y los introvertidos), lo segundo explica un $10 \%$ y lo tercero cerca del 40\% (Lyubomirsky, 2008a; Lyubomirsky, 2008b). Sin embargo, hay autores que indican que esto no puede generalizarse, en la medida que algunos hallazgos muestran que las circunstancias de vida sí tienen un efecto importante en la felicidad (Easterlin, 2003). Por su parte la Satisfacción con la Vida es una reacción afectiva que se produce al comparar la vida propia con parámetros y criterios también propios sobre cómo debe ser esa vida (Pavot, y Diener, 1993). Suele considerarse un indicador de bienestar subjetivo y permite una rápida aproximación para saber qué tan contenta o descontenta está la persona con su vida en general.

De acuerdo con la investigación se espera que las personas más optimistas estén más satisfechas con su vida (Vera-Villaroel et al., 2016), ya que las expectativas positivas sobre el futuro suelen favorecer la vivencia y experimentación de condiciones más favorables en contraste con lo que le sucede a los pesimistas (Seligman, 2004). Pero esta relación podría estar afectada por la edad de las personas, ya que la forma como se relacionan con su trabajo cambia en función de esta (Guevara, 2016; Smyer, \& Pitt-Catsouphes, 2007).

Por otra parte hay estudios que indican que el optimismo-pesimismo también puede variar en función de la edad (Herzberg, Glaesmer, \& Hoyer, 2006). Mientras que algunas investigaciones hablan de una correlación negativa en la que a menor edad habría más optimismo, y esto explicado por un sentido de "inmortalidad" e invulnerabilidad en edades tempranas (Dosedlová et al., 2015), otros sugieren que el nivel más alto del optimismo se encuentra en la mediana edad (35-40 años) mientras que antes y después de eso los niveles del mismo son más bajos (Antle, Doelman, Scott, \& Warr, (2013). Esto lleva a pensar que la edad puede interactuar con las variables del modelo, por lo que será importante controlar su efecto.

Finalmente la importancia del trabajo para la vida de las personas (Rentería, 2008) y el hecho de que el optimismo anteceda a la felicidad en general (Avia \& Vázquez, 2011) indica que la felicidad en el trabajo podría explicar la relación entre el optimismo y la satisfacción con la vida, pero solo parcialmente, ya que no es la única faceta o área de actuación del ser humano (Rentería, 2008). Es decir solo la Felicidad General (en la Vida) podría mediar totalmente la relación conocida entre Optimismo y Satisfacción con la Vida (Vera-Villarroel, et al., 2016), pero la Felicidad Laboral, al ser solo una dimensión más de la vida, mediará parcialmente. Esta última solo podrá ser una mediadora total cuando el antecedente sea el Optimismo en el Trabajo. 
De acuerdo con esto y partiendo de una visión holística del ser humano se hipotetiza que:

1. La Felicidad en la Vida mediará totalmente la relación entre el Optimismo y la Satisfacción con la Vida y la edad modulará dichas relaciones.

2. La relación entre el Optimismo en el Trabajo y la Satisfacción con la Vida estará mediada completamente por la Felicidad en el Trabajo. La edad modulará dichas relaciones.

3. La Felicidad en el Trabajo mediará parcialmente la relación entre el Optimismo y la Satisfacción con la Vida.

\section{Método}

\section{Participantes}

Participaron 197 personas trabajadoras de ocho empresas. La muestra fue por disponibilidad. 53,6\% son hombres, el $46.8 \%$ tiene entre 31 y 40 años, el $25,8 \%$ entre 21 y 30 , el $17,7 \%$ entre 41 y 50 , y el $9,7 \%$ más de 50 .

\section{Instrumentos}

Escala de Felicidad en la Vida y en el Trabajo ( $\alpha=>$.70; AFC, CFI y TLI > .90 y $\alpha=>.70$; AFC, $\mathrm{CFI}$ y TLI > .90, respectivamente). Adaptaciones para población trabajadora colombiana del Authentic Happiness Inventory de Seligman, et al. (2005) (Sanín, \& Salanova, 2015). Se responde eligiendo una de cinco opciones posibles que describen el estado de ánimo de las personas (v.g. A..., B..., C. Tengo más alegría que tristeza., D..., E...). Los mismos ítems se responden pensando en la vida en general y luego en el contexto de trabajo.

Escala de Optimismo/Pesimismo en la Vida y en el Trabajo ( $\alpha=>$.70; AFC, CFI y TLI > .90). Adaptación del LOT-R de Scheier, et al. (1994) para población trabajadora colombiana (Sanín, \& Salanova, s.f.). Cuenta con 10 reactivos que deben responderse pensando en la vida en general y luego en el trabajo. Se cumplimentan con base en una escala tipo Likert con extremos 4 "Totalmente de acuerdo" y 1 "Totalmente en desacuerdo" (v.g. En tiempos difíciles, suelo esperar lo mejor).

Escala de Satisfacción con la Vida ( $\alpha=>$.70; AFC, CFI y TLI > .90) Escala de Satisfacción con la Vida de Pavot y Diener (1993). Se usó la versión utilizada en el estudio de validación del Authentic Happiness Inventory de Seligman, et al. (2005) para población trabajadora colombiana (Sanín, \& Salanova, 2015). Cuenta con 5 ítems que se responden con base en una escala tipo Likert con extremos 6 "Totalmente de acuerdo" y 1 "muy en desacuerdo" (v.g. 3. Estoy satisfecho con mi vida). 
En las escalas tipo Likert se eliminó el punto central de la escala original (ni de acuerdo ni en desacuerdo), ya que introduce un valor que no aporta información real sobre el nivel de la variable. Las puntuaciones registradas son calculadas con baremos colombianos.

\section{Procedimiento}

Hubo aplicaciones vía web y lápiz y papel. Todos los participantes que contestaron vía Web pertenecían a la misma organización ( $\mathrm{N}=17$ ) mientras que los que respondieron vía lápiz-ypapel pertenecían a siete empresas $(\mathrm{N}=180)$. Las diferencias según el tipo de aplicación fueron significativas a nivel estadístico en Felicidad en el Trabajo ( $t=-3,9 p=.001)$, Felicidad en el Vida ( $t=-2,13 p=.048)$, Optimismo en el Trabajo $(t=-4,43 p=.000)$ y Optimismo en la Vida $(t=-2,19 p=.028)$. En Satisfacción en la Vida no hubo diferencias $(t=-0,51 p=.605)$. No obstante, no podemos saber si las diferencias se deben al tipo de aplicación o al tipo de organización. Ambas aplicaciones se hicieron siguiendo los estándares de aplicación de los instrumentos para evitar introducir error no muestral. A los participantes se les explicó el objetivo y el proceso. Se solicitó su consentimiento siguiendo los parámetros que exige la ley colombiana. Una vez recogidos los datos se calcularon las variables y se verificó su normalidad utilizando la prueba Kolmogorov-Smirnov. Ninguna mostró normalidad ( $p>$ .050). Para verificar la mediación se utilizó PROCESS 2.15 para SPSS, siguiendo el proceso de Precher y Hayes (2004) para estimar los efectos indirectos en procesos de mediación simple y el tamaño del efecto.

Las condiciones de manejo ético fueron revisadas y avaladas por el Comité Científico del Centro de Investigación en Comportamiento Organizacional Cincel, y por los directivos de gestión humana de cada empresa.

\section{Resultados}

Tabla 1. Medias (M), Desviaciones Estándar (DE) y Correlaciones entre las variables

\begin{tabular}{lllllll} 
& $\mathrm{M}$ & $\mathrm{DE}$ & 1 & 2 & 3 & 4 \\
\hline 1. Felicidad Trabajo & 53,04 & 9,69 & - & & & \\
2. Felicidad Vida & 52,41 & 10,11 &, $636^{* *}$ & - & & \\
3. Optimismo Trabajo & 50,03 & 10,25 &, $500^{* *}$ &, $365^{* *}$ & - & \\
4. Optimismo Vida & 50,99 & 9,09 &, $363^{* *}$ &, $432^{* *}$ &, $680^{* *}$ & - \\
5. Satisfacción Vida & 52,55 & 9,48 &, $472^{* *}$ &, $629^{* *}$ &, $289^{* *}$ &, $344^{* *}$ \\
\hline ** Rho de Spearman $p>0,01$ & & & & &
\end{tabular}

Se presentan correlaciones estadísticamente significativas entre las variables siendo las más altas las reportadas entre Felicidad en el Trabajo y Felicidad en la Vida, entre Optimismo en el Trabajo y Optimismo en la Vida y entre Felicidad en la Vida y Satisfacción con la Vida. 


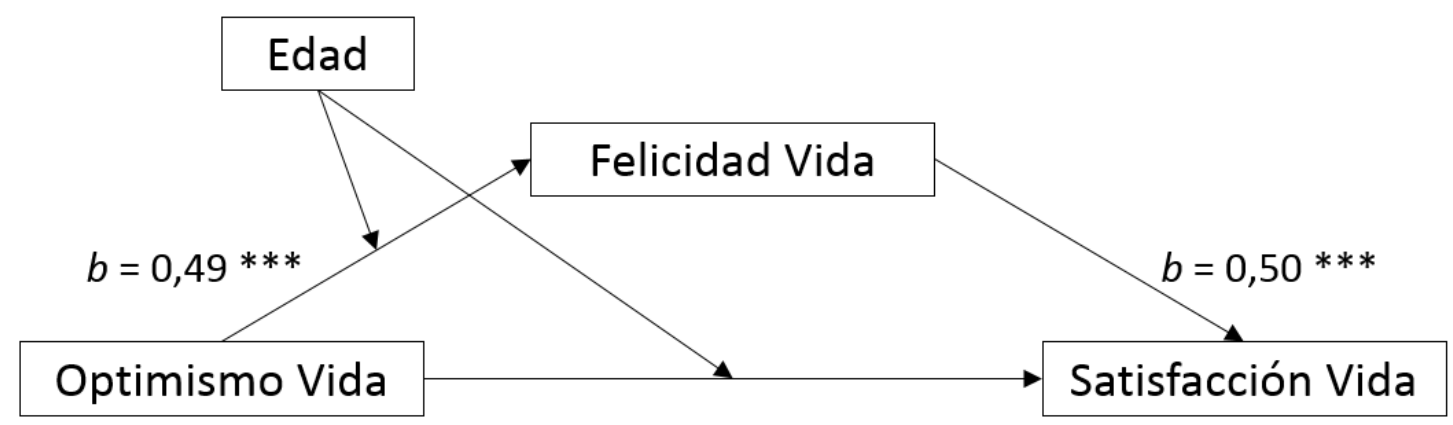

Efecto directo, $b=0,37 * * *$

Efecto indirecto, $b=0,24,95 \% \mathrm{Cl}[0.14,0.33]$

$* * * p=, 000$

Figura 1. Hipótesis 1

Se encontró un efecto indirecto significativo del Optimismo en la Vida en la Satisfacción con la Vida a través de la Felicidad en la Vida $(b=.24$. $\mathrm{BCa} \mathrm{Cl}[0.14,0.33])$, y representa un efecto apreciable $\left(K^{2}=0.23,95 \% \mathrm{BCa} \mathrm{Cl}[0.14,0.33]\right)$ (Ver Figura 1). La mediación en este caso es total. Adicionalmente se encuentra que la Edad no se relaciona con la variable mediadora $(B=2.27 ; \mathrm{t}=0.85, p=.397)$ y no existe efecto producto de su interacción con la independiente $(B=-0.42 ; t=-0.81, p=.417)$; lo mismo sucede en relación con la dependiente, no hay relación $(B=-1.80 ; t=-0.80, p=.423)$ ni efecto de interacción $(B=0.04 ; t=0.98$, $p=.329)$

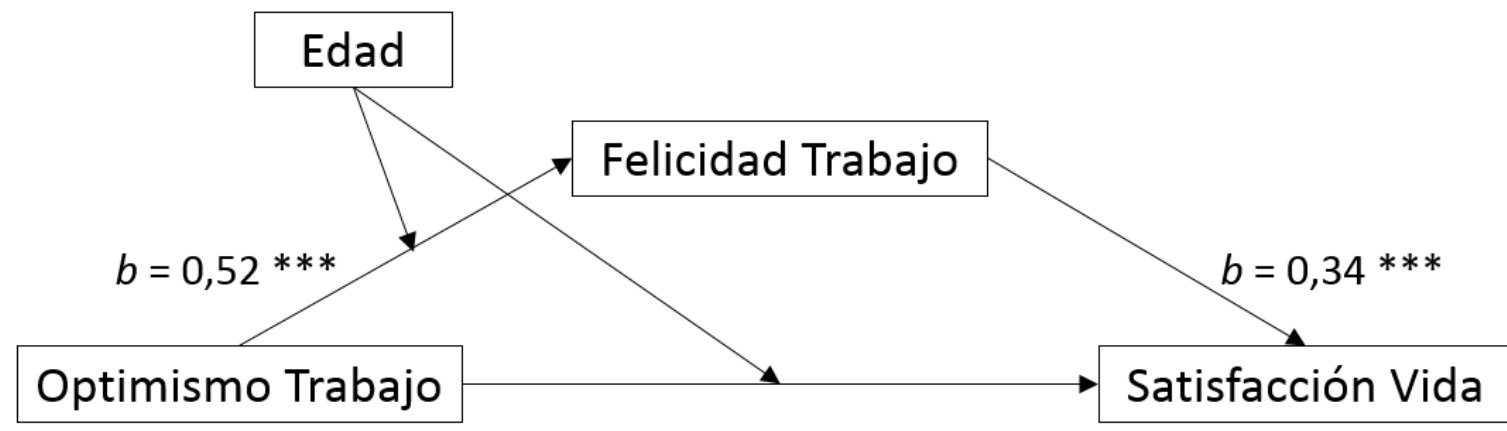

Efecto directo, $b=0,30 * * *$

Efecto indirecto, $b=0,18,95 \% \mathrm{Cl}[0.06,0.30]$

$* * * p=, 000$

Figura 2. Hipótesis 2

Se encontró también un efecto indirecto significativo del Optimismo en la Trabajo en la Satisfacción con la Vida a través de la Felicidad en el Trabajo ( $b=.18$. BCa Cl $[0.06,0.33])$, y representa un efecto apreciable $\left(K^{2}=0.17,95 \% \mathrm{BCa} \mathrm{Cl}[0.06,0.28]\right)$ (Ver Figura 2). La 
mediación es total. Adicionalmente se encuentra que la Edad no se relaciona con la variable mediadora $(B=1.70 ; \mathrm{t}=0.77, p=.444)$ y no existe efecto producto de su interacción con la independiente $(B=-0.02 ; \mathrm{t}=-0.60, p=.552)$; lo mismo sucede en relación con la dependiente, no hay relación $(B=-3.17 ; \mathrm{t}=-1.15, p=.253)$ ni efecto de interacción $(B=0.69 ; \mathrm{t}=1.31$, $p=.193)$.

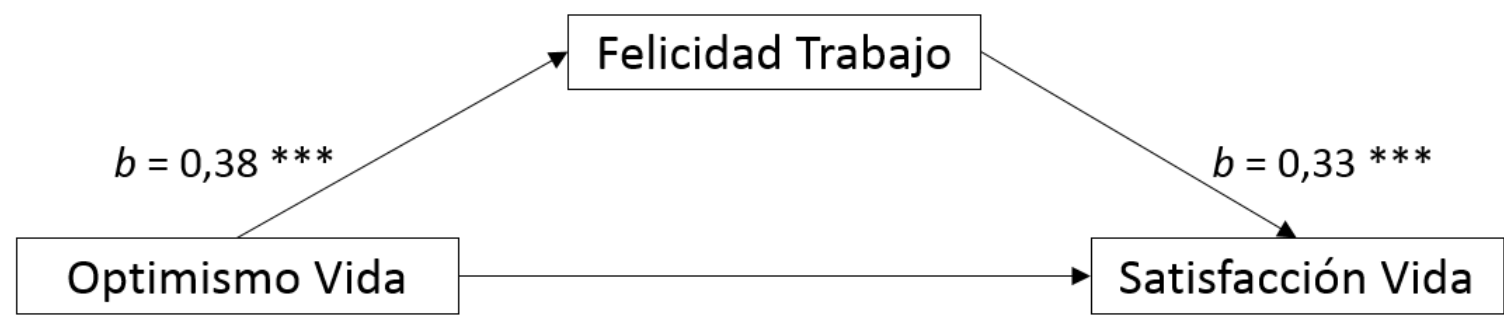

Efecto directo, $b=0,37 * * *$

Efecto indirecto, $b=0,13,95 \% \mathrm{Cl}[0.06,0.22]$

$* * * p=, 000$

Figura 3. Hipótesis 3

Existe un efecto indirecto significativo del Optimismo en la Vida en la Satisfacción con la Vida a través de la Felicidad en el Trabajo ( $b=.13$. $\mathrm{BCa} \mathrm{Cl}[0.06,0.22])$, y representa un efecto moderado $\left(K^{2}=0.12,95 \% \mathrm{BCa} \mathrm{Cl}[0.55,0.20]\right)$ (ver Figura 3$)$. La mediación es parcial en este caso.

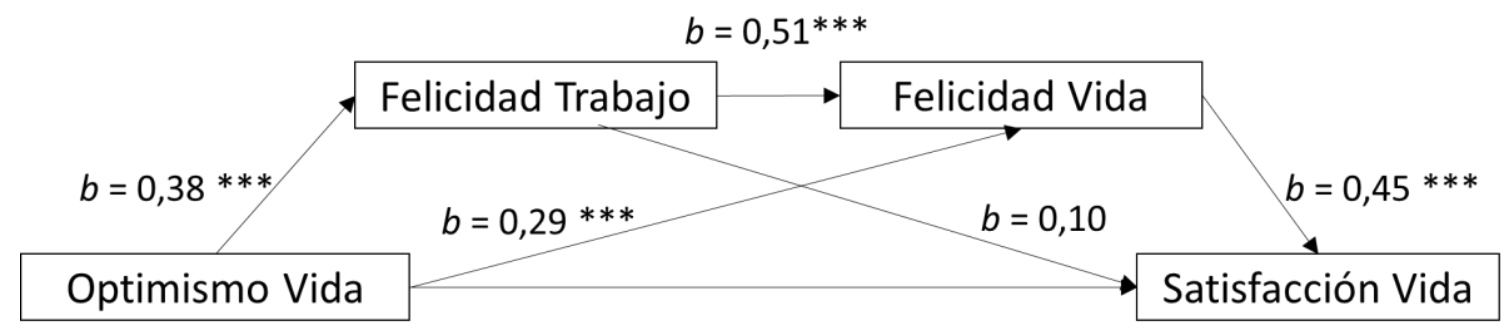

Efecto directo, $b=0,37 * * *$

Efecto indirecto $1, b=0,04,95 \% \mathrm{Cl}[-0.02,0.11]$

Efecto indirecto $2, b=0,09,95 \% \mathrm{Cl}[0.05,0.15]$

Efecto indirecto $3, b=0,13,95 \% \mathrm{Cl}[0.05,0.26]$

Efecto indirecto total, $b=0,26,95 \% \mathrm{Cl}[0.16,0.39]$

$* * * p=, 000$

Figura 4. Hipótesis 3. Modelo completo

Cuando se probó el modelo completo se encontró que: No hay un efecto indirecto significativo (1) del Optimismo en la Vida sobre la Satisfacción en la Vida a través de la Felicidad en el Trabajo $(b=.04$. BCa Cl $[-0.02,0.11])$, el tamaño del efecto es no significativo $(b=0.04,95 \% \mathrm{BCa} \mathrm{Cl}[-0.03,0.11])$. Hay un efecto indirecto significativo (2) del Optimismo 
en la Satisfacción con la Vida a través de la Felicidad en el Trabajo y de la Felicidad en la Vida $(b=.09 . \mathrm{BCa} \mathrm{Cl}[0.05,0.15])$, aunque con un efecto bajo $(b=0.08,95 \% \mathrm{BCa} \mathrm{Cl}[0.05,0.15])(2$ $b=.09$. BCa Cl $[0.05,0.15])$. Hay un efecto indirecto significativo (3) del Optimismo en la Vida en la Satisfacción con la Vida a través de la Felicidad en la Vida $(b=.13 . \mathrm{BCa} \mathrm{Cl}[0.05,0.26])$, con un efecto apreciable $(b=0.12,95 \% \mathrm{BCa} \mathrm{Cl}[0.05,0.23])$. Hay un efecto indirecto total significativo $(b=.26 . \mathrm{BCa} \mathrm{Cl}[0.16,0.39])$, con un efecto apreciable $(b=0.24,95 \% \mathrm{BCa} \mathrm{Cl}[0.15$, 0.36]).

\section{Discusión}

Se presentan las correlaciones esperadas entre las variables según se ha reportado en la literatura científica (Seligman, 2011). Se cuenta con las bases para suponer que las personas con creencias positivas sobre el futuro tienden a experimentar vivencias positivas de disfrute, gratificación y sentido. Esto sucede en la vida en general y en el contexto de trabajo.

Las personas más felices están más satisfacción con su vida, lo cual ya ha sido reportado en otros estudios (Cohn, Fredrickson, Brown, Mikels, \& Conway, 2009; Peterson, Park, \& Seligman, 2005). Si bien se trata solo de correlaciones, la teoría indica que el optimismo puede ser considerado el antecedente de la felicidad (Vera-Villarroel, Pávez \& Silva, 2012). Los modelos de mediación permiten confirmar el modelo de bienestar que pone al optimismo como antecedente de la Felicidad y el bienestar subjetivo (Vera-Villaroel et al., 2016). Esto ha sido tema de debate por considerar que el componente genético de la felicidad sería argumento suficiente para estimarla como antecedente ya que puede llevar a las personas a ser más optimistas (Lyubomirsky, 2001). Sin embargo al considerar el optimismo como antecedente se parte de una perspectiva epigenética, en la que no basta con el punto de partida genético de felicidad sino que se requiere un favorecedor de dicha expresión genética. Entonces, así como el nivel socioeconómico puede afectar la heredabilidad del coeficiente intelectual (Turkheimer, Haley, Waldron, D'Onofrio, \& Gottesman, 2003), el optimismo podría afectar la de la felicidad. Más estudios sobre este tema se requieren, pero este es un primer paso en esa línea.

Se parte entonces de un modelo menos determinista y más holístico que contribuye a reforzar la importancia del funcionamiento óptimo desde un punto de vista diferente (Bedregal, Shand, Santos, \& Ventura-Juncá, 2010). Desde esta línea se considera que es necesario que las personas sean optimistas para activar su felicidad, esto a pesar de que en términos temporales lo genético esté primero y el aprendizaje después. El hallazgo sugiere que se requiere aprendizaje orientado a desarrollar creencia positivas sobre el futuro para "activar" el componente biológico de felicidad tanto fuera como dentro del trabajo (Fernández, 2016).

Además de sustentar el modelo de bienestar, los modelos de mediación nos permitieron ver que la Felicidad con la Vida explica la relación entre el Optimismo y la Satisfacción con 
la Vida, mientras la Felicidad con el Trabajo lo hace solo parcialmente. Como se esperaba el trabajo y las emociones que genera son importantes para sentirse satisfecho con la vida pero no lo son todo (Greenhaus, Collins, \& Shaw, 2003). Se requiere entonces que las organizaciones se concentren en favorecer el equilibrio de la vida privada con la laboral y no solo en políticas de bienestar intralaborales. Aunque la búsqueda de este equilibrio podría tener algunas desventajas para la organización (López-lbor, Mangas, Cornejo, \& Vadillo, 2010), en general sus beneficiosos hacen que merezca la pena desarrollar prácticas organizacionales que lo aseguren (Beauregard, \& Henry 2009).

Los resultados indican que el optimismo en general hace que la gente esté más satisfecha con la vida. La Felicidad en la vida sería el mecanismo psicológico que explica esa relación. Resulta interesante ver que esto se replica en el contexto del trabajo. Las personas optimistas con su trabajo son más felices en su trabajo y están más satisfechos con la vida. Lo que implica que podemos incrementar la satisfacción con la vida de las personas si hacemos que tengan optimismo en su vida y su trabajo.

El hallazgo sugiere que las organizaciones interesadas en favorecer el bienestar de las personas deberán invertir no solo en el mejoramiento de las condiciones laborales sino, también en la conciliación de la vida privada y la laboral.

\section{Conclusiones y limitaciones}

Se aporta información a la confirmación de un modelo que pone énfasis en el optimismo como antecedente del bienestar, de la felicidad y de la satisfacción con la vida.

Se confirman las hipótesis de mediación que indican que para conseguir satisfacción con la vida se requiere de una visión más holística del ser humano. Además, se refuerza que no importa el nivel con el que se nace, la felicidad dependerá en mayor proporción de lo que se hace.

La felicidad en el trabajo es importante pero no suficiente para predecir la satisfacción con la vida. Para estar satisfecho con la vida se necesita estarlo con la vida en general y no solo con el trabajo. Más allá de lo intuitivo del hallazgo se refuerza con datos la importancia de favorecer el equilibrio de la vida laboral con otras áreas de la vida.

La edad no moduló las relaciones entre el optimismo y la felicidad y entre el optimismo y la satisfacción con la vida, lo que sugiere que a pesar de que esta variable sociodemográfica suele ser importante para diferenciar otros aspectos psicosociales, el hecho de que el optimismo prediga la satisfacción con la vida por vía de la felicidad general podría ser un principio aplicable a personas de cualquier generación.

Este estudio cuenta, no obstante, con algunas limitaciones que es preciso señalar antes de generalizar los resultados. Primero se trata una muestra por disponibilidad. Para generalizar los hallazgos sería necesario replicar el estudio con muestras más amplias y de otros lugares. 
Por otra parte al ser transversal se dificulta el control temporal de las variables, por lo que la confirmación de la ubicación de las variables en el modelo deberá hacerse con otro tipo de metodologías.

Pese a esta limitaciones se refuerza que trabajar en la felicidad y el optimismo son muy favorables desde el punto de vista de la calidad de vida de las personas, por ejemplo por su impacto en la salud y el bienestar de las personas (Norrish, \& Vella-Brodrick, 2008), lo que por cuenta propia son argumentos suficientes para que la empresas decidan volcar sus esfuerzos en la implementación de prácticas de mejora de la felicidad y el optimismo, las cuales, como se vio, deberían estar centradas no solo en mejorar el trabajo sino el equilibrio de la vida privada con la laboral. 
Capítulo 6. Los efectos del tipo de contrato laboral sobre la felicidad en el trabajo, el optimismo y el pesimismo laborales

\section{Resumen $^{8}$}

En el presente estudio se explora si el tipo de contrato laboral: término fijo, término indefinido, prestación de servicios o temporal, permite predecir la felicidad en el trabajo, el optimismo y el pesimismo laborales en una muestra de 802 personas trabajadoras de la ciudad de Medellín. Los resultados obtenidos a través del estadístico Kruskal Wallis indican que las diferencias en los niveles de las variables exploradas no se explican por el tipo de contratación que se posea. Se analizan el sentido y las implicaciones de este hallazgo.

\section{Introducción}

La felicidad en el trabajo y el optimismo laboral hacen parte de un grupo de conceptos que pueden clasificarse como pertenecientes a la psicología organizacional positiva. Este enfoque se centra en la investigación del funcionamiento óptimo, la salud y el bienestar de las personas y en encontrar las razones que explican por qué son psicológicamente saludables y se adaptan adecuadamente a los diferentes entornos (Seligman, Steen, Park \& Peterson, 2005), en este caso al laboral. Esta visión plantea un enfoque que responde a demandas emergentes en el cambiante mundo del trabajo. Propone pasar de un modelo patológico a uno orientado a la salud y el bienestar que potencializa las fortalezas humanas.

La investigación científica en Colombia se ha ido permeando con esta visión; un ejemplo de ello lo constituye el aumento de ponencias de esta disciplina en eventos nacionales y la aparición de asociaciones de psicología positiva (Colpsic, 2009, 2015; Martínez, 2008). Sin embargo, se trata aún de estudios incipientes, lo que pone de manifiesto y subraya la necesidad de desarrollar investigaciones que permitan comprender cómo los conceptos de la psicología positiva se asocian con las realidades laborales.

Es preciso señalar también que buena parte de las investigaciones que se han hecho en el ámbito laboral, y que han buscado comprender los efectos de conceptos de la psicología positiva, tales como el bienestar, la satisfacción y la calidad de vida en el trabajo, han sido realizadas en organizaciones atípicas, en las que las personas tienen asegurada su vinculación laboral. En Colombia la mayoría de organizaciones son pequeñas y medianas, generan cerca del $80 \%$ del empleo en el país y cuentan con condiciones administrativas muy diferentes de las grandes empresas (Giraldo, 2007) incluyendo la forma como contratan a su personal.

\footnotetext{
${ }^{8}$ Capítulo publicado como: Sanín Posada, A., López Velásquez, A. M., \& Gómez Granada, B. M. (2016). Los efectos del tipo de contrato laboral sobre la felicidad en el trabajo, el optimismo y el pesimismo laborales. Revista Interamericana de Psicología Ocupacional, 34(1), 9-21. http://doi.org/10.21772/ripo.v34n1a01
} 
El tipo de vinculación formal de las personas con las organizaciones ha cambiado. Cada vez hay más personas con contratos temporales y menos vinculadas indefinidamente (Chambel \& Alcover, 2011). Este cambio en la dinámica de la relación contractual supone también cambios en la forma en la que hasta ahora se han comprendido los fenómenos estudiados.

Asistimos entonces al encuentro de dos fenómenos emergentes cuya relación ha sido poco estudiada. Por un lado tenemos la incipiente inclusión de la psicología positiva en la investigación de fenómenos asociados con el trabajo en Colombia y, por otra, una realidad organizacional diferente a la de décadas pasadas. Esta confluencia puede tener como efecto que buena parte del desarrollo científico en psicología organizacional y del trabajo debe actualizarse teniendo en cuenta las nuevas formas de vinculación al mundo laboral.

La anterior afirmación señala entonces una importante oportunidad de desarrollo de conocimiento científico. Se trata de la comprensión de cómo aspectos psicológicos positivos varían o no dependiendo del tipo de vinculación de las personas con la organización. Como se aprecia es un campo muy amplio. Sin embargo, este trabajo, apelando a la necesidad de delimitar la investigación, se centrará en la exploración de la felicidad en el trabajo, el optimismo y pesimismo laborales, y su asociación con el tipo de vinculación. Más específicamente se quiere explorar si el tipo de contrato puede predecir los niveles de felicidad con el trabajo, y el optimismo y pesimismo laborales. Comprender esto permitiría ver si las diferencias en el tipo de contrato, algunas de las cuales lo precarizan (Blanch, 2014; Useche, 2002), influyen en asuntos personales y psicológicos con efectos sobre la calidad de vida de las personas y la productividad de las organizaciones.

La revisión bibliográfica permitió identificar que las investigaciones sobre felicidad en el trabajo se relacionan, típicamente, con variables como el nivel de ingreso, seguridad, redes sociales, educación, estabilidad laboral (Mendoza \& Gómez, 2011), desempeño (Wright, Larwood \& Denney, 2002), cumplimiento de valores, ciudadanía organizacional (Rego, Ribeiro \& Cunha, 2010), estrés (Schiffrin, Rezendes \& Nelson, 2008) y percepción de productividad personal (Zelenski, Murphy \& Jenkins, 2008), entre otros. Sin embargo, no aparecen hallazgos asociados con el tipo de contrato.

En el caso del optimismo, entendido como la "inclinación a esperar resultados favorables" (Marshall, Wortman, Kusulas, Hervig, \& Vickers, 1992. p. 1067) o como la creencia acerca de que todo resultará bien, se encontraron estudios que muestran que cuando hay resultados negativos las personas con creencias pesimistas tienden a empeorar en su trabajo, mientras las optimistas siguen igual (Avia \& Vázquez, 2011). El optimismo sería entonces una barrera contra el estrés. Otras investigaciones encuentran que las personas optimistas suelen reportar menos síntomas físicos en contraste con las pesimistas (Martínez, Reyes, García \& Gonzales, 2006), lo cual suele explicarse porque las estrategias de afrontamiento que utilizan unos u otros suelen variar (Chico, 2002). Otros estudios mostraron que el optimismo puede afectar la satisfacción, la felicidad y el desempeño 
(Youssef \& Luthans, 2007). Sin embargo, no se hallaron estudios asociados con el tipo de contrato. En la medida que la persona no puede decidir sobre las condiciones contractuales, dado que estas le son impuestas, se carece de argumentos para plantear la verdadera influencia que esta realidad tiene sobre el optimismo y pesimismo de las personas en el trabajo, lo cual reforzó la necesidad de abordar este tema desde esta perspectiva.

Respecto al tipo de contrato, la literatura científica ha revelado que este puede incidir en el compromiso afectivo con la organización, en la satisfacción laboral que las personas desarrollan en relación con su trabajo (Santos, Guillén y Montalbán, 2012), en la calidad de vida de las personas (Uribe, Garrido \& Rodríguez, 2011), en el contrato psicológico (Chambel, Alcover, \& Martínez, 2012; Solanes, 2010; Vesga, 2011), y en el esfuerzo laboral (Rodríguez \& Canal, 2011).

En el marco de este trabajo, se diferencian dos tipos de contrato, el laboral y el no laboral. El primero se rige por el Código Sustantivo del Trabajo de Colombia donde se define el contrato como aquel por el cual una persona natural se obliga a prestar un servicio personal a otra persona, natural o jurídica, bajo la continuada dependencia o subordinación de la segunda y mediante remuneración. Quien presta el servicio se denomina trabajador, quien lo recibe y remunera, empleador, y la remuneración, cualquiera que sea su forma, salario. Puede celebrarse por tiempo determinado (Fijo), por el tiempo que dure la realización de una obra o labor determinada, por un tiempo indefinido o para ejecutar un trabajo ocasional, accidental o transitorio.

El segundo tipo de contrato, el no laboral, corresponde a la prestación de servicios, está regulado por el Código Civil y el Código de Comercio Colombianos. Consiste en emplear a personas independientes de una forma específica en el sector público o privado, son las partes quienes definen si aceptan las obligaciones inherentes al contrato y se ciñen a los términos que el acuerdo estipula.

Según la Sentencia C-154/97 (Corte Constitucional de Colombia) para este tipo de contrato se establecen las siguientes características: a.

"La prestación de servicios versa sobre una obligación de hacer para la ejecución de labores en razón de la experiencia, capacitación y formación profesional de una persona en determinada materia, con la cual se acuerdan las respectivas labores profesionales. b. La autonomía e independencia del contratista desde el punto de vista técnico y científico, constituye el elemento esencial de este contrato. c. La vigencia del contrato es temporal y, por lo tanto, su duración debe ser por tiempo limitado y es indispensable para ejecutar el objeto contractual convenido."

En este trabajo se tendrán en cuenta como variables independientes los tipos de contratos laborales fijo, indefinido, temporal y prestación de servicios. 


\section{El contrato de trabajo una realidad compleja}

El contrato de trabajo ha sido un tema abordado principalmente por el derecho laboral y las ciencias económicas. Sin embargo, en los últimos años, este tema adquiere gran relevancia dentro de los análisis sociales debido a sus cambios como resultado del fenómeno de la globalización y las políticas neoliberales. De ahí que el contrato laboral se analice a la luz de otras realidades sociales y psicológicas que afectan la relación personatrabajo.

Por muchos años primó en las organizaciones la relación típica laboral, es decir basada en el modelo tradicional, en el que se contrataba a tiempo completo, con duración ilimitada, con un solo empleador y se gozaba de la protección contra el despido injustificado. Pero, a partir de los años 80 incursionaron nuevas formas de trabajo denominadas formas atípicas de empleo dando paso a los trabajos de tiempo parcial, contratos a término fijo, la tercerización y la prestación de servicios (OIT, 2013). Si bien estas nuevas formas de relación contractual han aumentado la flexibilidad del mercado, también han contribuido a que no esté clara la situación laboral de muchos trabajadores, desregulando la fuerza de trabajo y promoviendo la polivalencia (Novick, 2000). En consecuencia, se genera una situación de desventaja y exclusión frente a la protección y la justicia laboral.

Ante este panorama el contrato laboral es un tema que cobra gran interés por su efecto no sólo en el ámbito jurídico, político y económico, sino también por su influencia en variables psicosociales. Al respecto, se pueden encontrar diversas investigaciones.

Santos et al. (2012) analizaron cómo incide el tipo de contrato laboral en el compromiso afectivo con la organización y en la satisfacción laboral. Los resultados evidenciaron que el tipo de contrato predice la satisfacción y el compromiso, pero no son concluyentes. Uno de los hallazgos más relevantes es que los niveles de satisfacción más elevados los presentan los trabajadores con contrato permanente con la organización y con contrato temporal con la Agencia de Trabajo Temporal, lo cual resulta paradójico, puesto que estos dos grupos de trabajadores están en los extremos de la precariedad de empleo. Los primeros gozan de las mejores condiciones laborales y los segundos de las mínimas. Sin embargo, esto podría obedecer a las siguientes razones: la percepción de elevada satisfacción para los empleados con contrato permanente con la organización, según los autores, "puede resultar del hecho de sentir que trabajan en una organización que en su sector de actividad adopta las mejores prácticas de gestión de recursos humanos" (p. 355). Y para los empleados en la organización con contratos temporales a través de la Agencia de Trabajo Temporal, su nivel elevado de satisfacción podrá estar influenciado por sentir que trabajan en una organización que no discrimina en sus políticas y prácticas de gestión de recursos humanos entre trabajadores permanentes y temporales, las oportunidades de formación y evolución profesional son las mismas, así como las políticas salariales y de estímulos e incentivos. 
Respecto al compromiso afectivo, los valores más altos fueron evidenciados por los trabajadores que tienen contrato permanente con la organización y los que tienen contrato temporal con la Agencia de Trabajo Temporal. En este último caso, esto se debe a la perspectiva de vínculo futuro con la organización, demostrando que el compromiso no depende de la duración del contrato (Santos et al., 2012).

En otra investigación se pretendió analizar la influencia que tiene el tipo de contratación en la calidad de vida laboral de funcionarios de Santander (Colombia) atendiendo en especial a los factores de riesgo psicosocial generados por las diferentes modalidades contractuales. El análisis realizado indicó diferencias significativas en función del tipo de contratación para las siguientes cuatro variables: condiciones de trabajo, clima social de trabajo, política organizativa y efectos colaterales del trabajo (Uribe, et al., 2011). Los resultados obtenidos en la investigación señalaron en primer lugar que para los trabajadores con una contratación estable (contrato indefinido) existen mejores condiciones laborales, poseen un mejor ambiente social de trabajo y tienen menos efectos colaterales producto de su actividad laboral. En segundo lugar, que para el grupo de trabajadores con un contrato a término fijo (inestable) existen condiciones de trabajo menos favorables. Y por último, que para el colectivo de trabajadores con una contratación temporal (inestable) se evidencia un mayor dominio de las políticas organizacionales (Uribe, et al., 2011).

Vesga (2011) investigó los tipos de contratación laboral y sus implicaciones en el contrato psicológico; halló que para quienes se vinculan a una organización en modalidad de empleados, esto significa tranquilidad, seguridad, beneficios y su contrato psicológico está construido más sobre la base de compromisos que de expectativas. Mientras que para aquellos que están vinculados a través de outsourcing o cooperativas de trabajo asociado, los significados construidos sobre el trabajo están relacionados con el desmejoramiento de su calidad de vida, la discriminación y la inconformidad con este tipo de vinculación, pues tienen menos beneficios y tienen las mismas exigencias de desempeño que quienes están en la modalidad de empleo, por lo que su contrato psicológico se forma por la expectativa de vincularse algún día como empleado.

En la misma vía, Solanes (2010) estudió la importancia del tipo de contrato laboral en el contrato psicológico. La investigación muestra que el trabajador valora otras cuestiones además de poseer un contrato permanente con la organización, como su agrado por el trabajo desempeñado y la adecuación de su contrato laboral a sus necesidades. El 50\% de los sujetos encuestados que cuentan con un contrato temporal afirmaron que esta modalidad de contrato laboral se ajusta a sus necesidades. Por lo que se pone de manifiesto la necesidad de no incluir una única variable, como el tipo de contrato formal, como determinante del contrato psicológico.

Otros estudios han confirmado que las formas de contratación temporal y a término fijo generan efectos significativos para los trabajadores, en contravía de su satisfacción y calidad de vida laboral (Uribe, et al., 2011). Ello en gran medida ocasionado por las políticas neoliberales, las cuales han impactado a la sociedad en su conjunto, y en especial a los 
trabajadores, pues se han visto enfrentados a numerosos y diversos cambios en sus condiciones de trabajo (Useche, 2002).

En otra Investigación Sanín y Restrepo (2009) encontraron diferencias en el desempeño de empleados según si su tipo de vinculación era indefinida o a término fijo. Esto se explicó por asuntos motivacionales relacionados con las expectativas y los juicios de inequidad que se presentaban por razón del tipo de contrato. También se han hallado diferencias por tipo de contrato en cuanto a la calidad del clima organizacional. Se encontró que este predecía diferencias significativas en las percepciones compartidas de las personas en relación con el sentido de orgullo y pertenencia a la organización, la equidad en la remuneración y los beneficios derivados del trabajo, las posibilidades de permanencia en la organización, la claridad organizacional y la favorabilidad que se le concede al trabajo en equipo (Toro \& Sanín, 2013).

Este panorama sustenta que el tipo de vinculación puede incidir en las percepciones, la motivación, el compromiso, la calidad de vida, la satisfacción laboral y en otras variables de carácter psicosocial, lo cual permite suponer que podría tener influencia también en los niveles de felicidad y optimismo.

\section{Felicidad en el trabajo}

La felicidad se define como una condición de experimentación de emociones positivas y ausencia de negativas y se puede juzgar a partir de la satisfacción con la vida (Diener, 2000). Puede ser considerada como un rasgo o un estado (Moyano, Flores, \& Soromaa, 2011). Lo primero se fundamenta en el hecho de que es relativamente estable y en hallazgos que indican que aproximadamente el 50\% de la misma se explica genéticamente (Lyubomirsky, 2008). La sustentación de que es un estado radica en su naturaleza cambiante y dependiente de los eventos o situaciones particulares. Esto último se afirma a pesar de que se ha encontrado que la felicidad no está necesariamente asociada con objetos o circunstancias particulares, contrario a lo que sucede con la satisfacción (Littlewood, 2008). La felicidad se fundamenta más en los recuerdos, la trayectoria de vida y la búsqueda de metas valiosas para la persona (Avia \& Vásquez, 2011).

Durante años se trabajó la felicidad como sinónimo de bienestar subjetivo, considerando este último un concepto más técnico y científico, mientras que el primero se reservaba para el uso común (Diener, 2000; Diener, Suh, Lucas \& Smith 1999). Sin embargo, se empezó a entender que el bienestar es solo un componente de la felicidad, pues para ser feliz es necesario también disfrutar y encontrarle sentido y propósito a la propia vida (Seligman et al., 2005). De acuerdo con lo anterior, la felicidad es entonces un fenómeno relativamente estable (rasgo) pero que se puede modificar y que no caracteriza un momento específico de la vida de la persona, sino, más bien, lo que ha experimentado. 
También la felicidad ha sido definida como un estado que incluye el bien-estar y bien-hacer (Quick \& Quick, 2004). Coincide esto con la idea de entender el bienestar como componente y no como sinónimo de la felicidad. De esta manera se indica que el solo hecho de estar bien no garantiza la felicidad. Se requiere también hacer las cosas bien. Esta perspectiva resulta coherente con la propuesta por Seligman et al. (2005) quienes consideran que la felicidad está compuesta por tres dimensiones: la experimentación de emociones positivas y placer ("the pleasant life"), el compromiso con la vida ("the engaged life"), y encontrarle sentido a la vida ("the meaningful life").

De esta manera, la felicidad puede ser entendida como un constructo multidimensional que tiene un componente emocional en el que es fundamental el estado afectivo que caracteriza a las personas, el cual, a su vez, es producto de las múltiples relaciones con el ambiente y de la acumulación subjetiva de experiencias positivas. Se diferencia de las emociones que son momentáneas y derivadas de estímulos concretos y de los sentimientos que son más pasajeros y están más asociados con los sentidos (Ellis, 2001). Vista así puede ser entendida como un rasgo afectivo que caracteriza a las personas que experimentan satisfacción y que disfrutan la vida con frecuencia.

También la felicidad tiene un componente cognitivo. Este facilita juzgarse o no como feliz. Esta condición, relacionada con las creencias permite saber si se está bien y si las cosas van bien (Avia \& Vazquez, 2011). Por ser este un juicio sustentado en las propias impresiones y emociones podría suceder que lo feliz que me percibo no coincida con qué tan feliz me perciben quienes me rodean. Sin embargo, los efectos positivos de la felicidad suelen explicarse por el juicio propio.

En resumen la felicidad es una fenómeno multidimensional asociado con el bienestar y con la creencia de estar haciendo bien las cosas (Seligman, 2011). Aunque en ocasiones se experimenta como estado, es realmente un rasgo que se forma por el disfrute, el significado y el compromiso con la vida y posee un componente cognitivo que permite juzgar los propios niveles de felicidad.

Como el interés de este estudio es operacionalizarla en el contexto laboral es preciso complementar la definición. Se entenderá entonces la felicidad en el trabajo como la "existencia de emociones positivas y disfrute del trabajo, lo cual implica un juicio subjetivo sobre lo bien que se está en la empresa y en relación con qué tan bien marchan las cosas allí" (Sanín \& Salanova, 2015; Sanín, 2015).

\section{Optimismo laboral}

Puede entenderse como la "inclinación a esperar resultados favorables" (Marshall, Wortman, Kusulas, Hervig, \& Vickers, 1992. p. 1067). Es una creencia acerca de que todo 
resultará bien. Varía en cuanto a su sustentación y persistencia con base en la información con que cuente la persona (Avia \& Vázquez, 2011). Igual que sucede con el concepto de felicidad, algunas aproximaciones teóricas lo consideran un estado y otras un rasgo.

Su consideración como rasgo sugiere que todos los seres humanos poseen algún nivel de optimismo; si no fuese así, no emprenderían proyectos, no iniciarían actividades y no se embarcarían en relaciones y vínculos a mediano y largo plazo. También podría afirmarse que tienen algo de pesimistas, lo cual explicaría por qué, en ocasiones, se evita hacer cosas solo por el hecho de que creer que no resultarán bien. Realmente lo anterior tiene que ver más con los juicios de oportunidad (Toro, 2002); sin embargo, los niveles de optimismo o pesimismo que caracterizan a las personas podrían ser el antecedente de dichos juicios.

El optimismo es un rasgo que distingue al ser humano de otras especies, especialmente porque implica la capacidad de predecir el futuro. La anticipación puede ser positiva (optimista) o negativa (pesimista) (Marshall, et al., 1992). Y se podría confiar más o menos en estas anticipaciones, lo que implica una aproximación meta-cognitiva, proceso que influye el pensamiento, el afecto y el comportamiento (Briñol, Gandarillas, Horcajo, \& Becerra, 2010).

Típicamente el optimismo y el pesimismo se han considerado polos opuestos. Sin embargo, la investigación revela que son diferentes (Avia \& Vázquez, 2011) aunque correlacionan negativamente (Marshall, et al, 1992). Se sustenta este hallazgo en el hecho de que es posible ser optimistas y pesimistas al mismo tiempo. Es decir anticipar que un proyecto puede resultar bien y mal al mismo tiempo, dadas ciertas condiciones.

Son las creencias las que permiten anticipar el futuro. Es decir, las ideas y juicios subjetivos que se tienen acerca de lo positivo o negativo que será algo. La creencia puede fundamentarse en información objetiva o subjetiva, confiable o no (Scheier, Carver, \& Bridges, 1994), de ahí que no todo optimismo es bueno ni todo pesimismo malo.

Ahora bien, como el interés en este trabajo es explorar el optimismo laboral, se tratará como una creencia dependiente de las circunstancias del trabajo. En esta vía se entenderá el optimismo laboral "como la creencia de que se obtendrán buenos resultados en el trabajo". Esto puede tomar dos caminos: 1. "La creencia sobre lo que uno mismo podrá lograr" y 2. "La creencia sobre lo que podrá lograr el equipo o la empresa" (Sanín y Salanova, s.f.). Ambas consideraciones pueden estar antecedidas por el optimismo como rasgo. Se aprecian entonces dos categorías diferentes de optimismo. Una que está bajo el control de la propia persona y otra dependiente del contexto. Se podría suponer entonces que estas pueden estar en niveles distintos y, por tanto, tendrían efectos diferentes sobre el trabajo.

Se han presentado tres tipos de optimismo. El primero considerado rasgo y que constituye una creencia relativamente estable a esperar resultados positivos. El segundo referido a creencias positivas sobre lo que la persona puede lograr en su trabajo y el tercero a los 
resultados favorables que se espera obtengan el equipo o la empresa. Se considera que el primero es un antecedente de los otros dos.

Son entonces tres las variables dependientes en esta investigación: la felicidad en el trabajo, el optimismo y pesimismo laborales. El interés es entonces explorar si realidades asociadas con el tipo de vinculación o de contrato que poseen las personas inciden en estas variables dependientes, así como lo hacen en condiciones tan diversas como la satisfacción laboral y el compromiso afectivo (Santos, Guillén y Montalbán, 2012), el tipo de contrato psicológico (Chambel, Alcover, \& Martínez, 2012; Solanes, 2010; Vesga, 2011), las expectativas de la persona, su desempeño (Sanín y Restrepo, 2009) y la calidad del clima organizacional (Toro \& Sanín, 2013). Saber esto permitirá ver otras implicaciones del tipo de contrato para la vida y el trabajo. Todo lo anterior revela que el tipo de contrato tiene efectos importantes en variables psicológicas. Es lícito pensar que también la felicidad y el optimismo pueden verse influenciados dada su relación con estas variables.

Adicionalmente, considerando que el trabajo es importante por las representaciones cognitivas que genera, por ejemplo, como forma de identidad y relacionamiento (Rentería, 2008), cabe suponer un efecto del tipo de contrato en la felicidad y el optimismo en la medida que puede alterar los significados y el sentido que las personas le dan a su trabajo y a su vida. Lo cual es una de las principales dimensiones de la auténtica felicidad (Seligman, 2011).

Con base en lo anterior se formulan las siguientes hipótesis:

Existen diferencias estadísticamente significativas en los niveles de felicidad según tipo de contrato (fijo, indefinido, temporal y prestación de servicios).

Existen diferencias estadísticamente significativas en los niveles de optimismo según tipo de contrato (fijo, indefinido, temporal y prestación de servicios).

\section{Método}

\section{Procedimiento y participantes}

Investigadores de apoyo de la Facultad de Ciencias Económicas de la Universidad de Antioquia estuvieron a cargo de la aplicación de los instrumentos y la recolección de los datos. Estos recibieron formación especializada para el proceso. La recolección se hizo en lápiz y papel (92.4\%) y vía online (7.6\%). Se pidió siempre el consentimiento informado de los participantes, los cuales invirtieron aproximadamente una hora en el diligenciamiento de las encuestas. Se procedió cumpliendo las leyes que regulan el ejercicio de la psicología en Colombia (Ministerio de la Protección Social, 2006).

Los archivos de lápiz y papel fueron escaneados con el Programa Teleform. Los online fueron bajados de la plataforma Survey Monkey. 
La fusión de los datos de lápiz y papel con los virtuales arrojó 802 casos válidos. Aunque participaron más personas sus datos no fueron incluidos, pues los Investigadores de Apoyo encontraron durante el diligenciamiento displicencia, baja o nula comprensión del propósito del estudio o de la forma de calificación e intentos de manipulación. De esto se dejó constancia en actas. ${ }^{9}$

Los casos corresponden a personas trabajadoras de 181 empresas. Sector Económico de la empresa (servicios $31.1 \%$, educativo $22.6 \%$, comercial $21.3 \%$, industrial $14.5 \%$, otro $5.4 \%$, salud $2.4 \%$, financiero $1.9 \%$ y agroindustrial .9\%); tamaño de la empresa (más de 300 empleados [41.7\%], de 11 a 50 [21.2\%], menos de 10 [14.0\%], de 101 a 300 [10.9\%], de 51 a 100 [9.3\%] y unipersonal [2.9\%]); tipo de empleo (formal $89.5 \%$ ); tipo de contrato (término indefinido $49.9 \%$, término fijo $28.7 \%$, prestación de servicios $14.9 \%$ y temporal 6.5\%); estado civil (soltero $57.6 \%$, casado $25.1 \%$, unión libre $10.3 \%$, separado $3.9 \%$, divorciado $1.9 \%$ y viudo $1.3 \%$ ); nivel educativo (técnico/tecnológico $28.8 \%$, bachillerato $28.6 \%$, profesional $22.6 \%$, posgrado $17.7 \%$ y primaria $2.3 \%$ ); edad ( 21 a 25 años $25.5 \%$, de 26 a $3018.0 \%$, de 31 a $3514.0 \%$, de 41 a $4510.1 \%$, de 36 a $408.5 \%$, de 46 a $507.4 \%$, de 51 a $557.1 \%$, de menos de 20 años $6.0 \%$, de 56 a $602.6 \%$ y de más de 61 años .9\%); género (femenino $54.9 \%$ ); estrato socioeconómico (estrato tres $49.1 \%$, estrato dos $24.9 \%$, estrato cuatro $14.2 \%$, estrato cinco $7.8 \%$, estrato uno $2.9 \%$ y estrato seis $1.1 \%$ ). En contraprestación algunas empresas recibieron un informe particular por permitir la participación de sus empleados y empleadas. Esto se hizo solo cuando la muestra resultó representativa.

\section{Instrumentos}

La felicidad en el trabajo, el optimismo y el pesimismo laborales fueron evaluados con versiones adaptadas para Colombia por Sanín y Salanova (2015, s.f.) del Authentic Happiness Inventory (AHI) de Seligman, et al. (2005) y del LOT-R de Scheier, et al. (1994). La primera examina el grado en el que la persona posee un estado de ánimo positivo, considera que obtiene logros importantes y gratificantes y le encuentra sentido a su trabajo. La segunda evalúa el grado en el que la persona cree que obtendrá resultados positivos en su trabajo. Se trabajó con escala tipo Likert en el instrumento de optimismo/pesimismo con extremo 4 "Totalmente de acuerdo" y 1 "Totalmente en desacuerdo". Se incluye el valor 0 "No estoy seguro del asunto", pero se eliminó el punto central para favorecer la variabilidad y capacidad de discriminación de cada ítem, y reducir la deseabilidad del punto medio. En felicidad la escala era de selección múltiple con única respuesta.

\section{Análisis de Datos}

\footnotetext{
${ }^{9}$ Este archivo estará disponible para auditorías hasta diciembre de 2015. Luego de esa fecha se destruirá la información.
} 
Se verificó la normalidad de los datos para comprobar si eran aplicables estadísticas paramétricas o no paramétricas. Posteriormente se realizaron comparaciones entre grupos usando el estadístico Kruskal Wallis ya que se encontró que los datos eran no normales. El análisis se hizo con el paquete estadístico SPSS Versión 23.

\section{Resultados}

En la Tabla 1 se reportan las medias, desviaciones típicas y correlaciones entres las variables del estudio. Allí puede verse también el nivel de consistencia interna de cada escala. Se destaca que en el caso de las de optimismo y pesimismo fue preciso utilizar el coeficiente de confiabilidad compuesta ya que se trata de escalas de pocos ítems. Esta última se recomienda en este caso ya que el alfa de Cronbach es sensible al número de reactivos (Fornell \& Larcker, 1981).

Tabla 1. Fiabilidad, medias, desviaciones estándar y correlaciones entre las variables del estudio $(n=802)$

\begin{tabular}{|c|c|c|c|c|c|c|c|}
\hline & $\mathrm{n}$ & Fia. & $M$ & $D E$ & 1 & 2 & 3 \\
\hline 1. Felicidad en el Trabajo & 802 & 0.88 & 3.51 & .60 & - & & \\
\hline 2. Optimismo en el Trabajo & 802 & 0.77 & 3.45 & .56 & $.383^{* *}$ & - & \\
\hline 3. Pesimismo en el Trabajo & 802 & 0.79 & 1.95 & .73 & $-.236^{* *}$ & $-.191^{* *}$ & - \\
\hline
\end{tabular}

Nota: Correlaciones; ${ }^{* *} p<.01 ;{ }^{*} p<.05$. Fia ${ }^{10}=$ fiabilidad; $\mathrm{M}=$ Media; DE= Desviación Estándar

La felicidad y el optimismo correlacionaron de manera positiva. Al mismo tiempo se da una correlación negativa entre pesimismo en el trabajo y las demás variables de estudio.

Los resultados en la Tabla 1 también indican un sesgo positivo en las medidas de felicidad y optimismo, y negativo en el caso del pesimismo.

Por otra parte, se verificó la normalidad de los datos utilizando el estadístico de Shapiro Wilk. Se encontró que estos eran no-normales (felicidad en el trabajo $=.985,(782) ; p<.001$; optimismo en el trabajo $=.852,(782), p<.001$; pesimismo en el trabajo $=.937,(782), p$ $<.001)$. Por lo anterior se procedió a realizar comparaciones entre grupos haciendo uso del estadístico Kruskal Wallis. Los resultados revelaron ausencia de diferencias significativas en las medianas por tipo de contrato en las variables de Felicidad en el Trabajo $\left(\chi^{2} 5,547\right.$; gl 3; $p, 136)$, Optimismo en el Trabajo $\left(\chi^{2} 1,363 ; \mathrm{gl} 3 ; p, 714\right)$ y Pesimismo en el Trabajo $\left(\chi^{2} 1,078\right.$ gl $3 ; p, 782)$.

\section{Discusión}

\footnotetext{
${ }^{10}$ Se usa Fia y no Alpha teniendo en cuenta que en Optimismo y Pesimismo se calculó la consistencia interna a través de la fórmula de la confiabilidad compuesta
} 
Como era de esperarse se presentó una correlación positiva entre felicidad y optimismo y negativa entre pesimismo en el trabajo y las demás variables de estudio (Avia, \& Vázquez, 2011). Sin embargo, se destaca que a pesar de ser significativa, la correlación entre pesimismo y optimismo no es alta, lo que indicaría que no se trata de polos opuestos del mismo fenómeno.

Por otra parte, se observó que el tipo de contrato posee poca capacidad para predecir los niveles de felicidad, optimismo y pesimismo en las personas cuando se relaciona con el trabajo. Es decir que dichos fenómenos parecieran independientes del tipo de contrato que posee una persona.

Los resultados indican que el tipo de contrato laboral no predice la felicidad en el trabajo, el optimismo y el pesimismo laborales. Las tres variables analizadas muestran que no hay diferencias significativas con el tipo de contrato, evidenciando así que son aspectos estructurales, más estables, que no dependen de condiciones laborales o circunstancias externas.

Con esto se sugiere que la felicidad en el trabajo, el optimismo y el pesimismo laborales son aspectos intrínsecos del sujeto que no están condicionados por el tipo de contrato ni por las realidades asociadas a este. Esto podría deberse a que son rasgos relativamente estables y consistentes a lo largo de la vida (Lyubomirski, 2014). Este hallazgo es coherente con las investigaciones que señalan que la felicidad está determinada en un $50 \%$ por el componente genético, $10 \%$ corresponde a causas ambientales y el $40 \%$ restante es potencialmente modificable (Lyubomirsky, 2008) y con el hecho de que el optimismo es más una característica de personalidad que un estado (Avia \& Vázquez, 2011). Esto podría indicar que el tipo de contrato no es uno de los aspectos no genéticos que explican modificaciones en los niveles de felicidad. De esta manera, estos rasgos predisponen al individuo a tener pensamientos positivos y realizar acciones congruentes con sus emociones en sus diferentes esferas de la vida. Sin embargo, es posible que en interacción con otros aspectos o realidades organizacionales el Tipo de Contrato si pueda afectar la felicidad y el optimismo. Se trataría entonces de un efecto de interacción que convendría estudiarse en otras investigaciones.

Lo anterior indica que con independencia del tipo de contrato las personas con un funcionamiento psicológico óptimo, estarán inclinadas a elegir actividades gratificantes, es decir encaminadas al logro de objetivos o metas que se valoran y dan sentido a la vida. Seligman (2011) sugiere que la auténtica felicidad está facilitada por la práctica y desarrollo de las virtudes como la bondad, la gratitud, el optimismo, la curiosidad, la alegría, la mente abierta y la esperanza.

Estos hallazgos son contraintuitivos. Se esperaba que al ser el tipo de contrato una realidad con capacidad para predecir diferencias en el compromiso, el clima organizacional, el desempeño y el tipo de contrato psicológico, también habría diferencias en cuanto a los 
niveles de felicidad y optimismo. No obstante, en el caso de la felicidad y el optimismo, como se afirmó, suele tener más peso el rasgo que la circunstancia. En este caso la circunstancia sería el tipo de contrato y por tanto es una condición a la que las personas se pueden adaptar, para bien o para mal.

Así las cosas, es posible que una persona pueda ser feliz con su trabajo a pesar de su tipo de vinculación. También es posible que mantenga sus creencias positivas acerca de que todo resultará bien, especialmente porque esas creencias sobre el futuro no parecen estar relacionadas con asuntos organizacionales, sino, más bien, con asuntos personales e individuales, producto de las experiencias previas de la persona y de la manera como ha conceptualizado sus triunfos y sus fracasos (López \& Sanín, s.f.). Estos hallazgos podrían sustentar el hecho de que estos atributos sean más rasgo que estado, en la medida que los estados son más cambiantes y dependientes de las circunstancias y situaciones particulares, mientras los rasgos suelen ser estables y difíciles de modificar.

Las implicaciones de este resultado indican que el tipo de contrato no es una condición diferenciadora del optimismo y la felicidad de las personas en el trabajo. Pero esto no debe malentenderse pensando entonces que se puede ofrecer cualquier tipo de vinculación a las personas, solo por el hecho de que mantendrán sus creencias positivas y su disfrute y sentido de vida a pesar de como la organización las vincule. Por el contrario, hay una buena cantidad de investigaciones que señalan efectos distintos y negativos del tipo de contrato (Solanes, 2010; Vesga, 2011; Rodríguez \& Canal, 2011; Uribe, Garrido \& Rodríguez, 2011; Santos, Guillén y Montalbán, 2012; Chambel, Alcover, \& Martínez, 2012) y que sustentan que es un tema al que debe prestársele atención.

Adicionalmente, y tal como lo plantea Abramo (1999, citado por Useche, 75), la precarización no debería ser una consecuencia de la flexibilización puesto que tener a los trabajadores en condiciones desfavorables y precarias no es lo que favorece a la empresa. La calificación, protección e involucramiento de los trabajadores en los objetivos de la organización resultan claves para una modernización de las organizaciones que no se basa en reducción de costos.

El estudio nos muestra que el ser humano es capaz de ser feliz y optimista aún en situaciones y condiciones que le son contrarias y adversas. El efecto sobre la felicidad y el optimismo entonces podría deberse más a la forma como se trata a las personas por su tipo de contrato y por las condiciones a las que se debe hacer frente por ello y no al tipo de contrato per se. En este contexto la felicidad y el optimismo pueden incluso ser condiciones protectoras ante los cambios organizativos del trabajo.

\section{Limitaciones de la investigación}

Se trató de una muestra por disponibilidad, sin embargo, la cantidad de empresas representadas puede contrarrestar un poco esta deficiencia. También es una limitación no 
haber controlado otras variables como el género, la antigüedad y el nivel jerárquico. Futuras investigaciones podrían centrarse en ello; aun así, los hallazgos pudieron ser apoyados por la investigación previa, especialmente la que trata la felicidad y el optimismo como variables rasgo.

Se trató de una investigación netamente cuantitativa, esto impide conocer los significados y valoraciones de las personas en relación con su tipo de contrato. Futuras investigaciones podrían incluir análisis en los que la narrativa tenga más protagonismo y se pueda entender realmente por qué el tipo de contrato tiene efectos sobre unas variables psicosociales y no sobre otras.

\section{Futuras líneas de investigación}

Según los hallazgos el tipo de contrato laboral no predice la felicidad en el trabajo, el optimismo y el pesimismo laborales. No obstante, se abre la posibilidad de seguir explorando la relación del tipo de contrato y otras variables psicológicas como la satisfacción, la calidad de vida, la motivación, el bienestar, las actitudes, el engagement y el clima laboral, aportando a la comprensión del ser humano en la organización. Esto es importante porque con respecto a estas variables podrían darse resultados diferentes que sustenten la importancia de desarrollar acciones en contra de la precarización del trabajo.

Finalmente, los resultados también señalan que existe el imaginario de que el contrato a término fijo o de prestación de servicios per se es precario. Una línea de investigación podría centrarse en indagar si estos imaginarios se originan en que las personas con estos tipos de contrato no pueden acceder a todos los beneficios otorgados por la empresa o porque el contrato es en realidad precario en sí mismo. Se trataría entonces de explorar si el problema es el contrato o el tratamiento que se le da. 
Capítulo 7. Happiness and optimism interventions at work: Gender differences.

\begin{abstract}
$^{11}$
The aim of this quasi-experimental study was to analyze the changes derived from happiness and optimism interventions in 12 groups of employees chosen at random in two Colombian companies. For the happiness intervention, three conditions were applied: Expressing Gratitude, Acts of Kindness and Pencil in the Mouth. In the case of optimism, three other conditions were used: Breaking the Routine, Reformulating Goals and Resignifying Failure. In addition, answers from a control group, a placebo group and another group on a waiting list were included. 93 people completed the questionnaires at both Time 1 (before the intervention) and Time 2 (after the intervention). Testing of related samples was performed to verify the changes according to each condition. The results show that the condition of kindness alone and combined with the reformulation of goals tended to have more positive effects on happiness levels. There were differences in the effectiveness associated with gender and the employees' previous levels of happiness and optimism. The practical applications of these findings in the work context and their influence on work performance are discussed.
\end{abstract}

\title{
Introduction
}

Improving people's well-being and quality of life requires an understanding of the background and effects of how people think, feel and act. Years of research have brought important advances, with literature that explains the psychological processes underlying well-being and quality of life. However, the focus on the study of psychological pathology has been to the detriment of the study of optimal functioning (Seligman, Steen, Park \& Peterson, 2005). The same is occurring in the field of psychological intervention, particularly in work contexts. However, there has been an increase in research with this approach in the last decade (Meyers, van Woerkom, \& Bakker, 2013; Ouweneel, Le Blanc, \& Schaufeli, 2013; Rodríguez-Muñoz, \& Sanz-Vergel, 2013; Youssef \& Luthans, 2007).

This trend has been different in Latin America. There are few studies on intervention into positive aspects at work. The last reference about it was found in Calderón, Álvarez \& Naranjo (2006). This does not mean that positive interventions are not conducted at Region, but rather we believe that such a practice is not documented, which may be due to them being conducted at times with no clear idea of the effects they will have or to the difficulty in verifying their effectiveness in organizational contexts. Another obstacle to undertaking such research is the resistance organizations have in giving employees the time to participate (Lyubomirsky, Dickerhoof, Boehm \& Sheldon, 2011).

\footnotetext{
${ }^{11}$ Este capítulo está en proceso de envío a la Revista: Journal of Happiness Studies
} 


\section{Happiness Intervention at Work}

Happiness is understood as a phenomenon that characterizes people who usually feel satisfaction and enjoyment and obtain gratification from what they do in life (Seligman, 2011). This can be general or specific and associated with the person's spheres of action, such as work for example (Sanín \& Salanova, sometido). Happiness at Work is defined the same as the general, only delimiting its dimensions in that context. Like the general, it is susceptible to intervention.

Seligman et al. (2005) designed various actions to increase it. They found that describing positive events, exploring one's own strengths and expressing gratitude have long-term effects on happiness. Other authors have found that the activities related to social issues, membership and the search for support also work (González-Quiñones \& RestrepoChavarriaga, 2010). On the other hand, the experiments conducted by Abbe, Tkach and Lyubomirsky (2003) show that positive changes produce positive emotions that are resistant to the hedonic treadmill and benefit well-being over time. The most effective conditions indicated by these last authors are the expression of gratitude and exhibiting behaviors of goodness and kindness.

Other activities that have been effective in increasing happiness are those of affiliation and participation, mental control, goal-oriented work, actively taking advantage of free time or relaxing, being dedicated to religious activities and generally direct and intentional attempts at achieving happiness (Tkach \& Lyubomirsky, 2006). It was also found that asking people to recall three positive events increases it, particularly in those who put more effort into the activity (Chancellor, Layous \& Lyubomirsky, 2014). Of all interventions referred, only the last one was done in a work context, and it was not mentioned whether there were any differences with respect to its effectiveness in terms of gender. Other inventions made in organizations have shown positive effects and that is an incentive to think that it is possible to generate positive changes in the company (Meyers \& van Woerkom, 2016; Salanova, Llorens, Acosta, \& Torrente, 2013).

The conditions related to activities that people do for themselves are more beneficial (Ouweneel, et al., 2013). The context-dependent ones or the circumstances have little predictive power, and the context-dependent ones can also represent long-term changes in happiness and overcome the effect of the hedonic treadmill (Sheldon \& Lyubomirsky, 2006). Some circumstances can also have this effect in the long term (Easterlin, 2003), which suggests that adaptation is not always complete and depends on the circumstance.

Despite knowledge about the conditions for improving happiness, there is little research that reveals if its increase has any effect on people's work performance and productivity (Fisher, 2010). This is only mentioned as a possibility, which leaves open the debate on whether happiness affects work performance or not (Fisher, 2003).

This discussion is based on studies that show contradictory and inconclusive results. Some 
show no relation (Jones, 2006; Wright, Larwood \& Denney, 2002), while others do (Taris \& Schreurs, 2009; Whitman, Van Rooy \& Viswesvaran, 2010; Zelenski, Murphy \& Jenkins, 2008). It seems, however, that the more interesting question than whether there is a relation or not, is when it occurs and why that is. Some authors suggest that it is due to the relation being mediated by other variables (Wright, Cropanzano \& Bonett, 2007). Others explain the lack of relation by arguing that performance requires motivation and a certain "tension", and satisfaction goes against that, because it usually generates a different emotional state, one of calm, with dissatisfaction then being the one that affects performance (Crow \& Hartman, 1995). The lack of association may also be following the little uniformity in the measures of either constructs or methodological reasons (Jones, 2006). For example, it is common to assume the constructs of work satisfaction and happiness at work to be synonyms when, in fact, they are different. The former is an affective reaction resulting from the contrast between reality and the expectations and interests inherent to work (Wright \& Cropanzano, 2000). The latter tends toward stability and is considered more a trait.

All this indicates an interesting panorama for the present study. It shows first that it is possible to obtain changes in happiness; second, that these can occur in the long term; and third, it contributes to the debate about whether happiness does indeed benefit performance.

In this study, and considering the literature review, the improvement in happiness was treated with the expression of gratitude, actions of kindness and the pencil in the mouth. The first two are interventions that are social in nature (Seligman, et al., 2005; Sheldon \& Lyubomirsky, 2006; Tkach \& Lyubomirsky, 2006); the last is based on proprioceptive principles (Wiseman, 2009).

\section{Optimism intervention at work}

Optimism manifests in the favorable expectations related to the occurrence of upcoming events (Carver, Sheier \& Segerstrom, 2010). It tends to be stable, as it is configured as a system of beliefs (Londoño, Velasco, Alejo, Botero \& Vanegas, 2014; Vera-Villarroel, Córdova-Rubio \& Celis-Atenas, 2009), which can be supported by objective or subjective information, reliable or not (Scheier, Carver, Bridges, 1994) and be general or specific to a particular context, like work for example (Sanín \& Salanova, 2015.). In that context optimistic people can expect good results related to what they themselves will be able to achieve or what the team or the company can achieve.

The concept has been widely investigated and there is information about its background and consequences, but the effects of its intervention have scarcely been documented (Avia \& Vázquez, 2011). However, being a system of beliefs makes it susceptible to intervention. Thanks to the knowledge about its background, some activities can be defined that could increase it (Avia \& Vázquez, 2011). 
It is known that optimism is facilitated by the possibility of reaching valuable goals. Therefore, a strategy to develop it would be to have people formulate their goals as attainable, challenging and sensible objectives (Avia \&Vázquez, 2011). Additionally, it has been found that when people begin to think more about others than themselves, they are usually more optimistic. Managing to think that their goals respond to a greater purpose beyond themselves could then be useful for reinforcing their optimism. Other findings indicate that those who cope well with failure and accept themselves tend to be more optimistic, which is why helping people to see their failure as a learning element could be useful.

Moreover, there is a known association between optimism and extroversion (Scheier, Carver \& Bridges, 1994), which raises the question whether its development will lead to motivating people to share with others and be spontaneous.

On this basis, three conditions were designed for the optimism intervention at work: Breaking the Routine, Reformulating Goals, and Resignifying Failure. In addition it was decided to combine some strategies: Reformulating Goals with Kindness, Resignification of Failure with Gratitude and Breaking the Routine with Pencil in Mouth. The mix was random. Each strategy to enhance happiness was paired whit one that increase optimism. This in order to see if intervention of both at the same time has a different effect.

The conditions for improving happiness and optimism were implemented with the aim of verifying their effectiveness in work contexts. And these were reviewed as to whether they are the same in men and women. Differentiation by gender was done because in several studies it has been reported that the findings in psychology cannot be generalized to men and women (Piqueras, Kuhne, Vera-Villarroel, van Straten \& Cuijpers, 2011; Sanín 2007; Vera-Villarroel, Piqueras, Kuhne, Cuijpers \& van Straten, 2014). It is possible that the effects are different for this reason and that the practices do not work the same way (Anderson, Lievens, van Dam \& Born, 2006). Men and women are exposed to different parenting patterns, and on many occasions are treated differently (Ardila, 1988). According to the research, activities that involve social contact, such as breaking routine and kindness, could be more effective for women, because to the importance they attach to contact with others (Geary, 2010). Reformulation of goals can also be expected to be more effective for them, because women, usually, have double shift, and the possibility to focusing can help them to find sense of what they do (Bratberg, Dahl, \& Risa, 2002).

On the other hand, expressing gratitude and resignification of failure could be more effective for men, because their social role prevents them from doing this frequently, as they may appear weak or sentimental in a culture like Colombian (Ardila 1988). In addition, the development of concrete activities could favor men because the way they usually process the information (Geary, 2010), hence it is expected that the Pencil in the Mouth will be more effective to them. 
Hypothesis

$\mathrm{H1}$ : The expression of gratitude will increase happiness, but we expect significant differences depending on gender, with men having the greatest increase compared to women.

$\mathrm{H} 2$ : The behaviors of kindness will increase happiness, but we expect significant differences depending on gender, with women having the greatest increase compared to men.

H3: The pencil in the mouth will increase happiness, but we expect significant differences depending on gender, with men having the greatest increase compared to women.

H4: The Resignification of Failure will increase optimism, but we expect significant differences depending on gender, with men having the greatest increase compared to women.

H5: The Reformulation of Goals will increase optimism, but we expect significant differences depending on gender, with women having the greatest increase compared to men.

H6: Breaking the Routine will increase optimism, but we expect significant differences depending on gender, with women having the greatest increase compared to men.

$\mathrm{H7}$ : The combination of conditions will have effects on the happiness and optimism.

\section{Method}

Design

Quasi-experimental study with pretest and post-test, with equivalent control groups.

\section{Participants}

197 people from two companies participed in the study, $58.4 \%$ from company 1 . Ninetythree people completed the assessment at time one and two ( $52.8 \%$ of mortality). $55.9 \%$ were women, $63.2 \%$ were between 26 and 40 years of age, $14 \%$ were under $26,14 \%$ were over 45 and $8.8 \%$ were between 41 and $45.70 .2 \%$ had worked for their company less than 8 years.

\section{Instruments}

Happiness Scale General and at Work ( $\alpha=>$.70; AFC, CFI and TLI > .90 and $\alpha=>$.70; AFC, CFI and $\mathrm{TLI}>$.90, respectively). Adaptations for the Colombian working population from the Authentic Happiness Inventory by Seligman et al. (2005) (Sanín \& Salanova, 2015). They are completed by choosing one of five possible options that describe the person's mood (e.g. A..., B..., C. I am more happy than sad., D..., E...). The same items are answered with life in general in mind first and then in the work context. They evaluate Happiness in Life ( $\left.H_{-} L i f e\right)$ and Happiness at Work (H_Work).

Optimism/Pessimism Scale in Life, in the company and at Work $(\alpha=>$.70; AFC, CFI and TLI > .90). Adaptation of the LOT-R by Scheier, et al. (1994) for the Colombian working population (Sanín \& Salanova, n.d.). It has 10 test items that must be completed by thinking about life in general, then in the company and finally at work. Responses are based on a Likert scale with the extremes 4 "Totally agree" and 1 "Totally disagree" (e.g. In difficult times, I tend to 
hope for the best). They assess Optimism/Pessimism (O_Life/P_Life), Optimism/Pessimism in the company (O_Company/P_Company) and Optimism/Pessimism at Work (O_Work/P_Work).

Satisfaction with Life Scale (S_Life) ( $\alpha=>$.70; AFC, CFI and TLI > .90) Satisfaction with Life Scale (3) by Pavot and Diener (1993). The version used by Authentic Happiness Inventory validation for the Colombian working population was used (Sanín \& Salanova, 2015). It has 5 items that are answered on the basis of Likert scale extremes 6 "Totally agree" and 1 "Strongly disagree" (e.g. 3. I am satisfied with my life). It measures the degree to which a person feels satisfied with their life in general.

Performance Rating Scale (PRS). It examines: Intra-role performance (P_Intrarol) $(\alpha=0.93)$, Extra-role performance (P_Extrarol) $(\alpha=0.85)$ and Compliance with rules (C_Rules) ( $\alpha=$ 0.84) (Toro, 2010).

On the Likert scales, the central point of the original scale was eliminated (neither agree nor disagree), as it introduces a value that does not contribute any real information about the level of the variable. The recorded scores are calculated with Colombian scales.

\section{Procedure}

The aim and the process were explained in detail to the participants, and their consent was obtained according to the parameters set out by Colombian law. The ethical management conditions were reviewed and guaranteed by the Science Committee of the Cincel Center for Research in Organizational Behavior and by the human resource managers in each company.

In the two companies people who wanted to participate enrolled. These were distributed randomly into 12 groups. Table 1 shows the strategy assigned to each group and the resulting $\mathrm{n}$ after combining the data from the two companies ${ }^{12}$.

Table 1 Groups, conditions applied and $\mathrm{n}$.

\begin{tabular}{llllllll} 
Happiness & $\mathrm{n}$ & Optimism & $\mathrm{n}$ & Combination & $\mathrm{N}$ & Control & $\mathrm{n}$ \\
\hline Pencil in the Mouth & 9 & Resignification of Failure & 11 & Reformulation of Goals/Kindness & 9 & Placebo & 10 \\
Gratitude & 6 & Breaking the Routine & 9 & Resignification of Failure/Gratitude & 7 & Control & 9 \\
Kindness & 6 & Reformulation of Goals & 3 & Breaking Routine/Pencil in the Mouth & 6 & Waiting & 8 \\
\hline
\end{tabular}

The people in the twelve groups had the variables measured before beginning the interventions. Then they were given the corresponding protocol (see Annex), which they had a month to complete. When time was up, the variables were measured again. Monitoring took place three months later. Their respective managers were also asked to

\footnotetext{
${ }^{12}$ In the annex A it is present the detail of each strategy. There is displayed in the original language in which it was applied.
} 
participate in the study. The aim was to evaluate the participants' performance as an indicator of the effect of the practices. 36 managers described their staff's performance at times one and two. Of these only 22 could be matched with the participants' data. The remaining 14 were scores from managers whose employees did not complete the questionnaires at time two.

The participants were asked to refrain from practices that contribute to improving their performance in the task during the month in which they participated in the study to control the effect of the training.

Once the data were collected, the variables were calculated and their normality was verified using the Kolmogorov-Smirnov test. Only intra-role performance at times 1 and 2 showed normality $(p>.050)$. As a result of this and for being small groups, the decision was made to use nonparametric statistics. The test of related samples was applied to confirm whether there was any significant change in the level of the variables between times one and two. Due to mortality of the sample, neither data from the third time nor from that evaluated by the managers were analyzed. Although a repeated measures multivariate analysis of variance would have been more robust, it was not possible to apply it given the sample sizes and group distribution. The software SPSS v. 21 was used to calculate the statistics. G*Power v.3.1 (G*Power, 2014) was used to calculate the size of the effect (dz).

\section{Results}

Table 2. Means, Standard Deviations (SD) and Correlations between the study variables at time 1 and time 2.

\begin{tabular}{|c|c|c|c|c|c|c|c|c|c|c|c|c|c|c|}
\hline & Mean (SD) 1 & Mean (SD) 2 & 1 & 2 & 3 & 4 & 5 & 6 & 7 & 8 & 9 & 10 & 11 & 12 \\
\hline 1. H_Work & $52.83(9.43)$ & $52.80(9.33)$ & - & $.664^{* *}$ & $.412^{* *}$ & $-.221^{*}$ & $.472^{* *}$ & -.198 & $.436^{* *}$ & -.146 & $.582^{* *}$ & .321 & .112 & -.063 \\
\hline 2. H_Life & $52.03(10.74)$ & $53.63(11.14)$ & $.607^{* *}$ & - & $.250^{*}$ & -.190 & .195 & -.205 & $.528^{* *}$ & $-.275^{* *}$ & $.613^{* *}$ & .052 & .013 & .181 \\
\hline 3. O_Company & $50.85(9.32)$ & $51.07(9.30)$ & $.469^{* *}$ & $.333^{* *}$ & - & -.099 & $.669^{* *}$ & -.150 & $.604^{* *}$ & -.084 & $.355^{* *}$ & .335 & -.073 & .174 \\
\hline 4. P_Company & $47.01(8.78)$ & $45.48(8.07)$ & -.196 & $-.260^{*}$ & -.169 & - & -.165 & $.880^{* *}$ & $-.236^{*}$ & $.726^{* *}$ & $-.320^{* *}$ & .173 & .032 & .249 \\
\hline 5. O_Work & $50.00(10.27)$ & $49.61(10.12)$ & $.477^{* *}$ & $.360^{* *}$ & $.740^{* *}$ & -.078 & - & -.125 & $.639^{* *}$ & -.001 & $.352^{* *}$ & .162 & -.281 & -.253 \\
\hline 6. P_Work & $47.60(9.44)$ & $45.37(8.27)$ & $-.297^{* *}$ & $-.301^{* *}$ & $-.312^{* *}$ & $.752^{* *}$ & $-.346^{* *}$ & - & $-.237^{*}$ & $.832^{* *}$ & $-.323^{* *}$ & .109 & .095 & .098 \\
\hline 7. O_Life & $50.38(9.34)$ & $50.96(9.40)$ & $.326^{* *}$ & $.432^{* *}$ & $.542^{* *}$ & -.080 & $.725^{* *}$ & $-.297^{* *}$ & - & $-.259^{*}$ & $.528^{* *}$ & .093 & -.252 & .057 \\
\hline 8. P_Life & $46.69(8.62)$ & $44.77(8.43)$ & $-.245^{*}$ & $-.311^{* *}$ & -.148 & $.692^{* *}$ & -.115 & $.775^{* *}$ & -.202 & - & $-.307^{* *}$ & -.121 & .081 & .017 \\
\hline 9. S_Life & $51.64(9.51)$ & $52.50(9.70)$ & $.412^{* *}$ & $.634^{* *}$ & $.266^{* *}$ & -.154 & $.282^{* *}$ & $-.227^{*}$ & $.382^{* *}$ & -.172 & - & .071 & -.145 & .049 \\
\hline 10. D_Intrarol & $5.04(0.73)$ & $5.07(0.75)$ & .130 & .179 & $.337^{*}$ & -.099 & .171 & .003 & .289 & -.003 & .110 & - & .003 & .239 \\
\hline 11. D_Extrarol & $5.45(0.61)$ & $5.19(0.62)$ & -.120 & .013 & .075 & .111 & .001 & .063 & -.127 & .080 & .011 & .282 & - & .275 \\
\hline 12. C_Normas & $5.72(0.40)$ & $5.61(0.48)$ & -.107 & -.209 & .080 & -.037 & -.001 & -.046 & .013 & -.029 & -.197 & .296 & $.550^{* *}$ & - \\
\hline
\end{tabular}

Note: Below the diagonal are the correlations (Spearman) between the variables at time 1, above at time $2 .{ }^{* *} p<0.01,{ }^{*} p<0.05$.

Table 2 presents statistically significant correlations between the positive variables, with the 
highest being those reported between Happiness at Work, Happiness in Life and Satisfaction with Life. There are negative correlations between the positive aspects and pessimism. None of the performance types correlated with positive affects.

Happiness at Work improved due to application of the strategy of Breaking the Routine (1. $\bar{x}=55.0, s d=8.33,2 . \bar{x}=57.49, s d=9.20 ; r=.933 ; z=-2.073, p=.038 ; d z=0.75$, power=0.48), even though this was designed to increase optimism. Happiness in Life was increased as an effect of the strategy of Kindness, alone (1. $\bar{x}=45.22$, $s d=15.58,2 . \bar{x}=53.52$, $s d=15.50 ; r=.800 ; z=-$ $2,023, p=.043 ; d z=0.85$, power $=0.29$ ) and in combination with the Reformulation of Goals (1. $\bar{x}=56.23, s d=9.57,2 . \bar{x}=59.70, s d=9.92 ; r=.850 ; z=-2,524, p=.012 ; d z=0.65$, power=0.38). Pessimism in the Company and at Work was significantly reduced with the combination of the practice of Resignifying Failure and Gratitude (1. $\bar{x}=46.08, s d=6.41,2 . \bar{x}=38.96, s d=3.57$; $r=.272 ; z=-2,264, p=.024 ; d z=1.11$, power=0.66 and $1 . \bar{x}=47.38, s d=7.79,2 . \bar{x}=38.90, s d=3.60$; $r=.327 ; z=-2,226, p=.026 ; d z=1.14$, power=0.68, respectively). The control group behaved differently than expected. The people who comprised it had changes in their Pessimism with Work (1. $\bar{x}=47.09, \mathrm{sd}=9.36,2 . \overline{\mathrm{x}}=41.00, \mathrm{sd}=5.33 ; \mathrm{r}=.805 ; \mathrm{z}=-2,220, p=.026 ; \mathrm{dz}=1.02$, power=0.74) and with Life (1. $\bar{x}=51.65, s d=8.60,2 . \bar{x}=40.59, s d=4.84 ; r=.254 ; z=-2,692$, $p=.007 ; d z=1.27$, power=0.90) and in Optimism with the Company $(1 . \bar{x}=56.11, s d=5.96,2$. $\bar{x}=5.47, s d=7.95 ; r=.587 ; z=-2,111, p=.035 ; d z=0.71$, power=0.44). This may be the result of breaches of some conditions.

To ascertain the effect of gender, the analyses were replicated by separating the data for this category. With the women it was effective: Breaking the Routine improved their Happiness at Work, (1. $\bar{x}=53.52, s d=10.43,2 . \bar{x}=58.00, s d=12.14 ; r=.999 ; z=-2,023, p=.043$; $d z=0.84$, power $=0.45$ ) and combining the Reformulation of Goals and Kindness improved their Happiness in Life (1. $\bar{x}=56.50, s d=10.19,2$. $\bar{x}=59.72, s d=10.60 ; r=.810 ; z=-2,371, p=.018$; $\mathrm{dz}=0.50$, power $=0.34$ ). For men the strategy of the Pencil in the Mouth improved their Happiness with Work (1. $\bar{x}=59.72, s d=4.07,2 . \bar{x}=56.45, s d=2.98 ; r=.700 ; z=-2,023, p=.043$; $\mathrm{dz}=1.12$, power=0.64), and Resignifying Failure combined with Gratitude reduced their Pessimism with Work (1. $\bar{x}=48.82, \mathrm{sd}=7.65,2 . \overline{\mathrm{x}}=37.85$, $\mathrm{sd}=2.04 ; \mathrm{r}=.186 ; \mathrm{z}=-2,032, p=.042$; $\mathrm{dz}=1.45$, power=0.82). In the control group Optimism with the Company increased in the women (1. $\bar{x}=56.11, s d=7.22,2 . \bar{x}=51.14, s d=8.22 ; r=.898 ; z=-2,236, p=.025 ; d z=1.37$, power=0.78).

Finally, it was verified whether there were any differences between those who improved and who did not to see if the hedonic treadmill could be limiting the effect of the practices. For this each person's scores were taken at time one and time two and then the variance of each item was reviewed. Later, in agreement with a chi-squared distribution, the likelihood that this variance was significant or not was verified. With this information it was possible to identify those people who had indeed improved to then compare them with those who had not.

Table 3. Test of independent samples people who improve vs. people who do not improve. 


\begin{tabular}{lllll} 
& U & W & Z & $P$ \\
\hline H_Work1 & 718.000 & 1313.000 & -2.274 & .023 \\
H_Life1 & 614.000 & 1209.000 & -3.104 & .002 \\
O_Company1 & 977.000 & 1572.000 & -.214 & .831 \\
P_Company1 & 777.500 & 2547.500 & -1.824 & .068 \\
O_Work1 & 952.000 & 1547.000 & -.419 & .675 \\
P_Work1 & 741.500 & 2511.500 & -2.121 & .034 \\
O_Life1 & 857.500 & 1452.500 & -1.239 & .215 \\
P_Life1 & 734.000 & 2504.000 & -2.184 & .029 \\
S_Life1 & 518.500 & 1113.500 & -3.877 & .000 \\
D_Intrarol1 & 143.500 & 549.500 & -.329 & .742 \\
D_Extrarol1 & 131.000 & 197.000 & -.735 & .462 \\
C_Normas1 & 152.000 & 218.000 & -.067 & .946 \\
H_Work2 & 773.500 & 1368.500 & -1.831 & .067 \\
H_Life2 & 575.000 & 1170.000 & -3.138 & .002 \\
O_Company2 & 709.000 & 1304.000 & -2.092 & .036
\end{tabular}

Continues Table 3.

\begin{tabular}{lllll} 
& U & W & Z & P \\
P_Company2 & 787.500 & 2383.500 & -1.395 & .163 \\
O_Work2 & 789.500 & 1384.500 & -1.397 & .162 \\
P_Work2 & 836.000 & 2432.000 & -.990 & .322 \\
O_Life2 & 685.000 & 1280.000 & -2.399 & .016 \\
P_Life2 & 867.500 & 2463.500 & -.720 & .471 \\
S_Life2 & 575.500 & 1170.500 & -3.145 & .002 \\
D_Intraro2 & 54.500 & 225.500 & -.520 & .603 \\
D_Extrarol2 & 47.000 & 218.000 & -.978 & .328 \\
C_Normas2 & 57.000 & 85.000 & -.378 & .705 \\
\hline Note: U=Mann-Whitney U. W = Wilcoxon \\
\hline \multicolumn{4}{l}{}
\end{tabular}

At time one the people who improved presented significantly lower levels of Happiness, Happiness at Work and Satisfaction with Life and higher levels of Pessimism at Work and in Life than the people who did not improve. The distance was maintained, even after the improvement, in Happiness in Life and Satisfaction with Life.

\section{Discussion}


The aim of this study was to analyze the changes derived from intervention in the levels of happiness and optimism in 12 groups of employees chosen at random in 2 Colombian companies.

What was reported in the literature was confirmed in terms of the link between Optimism and Happiness (Seligman, 2011). This indicates that those with positive beliefs about the future and who see the favorable side of events usually derive greater benefit, gratification and meaning in what they do. This also happens in the work context. Optimism is considered a precursor to happiness (Vera-Villarroel, Pávez \& Silva, 2012), while happiness contributes to people experiencing greater satisfaction with life (Cohn, Fredrickson, Brown, Mikels \& Conway, 2009; Peterson, Park \& Seligman, 2005). Optimism (on its three levels) and happiness (on its two levels) were negatively associated with all types of pessimism. Similar findings are reported in the literature (Avia \& Vázquez, 2011). This indicates that it is difficult for a person to consider their future a problem if a positive idea has already been formed about it. However, the absence of negative correlations of greater magnitude indicates to us that although there are competing beliefs (Chang, Maydeu-Olivares \& D'Zurilla, 1997), these are not conflicting (Herzberg, Glaesmer \& Hoyer, 2006; Marshall, Wortman, Kusulas, Hervig \& Vickers Jr, 1992).

There are no relations between the performance scored by the managers and people's happiness at work, life and optimism; other studies have shown the same (Jones, 2006). This may be due to the relation being moderated by some variable not controlled in this study (Quick \& Quick, 2004).

Four intervention conditions had the expected impact: Breaking the Routine, Expression of Kindness, Reformulation of Goals/Kindness and Resignification of Failure/Gratitude. This partially confirms Hypotheses $\mathrm{H} 6, \mathrm{H} 2$ and $\mathrm{H} 7$.

In terms of the differences by gender, it was found that Breaking the Routine served to improve women's Happiness with Work. Although it was expected that this would affect Optimism and not Happiness, the effect on the latter may be due to actively doing things out of the ordinary, which implies an effort to help recover from work (Sonnentag, 2003). This is more difficult for women, because they must face a double workday, which leaves them more fatigued (Dean, 1992) and negatively affects their health (Bratberg, et al., 2002; Väänänen, Kevin, Ala-Mursula, Pentti, Kivimäki \& Vahtera, 2005). The improvement can also be attributed to the suggestion that these extra-routine activities were undertaken in the company of others. The study has revealed that social interaction enhances happiness because of the increase in social support (Lyubomirsky, et al., 2011). It is also known that women place greater value on social exchange than men (Geary, 2010).

An improvement was also seen in Happiness in Life derived from combining the strategy of the Reformulation of Goals and Kindness in women (H7). This may be due to the former contributing to the focus on important things (Avia \& Vázquez, 2011) and the latter on social 
interaction (Batson \& Powell, 2003). Again, this deals with aspects that are not always equal between men and women (Ardila, 1988).

The Pencil in the Mouth worked for the men to improve their Happiness with Work (H3). It is worth noting that this did not work to improve Happiness with Life, since the strategy focuses on a general improvement. It is possible that this is because, of the three times that the pencil had "to force" the smile, two were implemented just before or during work. Therefore, the muscles of the smile were being exercised more in a particular context (Ekman, Davidson \& Friesen, 1990). What improves men and not women with this strategy may be due to it dealing with a more concrete task, which helps men identify with it (Geary. 2010).

Gratitude added to the Resignification of Failure helped the men reduce their Pessimism at Work (H7). It could be due to a process of cognitive reorganization that helps put failure in perspective as a learning experience (Avia \& Vázquez, 2011), a condition for psychological growth (Sanin \& Salanova, 2014). In the case of gratitude, the effect is explained by our awareness of the good things that have happened to us making it more difficult to render that compatible with negative beliefs (Lyubomirsky, et al., 2011).

No evidence was found to confirm Hypotheses $\mathrm{H} 1, \mathrm{H} 2$ and $\mathrm{H} 5$. It is possible that the instructions in the first two cases did not help people understand well what expressing gratitude and acting with kindness and goodness meant. In the case of $\mathrm{H} 6$, this dealt with a task that perhaps requires more time to see the effects, because people need to be able to see the effects of reformulating their goals.

It should be noted that, despite not confirming all the hypotheses, the two conditions that include kindness affected happiness with life. That shows that being kind has an important positive effect. This can be explained by kindness being a behavior that unites us with other human beings and promotes the development of social support derived from reciprocity (Tkach \& Lyubomirsky, 2006). This finding reinforces what has been reported in other studies (Chamorro-Premuzic, Bennett \& Furnham, 2007; Otake, Shimai, Tanaka-Matsumi, Otsui \& Fredrickson, 2006). Improvements were even evident by requesting few acts of kindness in the week, even when it is known that if these are grouped in a single day the effect will be greater (Buchanan \& Bardi, 2010; Lyubomirsky, Sheldon \& Schkade, 2005).

Some authors point out that being kind increases happiness because it reduces the stress generated if we do not act with empathy; it avoids social sanction and increases the likelihood of receiving rewards for being kind, i.e., for selfish motives. It has also been found, however, that people can be kind for altruistic reasons (Batson \& Powell, 2003). From this perspective, happiness is improved by giving life and work meaning as these become connected to a greater purpose.

The general results also showed that of the nine variables that had significant changes, four were from pessimism. This may be related to the already demonstrated fact that it is much 
easier to bring about changes to what is bad than to what is good (Vera-Villaroel, et al, 2012). This argument is reinforced when it is noted that those who improved were people with lower levels of Happiness, Happiness at Work and Satisfaction with Life than those who did not improve. This may indicate that the improvements are appreciable when there is a greater margin of change and, at the same time, that those who are well could require other conditions or the same but applied with greater control if real change is desired. What was found here partly confirms the difficulty that exists, on the grounds of the hedonic treadmill, in generating changes in people's happiness and optimism levels (Lyubomirsky, et al., 2011). What has been reviewed until now indicates that there are indeed applicable conditions in work contexts. Nevertheless, the analyses by gender showed that although this is not a differentiator of people's happiness (Lyubomirsky, 2008) and optimism levels (Avia \& Vázquez, 2011), it must be taken into consideration when it comes to implementing them. It was not possible to verify the effects of the improvements in happiness and optimism on performance. The sample of managers who assessed their staff at times one and two was insufficient. Nevertheless, it became apparent from the beginning that there was an absence of correlations between the managers' scores and their employees' happiness and optimism, which might be a sign that we cannot wait for a direct relationship between these two realities.

This study has theoretical and practical implications. With respect to the former, it reflects the importance of testing the already proven conditions in other contexts and cultures where there is an intention to implement them. Not all the conditions work equally. Additionally, it shows that the effect of the ones that work can be different in men and women. From the practical point of view, companies can see that it is possible to intervene in the levels of people's optimism and happiness with simple, easily applied strategies. Organizations could do pilot testing with various conditions until they find the ones that best fit their culture and personnel.

\section{Conclusions and limitations}

The study revealed the success of some conditions for improving happiness, happiness in life, optimism, optimism at work, optimism in the company and the reduction of pessimism. They are not all equally effective and differ in their effectiveness according to gender. Additionally, the intervention faces the hedonic treadmill. However, the fact that significant changes were found shows that it is viable and it makes sense for organizations to strive to bolster people's well-being.

Although the effect on performance could not be confirmed, the study shows that positive changes are possible and that this can be achieved with easily applied management conditions that can be developed without interrupting work.

This study has, however, some limitations that must be noted. The small sample size and number of people who decided to participate in the study mean that it is not known how 
the conditions would work on people who have the application forced on them. However, its utility could be seen in those who considered participation important. In this sense companies could work on sensitizing people before beginning plans of this type, so as to increase their willingness to be involved in the exercise. On the other hand, being an exercise outside the laboratory, it is difficult to control the real application of the conditions. It is possible that with greater control more robust results could be obtained. Many people did not develop the process at the three times and many managers did not evaluate their employees' performance before and after implementation of the conditions, which limited the scope of the study.

Nevertheless, the findings of this study show that it is viable and feasible to achieve positive changes in people in work contexts, which will have a favorable impact on their health and well-being (Norrish \& Vella-Brodrick, 2008). Furthermore, thanks to this study, we understand the importance of bearing people's gender in mind when implementing conditions to increase their happiness and optimism, because their effectiveness varies according to this factor.

It is worth remembering that both people and companies benefit with the design and implementation of effective, useful and validated conditions to improve workers' quality of life. These are conditions where everyone wins and that can be implemented easily in organizations. Thus it is shown that people's happiness and optimism can be the result of good and serious management. 


\section{Capítulo 8. Discusión General}

El objetivo de este trabajo fue abordar el concepto de felicidad y optimismo en el trabajo con el fin de entender sus efectos en el desempeño y la productividad organizacional. Con eso en mente se hizo una revisión de la literatura más actual para poder definir los conceptos. Luego se abordó el problema de la medida de ambas variables en el contexto del trabajo. Esto implicó revisar si la felicidad y el optimismo podían ser definidos también con base en un contexto particular. En la revisión teórica se insistió en que la Felicidad es un concepto superior y más complejo que los de bienestar y satisfacción. Para verificarlo se probó un modelo que nos permitió ver el rol de la satisfacción laboral en función del desempeño. Luego se avanzó en un modelo más complejo que muestra el rol de la felicidad y la satisfacción con la vida en el trabajo.

Una vez comprendido esto se pasó a ver si los niveles de felicidad y optimismo eran diferentes según el tipo de contrato de las personas. Esta parte de la investigación reviste importancia ya que se ha hipotetizado sobre los efectos del tipo de contrato en otras variables psicosociales. Se quiso ver si la felicidad y el optimismo hacían parte de esas variables. Finalmente, para que la investigación permitiera conectar con la práctica organizacional se revisó qué estrategias, que pudieran ser aplicables en el trabajo, podían incrementar el optimismo y la felicidad y si el género hacía que estas funcionaran de forma diferente.

En consonancia con tolo lo anterior el primer capítulo nos permitió reflexionar sobre la importancia de continuar con la investigación en torno al concepto de felicidad. Dese hace ya una década se especificó que no hay homogeneidad ni acuerdo en los investigadores sobre su definición (Alarcón, 2006) e incluso Seligman insiste en volver a hablar de Bienestar Subjetivo en lugar de felicidad (Seligman, 2016). Pese a esto ha habido acercamientos que nos permiten proponer una conceptualización general y entender que la felicidad es un fenómeno multidimensional que incluye estados afectivos positivos, tiene efectos favorables en el trabajo y la empresa y puede ser gestionada dentro de la organización ( Meyers, \& van Woerkom, 2016; Wright \& Cropanzano, 2000). Esto en la medida que, a pesar de la adaptación hedónica, existen condiciones favorecedoras de la felicidad en el trabajo ( Salanova, Llorens, Acosta, \& Torrente, 2013; Seligman, 2011).

Se concluyó con el primer estudio que la felicidad no es una moda empresarial (Sanín Posada, 2016). Múltiples hallazgos sustentan su relevancia y muestran las bondades de desarrollar acciones que ayuden a las personas en su trabajo a ser y sentirse felices (Fernandez, 2015).

El segundo trabajo fue de vital importancia para el resto de la investigación pues nos permitió contar con un instrumento con condiciones psicométricas adecuadas para medir la felicidad en la vida y en el trabajo. Se pudo apreciar que este posee una estructura adecuada que se ajustaba a los datos, validez convergente y un índice de consistencia interna favorable. Fundamental de este trabajo fue el hallazgo acerca de la posibilidad de 
medir la felicidad enmarcada en el contexto del trabajo. Por otra parte la relación encontrada entre la felicidad en la vida y en el trabajo nos habla de dos constructos íntimamente relacionados pero diferentes. Esto nos permite reflexionar acerca de que no toda persona feliz en su trabajo lo es en su vida y viceversa. Aunque eso suele ser lo común, la posibilidad de identificar cuándo no se presenta es un gran avance.

El tercer trabajo, al igual que el anterior, marca un hito importante pues es el primero que intenta medir el optimismo más no sólo desde lo disposicional, sino, también como una creencia asociada con un contexto particular. La posibilidad de ver que en determinados contextos dicho rasgo puede verse inhibido o, por el contrario, exacerbado, es fundamental para entender el optimismo también como una condición dependiente del contexto. En el trabajo se corroboró la estructura factorial del LOT-R, la cual se mantuvo cuando las personas respondieron los mismos ítems pensando en su trabajo y en su empresa. Además de esta importante evidencia de validez, se pudo constatar que el instrumento posee validez convergente y un nivel alto de consistencia interna, lo cual es común encontrar en la investigación (Bérdi \& Köteles, 2010; Giannini, Schuldberg, Di Fabio, \& Gargaro, 2008; Glaesmer et al., 2012; Rondón-Bernard \& Angelucci-Bastidas, 2016). Constituye el estudio un avance importante para la psicología positiva laboral. Permite a la población trabajadora contar con evidencias del funcionamiento psicométrico de un instrumento que mide Optimismo/Pesimismo en el trabajo, en la empresa y en la vida en general.

El capítulo cuatro ayudó a corroborar que la satisfacción laboral, la cual muchas veces es tratada como sinónimo de felicidad, no es un antecedente importante del desempeño laboral. Ayuda esto a entender los resultados dispares en la literatura que señalan, algunos sí y otros no, que la felicidad es determinante del desempeño intrarol (Wright \& Cropanzano, 2000). Todo parece indicar que se encuentra la relación con desempeño dependiendo de si se midió felicidad o satisfacción laboral (Zelenski et al., 2008). El error ha sido entonces tratarlos como sinónimos.

El trabajo nos mostró que de las tres dimensiones que integran el concepto de crecimiento psicológico únicamente Apertura al Cambio muestra relación con uno de los tipos de desempeño examinados (el extrarrol). La Satisfacción Laboral se asoció con el Cumplimiento de Normas y el Desempeño Extrarrol. La Apertura al Cambió reveló efectos sobre las conductas extra rol, pero el efecto no desapareció al ubicar la satisfacción laboral como variable mediadora. Esto indica que la mediación es parcial. Una interpretación posible al hallazgo es que las personas abiertas y que tienen una actitud positiva ante el cambio se sienten más satisfechos e involucrados con actividades que exceden las formuladas para sus cargos, lo cual es consistente con hallazgos previos que muestran que las personas obtusas y cerradas al cambio suelen estar más insatisfechas (Wanberg \& Banas, 2000). También es posible que los juicios de los jefes ayuden a que se dé la relación pues se ha encontrado que estos consideran a las personas abiertas al cambio como trabajadores que agregan valor a su trabajo (Omar \& Uribe, 2005). 
Por su parte, la relación entre la Apertura al Cambio y la Satisfacción puede explicarse porque que quienes poseen esta actitud son más adaptativos y capaces de ajustar sus propias impresiones mara adecuarse con más facilidad al trabajo, lo que los hace sentirse mejor (Morales, 2008). Esto tiene que ver con la regulación de las expectativas que caracteriza a las personas abiertas al cambió (Eljuri \& Salom, 1194; Romero, 1994).

Por otra parte los resultados de este trabajó no permitieron confirmar la hipótesis de la relación entre una visión positiva del fracaso y la satisfacción laboral de la cual habla la literatura (Romero, 1994). Se explicó entendiendo que aunque el fracaso es útil para el éxito, la experiencia de fracasar sigue siendo experimentada negativamente. Tampoco hubo relación entre Manejo del Fracaso y Desempeño, lo que indica que no basta con que se tenga una visión positiva del fracaso para aprender. La Flexibilidad no se relacionó con ninguna de las dimensiones del desempeño estudiadas (intrarol, extrarol y cumplimiento de normas). Al final se concluye que la satisfacción de las personas puede llevarlas a dar más de lo que se requiere (Omar \& Uribe, 2005) y a actuar en concordancia con las normas y principios definidos por la organización, pero no afecta el desempeño intrarol de las personas.

El quinto capítulo tuvo por objetivo ver la dinámica de la interacción entre el Optimismo, la Felicidad, la Felicidad en el Trabajo y la Satisfacción con la Vida. Allí se confirma la hipótesis de que la relación entre optimismo y satisfacción con la vida está mediada completamente por la felicidad general, pero solo parcialmente por la felicidad en el trabajo. Esto indica que la preocupación por la satisfacción vital no debe estar circunscrita solo al trabajo, pese a que las personas dedican buena parte de su tiempo diario a esta actividad. Así las cosas, la felicidad en el trabajo aparece como una dimensión importante pero insuficiente para predecir la satisfacción con la vida. El hallazgo es intuitivo pero refuerza la importancia de implementar políticas en la organización y en los países que favorezcan el equilibrio de la vida laboral con la vida privada.

Por otra parte el hecho de que la edad, variable que suele explicar algunas diferencias en los niveles de felicidad de las personas (Dolan, 2015), no modulará las relaciones entre optimismo, felicidad y satisfacción con la vida, indica que se trata de un proceso psicológico aplicable a personas de cualquier generación. El impacto en la salud y el bienestar de las personas del optimismo y la felicidad (Norrish \& Vella-Brodrick, 2008) es un argumento suficiente para que la empresas trabajen en su mejora.

El sexto capítulo nos permitió ver que el tipo de contrato no predice los niveles de felicidad, optimismo y pesimismo de los trabajadores. Eso puede deberse a que la felicidad y el optimismo son relativamente estables (Avia \& Vázquez, 2011; Tkach \& Lyubomirsky, 2006, Selugman, 2016). Pese a esto cabe la posibilidad de que en asocio con otras realidades organizacionales el Tipo de Contrato si tenga injerencia sobre la felicidad y el optimismo. Se trataría de un efecto de interacción que podría revisarse en otras investigaciones. Teniendo en cuenta que la felicidad se deriva de la experimentación de vivencias positivas, gratificación y sentido (M. Seligman, 2011). El hallazgo indica que esto se puede seguir 
experimentando con independencia del tipo de contrato con el cual las personas están vinculadas a la organización. Esto es contraintuitivo. La abundante literatura sobre precarización del trabajo señala al tipo de contrato como una barrera para el compromiso, el clima organizacional, el desempeño y el establecimiento del contrato psicológico (Chambel et al., 2012; Rodríguez-Gutiérrez \& Canal-Domínguez, 2012; Santos et al., 2012; Solanes \& Zaragoza, 2010; Uribe-Rodríguez et al., 2011; Vesga Rodríguez, 2011). Se esperaba, por tanto, que afectara los niveles de felicidad y optimismo, pero no fue así. Pero esto no debe utilizarse como excusa para mantener un tipo de contrato inconveniente. El hallazgo solo muestra consistencia con la teoría que señala que la felicidad y el optimismo son fenómenos estables y, como tales, condiciones de más difícil modificación. Es decir que las personas pueden ser felices a pesar de su tipo de contrato y mantener sus creencias positivas sobre el futuro. En este sentido el estudio muestra que el ser humano puede ser feliz y optimista aun en situaciones y condiciones un tanto adversas (Dolan, 2015).

El séptimo estudio desarrollado para revisar qué actividades desarrolladas por los trabajadores ayudan a la mejora de la felicidad, la felicidad en la vida, el optimismo, el optimismo en el trabajo, el optimismo en la empresa y la reducción del pesimismo reveló que no todas son efectivas y que esto difiere en función del género. Se observó también que el efecto disminuye con el tiempo, lo que se debe a la adaptación hedónica (Sheldon \& Lyubomirsky, 2006). Lo encontrado indica que es lícito que la organización piense y se comprometa con ayudar a las personas a incrementar sus niveles de felicidad, al tiempo que señala que esto debe convertirse en un hábito ya que cuando deja de ejecutarse se presentan reducciones. Esto le conviene a la organización por los efectos en la salud y bienestar de su personal (Norrish \& Vella-Brodrick, 2008). Este estudio además permitió que ver el género debe tenerse en cuenta en la intervención. Hombres y mujeres están expuestos a condiciones diferentes que pueden hacer que el efecto no sea el mismo.

Estos trabajos se desarrollaron entre 2011 y 2016. El primero fue el presentado en el capítulo 4. Fue el que marcó el inicio y abrió el camino. Luego se hizo la revisión de la literatura para poder tener una base en la cual anclar todos los demás trabajos (2012). Se revisó la calidad de instrumentos para medir los constructos centrales (2013 y 2014), y luego se pasó a revisar la interacción entre las variables de interés (2015 y 2016). El último trabajo se inició en 2014 y concluyó en 2016.

\section{Implicaciones Teóricas}

Cada capítulo aporta conocimiento y reflexiones teóricas que pasan a hacer parte de la literatura científica y constituyen avances importantes en cuanto a la compresión de la felicidad y el optimismo en contextos de trabajo. A continuación, se hará mención de lo que cada capítulo nos aporta.

1. Felicidad Laboral: Reflexiones sobre su aplicación al contexto del trabajo 
Este capítulo constituye un marco conceptual amplio sobre medidas de felicidad, estrategias de intervención, y comprensión sobre la felicidad en el largo plazo. Uno de sus principales aportes es la propuesta de definición de la felicidad en el trabajo, derivada de la de felicidad general. En el trabajo se argumenta porque esta no debe tratarse como sinónimo de Satisfacción con la Vida, ni de Bienestar Subjetivo. Se indica que estos dos conceptos son parte de la felicidad pero no la definen completamente.

\section{Adaptación del Authentic Happiness Inventory (AHI) para población trabajadora}

Este trabajo no se limita a adaptar un instrumento psicométrico. Va más allá. Se explora y revisa si lo propuesto en el capítulo uno, a saber, el constructo de Felicidad en el Trabajo, existe y puede ser medido. Gracias a este trabajo la expresión "felicidad en el trabajo" deja de ser una idea sobre cómo se sienten las personas allí y avanza hacia la comprensión sobre como el trabajo favorece vivencias positivas, gratificación y sentido. Futuras investigaciones podrán utilizar esta conceptualización y estos instrumentos para desarrollar conocimiento científico en torno a un constructo que hasta el momento se había trabajado de manera indirecta y medido de forma genérica.

3. Verificación de las condiciones psicométricas del Test de Orientación en la Vida (LOTR) aplicado en población trabajadora Colombiana.

Apelando a los hallazgos del estudio anterior y luego de demostrar que la felicidad además de ser un rasgo puede ser un estado asociado a un contexto particular de la vida, en este tercer capítulo nos propusimos verificar si algo parecido sucede con el Optimismo. Es decir si ese sistema de creencias que puede caracterizar a la persona y la forma como interpreta el mundo y su futuro, puede circunscribirse al contexto del trabajo y depender de como este funcione. El artículo nos permite proponer una definición de Optimismo relacionado con la Empresa y con el Trabajo, lo que contribuye a revisar esta realidad con una nueva perspectiva que aporta a la comprensión de los procesos psicológicos que explican las decisiones y reacciones de las personas en el trabajo.

4. Satisfacción Laboral: el camino entre el Crecimiento Psicológico y el Desempeño Laboral

Este trabajo retoma un tema olvidado de la psicología positiva, el Crecimiento Psicológico. Nos permite ver su función como antecedente de la satisfacción y el desempeño laboral. Pasa a formar parte del cuerpo de investigación que señala que la satisfacción laboral es un predictor pobre del desempeño intrarol. Permite además sustentar lo señalado en los capítulos anteriores en relación con la importancia de separar el concepto de satisfacción del de felicidad. Teóricamente nos indica que al considerar sinónimos la satisfacción y la 
felicidad, se ha incurrido en errores que posiblemente son los que explican el antagonismo de los hallazgos científicos en relación con los efectos de la felicidad sobre el desempeño.

5. Satisfacción con la Vida: El rol de la Felicidad en el Trabajo y la Vida.

Este artículo es un aporte fundamental a la comprensión del proceso psicológico que explica la relación entre el optimismo y la satisfacción con la vida. Señala la dificultad de definir si es el optimismo un antecedente de la felicidad o si, por el contrario, esta es la que contribuye en las primeras etapas de la vida a que las personas aprendan a ser optimistas. Se puede ver además en perspectiva la felicidad en el trabajo como una condición favorecedora pero no suficiente de la satisfacción vital. Esta es solo posible si la persona en general se siente feliz en todas las áreas de su vida.

6. Los efectos del tipo de contrato laboral sobre la felicidad en el trabajo, el optimismo y el pesimismo laborales

Este capítulo permite ver que es inadecuado, desde el punto de vista teórico, generalizar y transferir los efectos negativos de una realidad a otra, a pesar de la aparente relación que puede haber entre ellas. Se partió del supuesto que mostraba el tipo de contrato como factor que podía afectar la felicidad, amparados en la idea de que esta condición es contraria al compromiso, la calidad del clima organización y al bienestar laboral. Sin embargo, mostró que aunque la lógica y la intuición suponían unos hallazgos, la investigación seria y cuidadosa puede encontrar que las cosas no siempre funcionan como se espera.

Si bien podría ser un hallazgo riesgoso en el cual las empresas se apamparen para ofrecer tratos precarios a los trabajadores, la verdadera intención del artículo no es esa. Simplemente muestra que, por fortuna para las personas, no todas sus realidades se ven afectadas por razón de su tipo de contrato. Por otra parte, este trabajo no hace más que reforzar lo que la teoría ya ha dicho sobre la felicidad ye I optimismo y es su condición de fenómenos estableces difíciles de modificar. De ahí que esto no suceda espontáneamente y que se requiera de estrategias de intervención para incrementar los niveles de ambas variables.

7. Intervención de la felicidad y el optimismo en contextos de trabajo. Diferencias por género

Producto del anterior trabajo y de las múltiples investigaciones que señalan que para incrementar la felicidad y el optimismo es necesario desarrollar practicas consientes e intencionadas, se desarrolla este estudio. Teóricamente mucho de lo que acá se encuentra 
sugiere la importancia de controlar el género en los procesos de intervención ya que el funcionamiento de las estrategias varía según esta condición.

En resumen, los aportes teóricos de esta tesis doctoral son:

- Concepto de felicidad revisado, redefinido y propuesta de definición de la felicidad en el trabajo.

- Concepto de optimismo redefinido en función del trabajo y la organización.

- Instrumentos válidos y confiables para medir, en población trabajadora, la felicidad, la felicidad en el trabajo, el optimismo, el optimismo en la empresa y el optimismo en el trabajo.

- Hallazgos que sustentan la distinción entre felicidad, satisfacción, bienestar subjetivo y satisfacción con la vida.

- Se retoma y da cabida de nuevo en la investigación al concepto de crecimiento psicológico.

- Comprensión sobre el rol de la satisfacción laboral en función del desempeño y del rol de la felicidad general y en la vida en función de la satisfacción con la vida.

- Revisión del optimismo como antecedente de la felicidad desde una postura epigenética.

- Revisión de estrategias aplicables al mundo del trabajo para mejorar la felicidad y el optimismo.

\section{Implicaciones Prácticas}

Una vez realizados los estudios correspondientes a esta tesis doctoral y vistos los hallazgos encontrados, señalo a continuación las principales implicaciones prácticas derivadas de la misma:

1. Las empresas y los gobiernos pueden tomar como base las diferencias conceptuales entre Felicidad, Bienestar Subjetivo y Satisfacción con la Vida para formular políticas que les permita aportar realmente a cada una de esas variables.

2. Se cuenta con instrumentos válidos y confiables para medir en población colombiana trabajadora la felicidad y el optimismo, tanto de forma genérica como asociada al trabajo.

3. Las organizaciones pueden formular estrategias de incremento de la satisfacción laboral entendiendo que los efectos de esto se darán en el desempeño extrarol y en el cumplimento de normas pero no necesariamente en el desempeño intrarol.

4. Las áreas de gestión humana contarán con bases y fundamentos fuertes para insistir en la importancia de que las empresas favorezcan la conciliación de la vida privada con la vida laboral.

5. Entender el optimismo como antecedente de la felicidad y como un sistema de creencias aprendido, puede ayudar a que los gobiernos y las empresas desarrollen 
planes para dotar a las personas de creencias positivas sobre el futuro. iPor supuesto de creencia inteligentes!

6. Dimensionar el tipo de Contrato como una realidad con efectos inconvenientes pero que no logra afectar la felicidad y el optimismo permite una mejor argumentación por parte de las áreas de gestión humana sobre el impacto de esta condición ajena a las personas. El efecto podría deberse más a como se trate a las personas por razón de su tipo de vínculo con la organización que por la denominación del vínculo en sí misma.

7. Se cuenta con evidencia científica del éxito de una serie de estrategias para incrementar la felicidad. Con el debido proceso de adaptación estas podrían llevarse a otras organizaciones interesadas en incrementar los niveles de felicidad y optimismo en el trabajo y en la vida de su personal.

\section{Limitaciones y futuras investigaciones}

Como en toda investigación los estudios realizados cuentan con diversas limitaciones. Una de las principales es que es posible que no todas las fuentes y estudios clásicos estén referidos, dada la dificultad de consultar toda la literatura que se genera sobre el tema que se está estudiando. Esto puede dejar por fuera perspectivas y puntos de vista que podrían alimentar y mejorar los propios argumentos o, por el contrario, controvertir los hallazgos. Pese a esto siempre se recurrió a la revisión de literatura disponible en bases de datos bibliográficas de prestigio internacional e indexadas en bases de datos científicas, y se hizo el ejercicio de actualizarla periódicamente de forma tal que, al menos, se pudiera tener una idea general sobre lo que la ciencia estaba diciendo sobre los temas tratados.

Otra limitación es que en todos los estudios se trabajó con muestras por disponibilidad. Se trató de personas y empresas que dieron su visto bueno para participar. Sin embargo, no se hizo un muestreo estratificado y aleatorio que nos permitiera hacer generalizaciones de los resultados. La investigación aplicada en las organizaciones tiene esta desventaja por la dificultad de disponer de la posibilidad de ensayos controlados aleatorizados. Pese a esto las muestras fueron grandes en general y heterogéneas. Si bien esto no elimina las desventajas de no haber hecho un muestreo aleatorio y estratificado, si mitiga el impacto negativo de las muestras por disponibilidad y dota de confianza a los hallazgos.

Los estudios, con excepción del último, fueron todos transversales. No fue posible ver la evolución a lo largo del tiempo, por lo que se extrajeron conclusiones basadas en momentos particulares de la toma de muestra. Pese a esto se utilizaron estadísticos robustos y adecuados al tipo de muestra y a la forma de recolección.

No se pudo medir el impacto del incremento de la felicidad laboral en el desempeño intrarol. Era uno de los objetivos de esta tesis. Sin embargo, en repetidas ocasiones nos percatamos de la dificultad que existe de que los jefes se comprometan con la evaluación del desempeño de los colaboradores. Por lo anterior las conclusiones sobre el impacto de 
una variable sobre la otra se hicieron basándose en otras investigaciones y de lo reportado en la literatura.

La visión del optimismo como antecedente de la felicidad se estableció con base en investigaciones que señalan las razones por las cuales este se considera en tal posición. Sin embargo, convendría diseñar experimentos que permitan realmente confirmar su rol. Es posible que se trate también de una relación circular en la que no se puede decir que el uno es siempre antecedente del otro.

El ejercicio de intervención se hizo fuera del laboratorio. Por tanto, no hubo control total de las múltiples variables que pueden afectar el optimismo y la felicidad de las personas. Sin embargo, se controlaron las conocidas en la ciencia, tales como edad, género y estado civil.

Teniendo en cuenta las limitaciones y los hallazgos futuras investigaciones podrían indagar sobre los efectos del incremento de la felicidad y el optimismo en el desempeño laboral calificado por los jefes; la estabilidad de los cambios en los niveles de felicidad y optimismo. Hasta ahora sabemos cuáles estrategias sirven pero no qué tanto perduran sus efectos. También se podría rastrear longitudinalmente qué pasa con la felicidad en el trabajo y la vida de los niños que fueron educados como optimistas y los que no. Podría también verificarse el efecto de las estrategias de incremento de la felicidad en el laboratorio o ampliando, fuera de este, el control sobre las variables que tienen potencial de afectar el resultado. 


\section{REFERENCIAS}

Abbe, A., Tkach, C., y Lyubomirsky, S. (2003). The art of living by dispositionally happy $\begin{array}{llll}\text { people. Journal of Happiness } & \text { 385-404. }\end{array}$ doi:10.1023/B:JOHS.0000005769.54611.3c

Aguilar, M., \& Rentería, E. (Eds.). (2009). Psicología del Trabajo y de las Organizaciones. Reflexiones y Experiencias de Investigación. Bogotá: Universidad de Santo Tomas.

Alarcon, R. (2006). Desarrollo de una escala factorial para medir la felicidad. Revista Interamericana de Psicología, 40(1) 99-106.

Alper Köse, İ. (2015). Psychometric properties of the Orientations to Happiness Scale and measurement invariance between samples of Turkish and Russian university students. Social Indicators Research, 122(3), 945-959. http://doi.org/10.1007/s11205-014-0721-8

Anderson, N., Lievens, F., van Dam, K. \& Born, M. (2006). A Construct-Driven Investigation of Gender Differences in a Leadership-Role Assessment Center. Journal of Applied Psychology, 91(3), 555-566. Doi: 10.1037/0021-9010.91.3.555

Andersson, M. A. (2004). Identity Crises in Love and at Work: Dispositional Optimism as a Durable Personal Resource. Dissertation, lowa: The University of lowa.

Antle, L., Doelman, N., Scott, H., \& Warr, A. (2013). Durham Area Survey 2011: Report on optimism. University of Ontario.

Arce, C. (1994). Técnicas de Construcción de Escalas Psicológicas. Madrid: Síntesis.

Arce, C. (2010). Técnicas de construcción de escalas psicológicas. (Sintesis, Ed.). Madrid.

Ardila, R. (1988). Psicología del hombre colombiano. Bogotá: Planeta.

Arias, F., \& Heredia, V. (2006). Administración de Recursos Humanos para el Alto Desempeño. México: Trillas.

Atherton, J., Graham, E., \& Steedman, I. (2010). The Practices of Happiness. Routledge. http://doi.org/10.4324/9780203846902

Augusto-Landa, J. M., Pulido-Martos, M., \& Lopez-Zafra, E. (2011). Does Perceived Emotional Intelligence and Optimism/pessimism Predict Psychological Well-being? Journal of Happiness Studies, 12(3), 463-474. http://doi.org/10.1007/s10902-010-9209-7

Avia, M., \& Vázquez, C. (2011). Optimismo Inteligente (2da. Edición). Madrid: Alianza Editorial.

Ayala, Y., Peiró Silla, J. M., Tordera, N., Lorente, L., \& Yeves, J. (2016). Job Satisfaction and Innovative Performance in Young Spanish Employees: Testing New Patterns in the Happy- 
Productive Worker Thesis-A Discriminant Study. Journal of Happiness Studies. http://doi.org/10.1007/s10902-016-9778-1

Bailey, T. C., Eng, W., Frisch, M. B., \& Snyder, C. R. (2007). Hope and optimism as related to life satisfaction. The Journal of Positive Psychology, 2(3), 168-175. JOUR. http://doi.org/10.1080/17439760701409546

Bandeira, M., Bekou, V., Lott, K. S., Teixeira, M. A., \& Rocha, S. S. (2002). Validação transcultural do teste de orientação da vida (TOV-R). Estudos de Psicologia (Natal), 7(2), 251-258. http://doi.org/10.1590/S1413-294X2002000200006

Baron, R. M., y Kenny, D. A. (1986). The moderator-mediator variable distinction in social psychological research: Conceptual, strategic and statistical considerations. Journal of Personality and Social Psychology, 51, 1173-1182.

Bastianello, M. R., Pacico, J. C., \& Hutz, C. S. (2014). Optimism, self-esteem and personality: adaptation and validation of the Brazilian Version Of The Revised Life Orientation Test (LOTR). Psico-USF, 19(3), 523-531. http://doi.org/10.1590/1413-82712014019003014

Batson, C., \& Powell, A. (2003). Altruism and prosocial behavior. En Millon, T. \& Lerner, M. (eds.) Handbook of psychology. Volumen 5. Personality and social psychology. New Jersey: John Wiley \& Sons, Inc.

Beauregard, T. \& Henry, L. (2009). Making the link between work-life balance practices and organizational performance. Human Resource Management Review, 19(1), 9-22. Doi: 10.1016/j.hrmr.2008.09.001

Bedregal, P., Shand, B., Santos, M., \& Ventura-Juncá, P. (2010). Aportes de la epigenética en la comprensión del desarrollo del ser humano. Revista Médica de Chile, 138(3). Doi: $10.4067 /$ s0034-98872010000300018

Bérdi, M., \& Köteles, F. (2010). Az optimizmus mérése: Az Életszemlélet Teszt átdolgozott változatának (LOT-R) pszichometriai jellemzői hazai mintán. [The measurement of optimism: The psychometric properties of the Hungarian version of the Revised Life Orientation Test (LOT-R).]. Magyar Pszichológiai Szemle, 65(2), 273-294. JOUR. http://doi.org/10.1556/MPSzle.65.2010.2.7

Bieda, A., Hirschfeld, G., Schönfeld, P., Brailovskaia, J., Zhang, X. C., \& Margraf, J. (2016). Universal Happiness? Cross-Cultural Measurement Invariance of Scales Assessing Positive Mental Health. Psychological Assessment, 1-14. http://doi.org/10.1037/pas0000353

Blanch, J. (2014). El capitalismo informacional como riesgo psicosocial. Memorias Cátedra abierta de Talento Humano. Universidad de Antioquia. 
Bond, F., Flaxman, P. y Bunce, D. (2008). The Influence of Psychological Flexibility on Work Redesign: Mediated Moderation of a Work Reorganization Intervention. Journal of Applied Psychology, 93(3), 645-654.

Bratberg, E., Dahl, S. Å., \& Risa, A. E. (2002). 'The double burden': do combinations of career and family obligations increase sickness absence among women? European Sociological Review, 18(2), 233-249. Doi: 10.1093/esr/18.2.233

Brickman, P., \& Campbell, D. T. (1971). Hedonic relativism and planning the good society. In M. H. Appley (Ed.), Adaptation-level theory (pp. 287-305). New York: Academic Press.

Brief, A. and Nord, W. (1990). Meanings of occupational work. Lexington, Mass.: Lexington Books.

Briñol, P., Gandarillas, B., Horcajo, J. y Becerra, A. (2010). Emoción y meta-cognición: Implicaciones para el cambio de actitud. Revista de Psicología Social, 25(2), 157-183.

Buchanan, K. E., \& Bardi, A. (2010). Acts of kindness and acts of novelty affect life satisfaction. The Journal of social psychology, 150(3), 235-237. Doi: $10.1080 / 00224540903365554$

Burke, K. L., Joyner, A. B., Czech, D. R., \& Wilson, M. J. (2000). An investigation of concurrent validity between two optimism/pessimism questionnaires: The Life Orientation TestRevised and the Optimism/Pessimism Scale. Current Psychology: A Journal for Diverse Perspectives on Diverse Psychological Issues, 19(2), 129-136. JOUR. http://doi.org/10.1007/s12144-000-1009-5

Calderón, G., Álvarez, C. \& Naranjo, J. (2006). Gestión humana en las organizaciones un fenómeno complejo: Evolución, retos, tendencias y perspectivas de investigación. Cuadernos de Administración, 19(32), 225-254.

Campbell, A. (1981). The sense of well-being in America. New York: McGraw-Hill.

Cano-García, F. J., Sanduvete-Chaves, S., Chacón-Moscoso, S., Rodríguez-Franco, L., GarcíaMartínez, J., Antuña-Bellerín, M. A., \& Pérez-Gil, J. A. (2015). Factor structure of the Spanish version of the Life Orientation Test-Revised (LOT-R): Testing several models. International Journal of Clinical and Health Psychology, 15(2), 139-148. http://doi.org/10.1016/j.ijchp.2015.01.003

Carver, C. S., \& Scheier, M. F. (2014). Dispositional optimism. Trends in Cognitive Sciences. http://doi.org/10.1016/j.tics.2014.02.003

Carver, C., Scheier, M., \& Segerstrom, S. (2010).Optimism. Clinical Psychology Review, 30(7), 879-889. Doi:10.1016/j.cpr.2010.01.006.

Castillo, J. (1998). El significado del trabajo hoy. Revista Española de Investigaciones Sociológicas, 82, 215-229. Doi: 10.2307/40184057 
Chambel, M, Alcover, C. (2011). The psychological contract of call-centre workers: Employment conditions, satisfaction, and civil virtue behaviours. Economic and Industrial Democracy. 32 (1), 115-134. doi: 10.1177/0143831X10376421

Chambel, M., Alcover, C. Martínez, D. (2012). Perceptions of employment relations and permanence in the organization: mediating effects of affective commitment in relations of psychological contract and intention to quit. Psychological Reports, 110 (3), 839-853. Doi:10.2466/01.07.21.PR0.110.3.839-853

Chamorro-Premuzic, T., Bennett, E., \& Furnham, A. (2007). The happy personality: Mediational role of trait emotional intelligence. Personality and individual differences, 42(8), 1633-1639. Doi 10.1016/j.paid.2006.10.029

Chancellor, J., Layous, K., \& Lyubomirsky, S. (2014). Recalling positive events at work makes employees feel happier, move more, but interact less: A 6-week randomized controlled intervention at a japanese workplace. Journal of Happiness Studies, 16(4), 871-887. Doi: 10.1007/s10902-014-9538-z

Chang, E. C., Maydeu-Olivares, A., \& D'Zurilla, T. J. (1997). Optimism and pessimism as partially independent constructs: Relationship to positive and negative affectivity and psychological well-being. Personality and individual Differences, 23(3), 433-440. Doi: 10.1016/S0191-8869(97)80009-8

Cheng, T., Mauno, S., \& Lee, C. (2014). Do job control, support, and optimism help job insecure employees? A three-wave study of buffering effects on job satisfaction, vigor and work-family enrichment. Social Indicators Research, 118(3), 1269-1291.

Chico, E. (2002). Optimismo disposicional como predictor de estrategias de afrontamiento. Psicothema, 14 (3), 544-550.

Chiesi, F., Galli, S., Primi, C., Innocenti Borgi, P., \& Bonacchi, A. (2013). The accuracy of the Life Orientation Test-Revised (LOT-R) in measuring dispositional optimism: evidence from item response theory analyses. Journal of Personality Assessment, 95(5), 523-529. http://doi.org/10.1080/00223891.2013.781029

Cohn, M., Fredrickson, B., Brown, S., Mikels, J., \& Conway, A. (2009). Happiness unpacked: positive emotions increase life satisfaction by building resilience. Emotion, 9(3), 361-368. Doi: $10.1037 / \mathrm{a} 0015952$

Colpsic (2009). Il Congreso Nacional de Psicología y I Congreso Internacional de Psicología. Cartagena Colombia. 20 a 23 de agosto.

Colpsic (2015). IV Congreso Colombiano de Psicología y 1ra Conferencia Regional Latinoamericana de Psicología. Armenia Colombia. 2 al 5 de septiembre

Congreso de la República de Colombia. Ley número 1090 de 2006 (2006). 
Crow, S., \& Hartman, S. (1995). Can't get no satisfaction. Leadership, \& Organization Development Journal, 16(4), 34-38. Doi: 10.1108/01437739510089085

Dean, K. (1992). Double burdens of work: the female work and health paradox. Health Promotion International, 7(1), 17-25. Doi: 10.1093/heapro/7.1.17

Diener, E. (2000) Subjective well-being: The science of happiness and a proposal for a national index. American Psychologist, 55(1), 34-43. doi: 10.1037/0003-066X.55.1.34

Diener, E., Emmons, R., Larsen, J., \& Griffin, S. (1985). The satisfaction with life scale. Journal of Personality Assessmemt, 49(1), 71-75. http://doi.org/10.1207/s15327752jpa4901_13

Diener, E., Suh EM., Lucas, RE. y Smith, HI. (1999). Subjective well-being: three decades of progress. Psychological Bulletin, 125 (2), 267-302.

Dockray, S., Grant, N., Stone, A. A., Kahneman, D., Wardle, J., \& Steptoe, A. (2010). A Comparison of Affect Ratings Obtained with Ecological Momentary Assessment and the Day Reconstruction Method. Social Indicators Research, 99(2), 269-283. http://doi.org/10.1007/s11205-010-9578-7

Dolan, P. (2015). Diseña tu Felicidad. Barcelona: España: Espasa Libros.

Dosedlová, J., Klimusová, H., Burešová, I., Jelínek, M., Slezáčková, A., Vašina, L., \& Warr, A. (2015). Optimism and Health-related Behaviour in Czech University Students and Adults. Procedia - Social and Behavioral Sciences, 171, 1051-1059. http://doi.org/10.1016/j.sbspro.2015.01.278

Easterlin, R. (2003). Explaining happiness. Proceedings of the National Academy of Sciences, 100(19), 11176-11183. Doi: 10.1073/pnas.1633144100

Easterlin, R. A. (2006). Life cycle happiness and its sources: Intersections of psychology, economics, and demography. Journal of Economic Psychology, 27(4), 463-482. doi:10.1016/j.joep.2006.05.002

Ekman, P., Davidson, R., \& Friesen, W. (1990). The Duchenne smile: Emotional expression and brain physiology: II. Journal of personality and social psychology, 58(2), 342-353. Doi: 10.1037/0022-3514.58.2.342

Elaine D., Pulakos, E., Arad, S., Donovan, M. y Plamondon K. (2000). Adaptability in the Workplace: Development of a Taxonomy of Adaptive Performance. Journal of Applied Psychology, 85(4), 612-624.

Eljuri, M., \& Salom, C. (1994). Motivaciones sociales y crecimiento psicológico en trabajadores industriales. Revista Interamericana de Psicologia Ocupacional, 13(2), 107115. 
Ellis, A. (2001). Feeling Better, Getting Better, Staying Better: Profound Self-Help Therapy For Your Emotions. USA: Impact Publishers.

Extremera, N., \& Fernández-Berrocal, P. (2013). The Subjective Happiness Scale: Translation and Preliminary Psychometric Evaluation of a Spanish Version. Social Indicators Research, 119, 473-481. http://doi.org/10.1007/s11205-013-0497-2

Fernandez, I. (2016). Felicidad Organizacional. Cómo construir felicidad en el trabajo. (G. Zeta, Ed.) (3ed ed.). Chile.

Ferrando, P. J., Chico, E., \& Tous, J. M. (2002). Propiedades psicométricas del test de optimismo Life Orientation Test. Psicothema, 14(3), 673-680. http://doi.org/0214 - 9915

Field, L. K., \& Buitendach, J. H. (2011). Happiness, work engagement and organizational commitment of support staff at a tertiary education institution in South Africa. Journal of Industrial Psychology, 37(1), 01-10.

Figueras, A. (2012). Pura Felicidad. Ser feliz es saludable. (P. Editorial, Ed.). Barcelona.

Fisher, C. (2003). Why do lay people believe that satisfaction and performance are correlated? Possible sources of a commonsense theory. Journal of Organizational Behavior. 24 (6), 753-777. Doi: 10.1080/00224540903365554

Fisher, C. (2010). Happiness at work. International journal of management reviews, 12(4), 384-412. Doi: 10.1111/j.1468-2370.2009.00270.x

Fogaça, N., \& Coelho-Junior, F. A. (2016). Is "Happy Worker" More Productive. Management Studies, 4(4), 149-160. http://doi.org/10.17265/2328-2185/2016.04.002

Fogarty, G. J., Perera, H. N., Furst, A. J., \& Thomas, P. R. (2016). Evaluating Measures of Optimism and Sport Confidence. Measurement in Physical Education and Exercise Science, 20(2), 81-92. http://doi.org/10.1080/1091367X.2015.1111220

Fornell, C. y Larcker, D.F (1981). Evaluating structural equation models with unobservable variables and measurement error. Journal of Marketing Research .18 (1), 39-50.

$\begin{array}{lllll}\text { G*Power } & 3.1 & \text { manual. } & 2014 & \text { Available }\end{array}$ from:http://www.gpower.hhu.de/fileadmin/redaktion/Fakultaeten/MathematischNaturwissenschaftliche_Fakultaet/Psychologie/AAP/gpower/GPowerManual.pdf

García-Naveira, A., Ruiz-Barquín, R., \& Ortín, F. J. (2015). Optimismo y competitividad en jóvenes atletas de rendimiento. Revista Latinoamericana de Psicología, 47(2), 124-135. http://doi.org/10.1016/j.rlp.2014.08.001

Geary, D. (2010). Male, female. Washington, D.C.: American Psychological Association.

Giannini, M., Schuldberg, D., Di Fabio, A., \& Gargaro, D. (2008). Misurare l'ottimismo: Proprietà psicometriche della versione Italiana del Life Orientation Test-Revised (LOT-R). 
[Measuring optimism: Psychometric properties of the Italian version of the Life Orientation Test-Revised (LOT-R).]. Counseling: Giornale Italiano Di Ricerca E Applicazioni, 1(1), 73-84. JOUR.

Giraldo, B. (2007). Estadísticas de la microempresa en Colombia. Análisis comparativo 1990 y 2005. Corporación para el Desarrollo de la Microempresa y Observatorio Colombiano de la Microempresas OCM. Disponible en http://www.meda.org.co/documentos/biblioteca/ESTADISTICASMICROEMPRESARevisfinal.pdf?meda=08c98fbf21aa1ab6c66c2e4dd9069d54 .Consultado el 29/03/12.

Glaesmer, H., Hoyer, J., Klotsche, J., \& Herzberg, P. Y. (2008). Die deutsche version des LifeOrientation-Tests (LOT-R) zum dispositionellen optimismus und pessimismus. [The German version of the Life-Orientation-Test (LOT-R) for dispositional optimism and pessimism.]. Zeitschrift Für Gesundheitspsychologie, 16(1), 26-31. JOUR. http://doi.org/10.1026/09438149.16.1.26

Glaesmer, H., Rief, W., Martin, A., Mewes, R., Brähler, E., Zenger, M., \& Hinz, A. (2012). Psychometric properties and population-based norms of the Life Orientation Test Revised (LOT-R). British Journal of Health Psychology. JOUR PMID - 22106985, Wiley-Blackwell Publishing Ltd. http://doi.org/10.1111/j.2044-8287.2011.02046.x

Gómez, I. (2007). Salud laboral: una revisión a la luz de las nuevas condiciones del trabajo. Universitas Psychologica. 6(1). 105-113.

Gómez, V., Villegas, C., Barrera, F. y Cruz, J. (2007). Factores predictores de bienestar subjetivo en una muestra colombiana. Revista Latinoamericana de Psicología. 39(2), 311325.

González, J. y Restrepo, G. (2010). Prevalencia de felicidad en ciclos vitales y relación en redes de apoyo en población colombiana. Revista de Salud Pública, 12(2), 228-238.

González-Quiñones, J. C., \& Restrepo-Chavarriaga, G. (2010). Prevalencia de felicidad en ciclos vitales y relación con redes de apoyo en población colombiana. Revista de Salud Pública, 12(2), 228-238. Doi: 10.1590/s0124-00642010000200006

Greenhaus, J., Collins, K., \& Shaw, J. (2003). The relation between work-family balance and quality of life. Journal of Vocational Behavior, 63(3), 510- 531. Doi: 10.1016/s00018791(02)00042-8

Guevara, L. (2016). Prácticas de gestión humana y su impacto en jóvenes. Conferencia presentada en el VII Simposio Internacional de Calidad de Vida Laboral: El reto de motivar sin dinero. Bogotá.

Hervás, G., \& Vázquez, C. (2013). Construction and validation of a measure of integrative well-being in seven languages: the Pemberton Happiness Index. Health and Quality of Life Outcomes, 11(66), 1-13. http://doi.org/10.1186/1477-7525-11-66 
Herzberg, P. Y., Glaesmer, H., \& Hoyer, J. (2006). Separating optimism and pessimism: a robust psychometric analysis of the revised Life Orientation Test (LOT-R). Psychological Assessment, 18(4), 433-438. http://doi.org/10.1037/1040-3590.18.4.433

Hodge, D. R., \& Gillespie, D. (2003). Phrase completions: An alternative to likert scales. Social Work Research, 27(1), 45-55. http://doi.org/10.1093/swr/27.1.45

Homan, A., van Knippenberg, D., van Kleef, G. y de Dreu, C. (2007). Bridging Faultlines by Valuing Diversity: Diversity Beliefs, Information Elaboration, and Performance in Diverse Work Groups. Journal of Applied Psychology. 92 (5) 1189-1199.

Ilies, R., Schwind, K. M., Wagner, D. T., Johnson, M. D., DeRue, D. S., \& Ilgen, D. R. (2007). When can employees have a family life? The effects of daily workload and affect on workfamily conflict and social behaviors at home. Journal of Applied Psychology, 92(5), 13681379. Doi: 10.1037/0021-9010.92.5.1368

Jiménez, A., \& Gómez, V. (2015). Conciliando trabajo-familia: análisis desde la perspectiva de género. Diversitas: Perspectivas en Psicología, 11(2), 289-302. Doi: 10.15332/s17949998.2015.0002.09

Jones, M. (2006). Which is a better predictor of job performance: Job satisfaction or life satisfaction? Journal of Behavioral and Applied Management, 8(1), 20-42. Retrieved from http://search.proquest.com/docview/196683486?accountid=15297

Jöreskog K.G. y Sörbom D. (1986) LISREL user guide version VI (4th Ed). Scientific Software International, Mooresville.

Jovanović, V., \& Gavrilov-Jerković, V. (2013). Dimensionality and validity of the Serbian version of the Life Orientation Test-Revised in a sample of youths. Journal of Happiness Studies, 14(3), 771-782. JOUR. http://doi.org/10.1007/s10902-012-9354-2

Judge, T., \& Bono, J. (2001). A Rose by any other name. Are Self-esteem, Generalized Selfefficay, neuroticism an Locus of Control Indicators of com $\neg$ mon construct? In B. W. Robert, y R. Hogan, Personality Psychology in the work place. Washington: APA.

Kaczmarek, L. D., Bujacz, A., \& Eid, M. (2014). Comparative Latent State-Trait Analysis of Satisfaction with Life Measures: The Steen Happiness Index and the Satisfaction with Life Scale. Journal of Happiness Studies, 16, 443-453. http://doi.org/10.1007/s10902-014-95174

Kaczmarek, L. D., Stanko-Kaczmarek, M., \& Dombrowski, S. U. (2011). Adaptation and Validation of the Steen Happiness Index into Polish. Polish Psychological Bulletin, 41(3), 98104. http://doi.org/10.2478/v10059-010-0013-3 
Kahneman, D. (1999). Objective happiness. In D. Kahneman, E. Diener, y N. Schwarz (Eds.), Well-being: The foundations of hedonic psychology (pp. 3-25). New York: Russell Sage Foundation.

Kaiser, B. y DeVries, K. (2010). Introduction to the Special Issue on Developing Flexible and Adaptable Leaders for an Age Of Uncertainty. Consulting Psychology Journal, 62(2), 77-80.

Kaplan, R., \& Saccuzzo, D. (2006). Pruebas Psicológicas. (Thomson, Ed.) (6th ed.). México.

Kirkpatrick, J. y Kirkpatrick, W. (2009). The Kirkpatrick Model: Past, Present and Future. Chief Learning Officer. Noviembre. 20-23.

Köverová, M., \& Ferjenčik, J. (2013). Adaptácia a orientačné overovanie psychometrických charakteristík testu životnej orientácie LOR-R. [Slovak adaptation of Life Orientation test (LOT-R): Psychometric characteristics.]. Československá Psychologie: Časopis Pro Psychologickou Teorii a Praxi, 57(5), 461-473. JOUR.

Lai, J. C. L., Cheung, H., Lee, W., \& Yu, H. (1998). The utility of the revised Life Orientation Test to measure optimism among Hong Kong Chinese. International Journal of Psychology, 33(1), 45-56. JOUR. http://doi.org/10.1080/002075998400600

Landero Hernández, R., \& González Ramirez, M. T. (2009). Propiedades psicosométricas de la versión española del test de optimismo revisado (LOT-R) en una muestra de personas con fibromialgia. Ansiedad Y Estrés, 15(1), 111-117.

Laranjeira, C. A. (2008). Tradução e validação portuguesa do revised life orientation test (LOT-R). Universitas Psychologica, 7(2), 469-476.

Larson, R. (1989). Is feeling "in control" related to happiness in daily life? Psychological Reports, 64, 775-784.

Li, C.-H. (2012). Validation of the Chinese version of the Life Orientation Test with a robust weighted least squares approach. Psychological Assessment, 24(3), 770-776. http://doi.org/10.1037/a0026612

Liberalesso, A. (2002). Bienestar subjetivo en la vida adulta y en la vejez: Hacia una psicología positiva en América latina. Revista Latinoamericana de Psicología, 34 (1 y 2). 5574.

Lisbona, A. (2004). La diversidad en las organizaciones. En F.J. Palací (Dir.), Psicología de las organizaciones (págs. 279-300). Madrid: Pearson Prentice may.

Littlewood, H. F. (2008). Evitación del trabajo, satisfacción en el trabajo y bienestar emocional: Potenciales consecuencias de prácticas gerenciales y la percepción de justicia organizacional. En Uribe, J.F. (Ed.). Psicología de la Salud Ocupacional en México. México: UNAM. 
Lock. E. y Latham, G. (1990) Work Motivation, The High Performance Cycle. New Jersey: Lea. Londoño, C. (2009). Optimismo y salud positiva como predictivos de la adaptación a la vida universitaria. Acta Colombiana de Psicología, 12(1), 95-107.

Londoño, C., Velasco, M., Alejo, I., Botero, P., \&Vanegas, J. (2014). ¿Qué nos hace optimistas?: Factores psicosociales predictores al optimismo disposicional en jóvenes. Terapia Psicológica, 32 (2), 153-164. Doi: 10.4067/S0718-48082014000200008

Londoño-Pérez, C. (2009). Optimism and positive health as predictors of adjustment to university life. Acta Colombiana de Psicologia, 12(1), 95-107.

Londoño-Pérez, C., \& Velasco-Salamanca, M. (2015). Estilo de afrontamiento, optimismo disposicional, depresión, imagen corporal, imc, y riesgo de tca como predictores de calidad de vida relacionada con la salud. Psychologia: Avances de La Disciplina, 9(2), 35-47.

López, J. y Sanín, A. (s.f.). Clima organizacional, compromiso, motivación, felicidad y optimismo por género. Sometido

López-Ibor, R., Mangas, L., Cornejo, J., \& Vadillo, M. (2010). Las políticas de conciliación de la vida familiar y laboral desde la perspectiva del empleador: Problemas y ventajas para la empresa. Cuadernos de Trabajo. Escuela Universitaria de Estadística, (2), 1-29.

Lykken, D., y Tellegen, A. (1996). Happiness is a stochastic phenomenon. Psychological Science, 7, 186-189.

Lyrakos, G. N., Damigos, D., Mavreas, V., Georgia, K., \& Dimoliatis, I. D. K. (2010). A translation and validation study of the life orientation test revised in the Greek speaking population of nurses among three hospitals in Athens and Ioannina. Social Indicators Research, 95(1), 129-142. http://doi.org/10.1007/s11205-009-9453-6

Lyubomirsky, S. (2001). Why are some people happier than others? The role of cognitive and motivational processes in well-being. American Psychologist, 56(3), 239-249.Doi: 10.1037/0003-066x.56.3.239

Lyubomirsky, S. (2008a). La ciencia de la felicidad. Barcelona: Urano.

Lyubomirsky, S. (2008b). The how of happiness. New York: Penguin Press.

Lyubomirsky, S. (2014). Los mitos de la felicidad. Ediciones Urano: España

Lyubomirsky, S., \& Lepper, H. (1999). A measure of subjective happiness: Preliminary reliability and construct validation. Social Indicators Research, 46, 137-155.

Lyubomirsky, S., Dickerhoof, R., Boehm, J. K., \& Sheldon, K. M. (2011). Becoming happier takes both a will and a proper way: An experimental longitudinal intervention to boost wellbeing. Emotion, 11(2), 391-402. http://doi.org/10.1037/a0022575 
Lyubomirsky, S., Sheldon, K. M., \& Schkade, D. (2005). Pursuing happiness: The architecture of sustainable change. Review of General Pscyhology, 9(2), 111-131. Doi: 10.1037/10892680.9.2.111

Lyubomirsky, S., y Lepper, H. S. (1999). A measure of subjective happiness: Preliminary reliability and construct validation. Social Indicators Research, 46 (2), 137-155.

Lyubomirsky, S., y Tucker, K. (1998). Implications of individual differences in subjective happiness for perceiving, interpreting, and thinking about life events. Motivation and Emotion, 22(2), 155-186. doi:10.1023/A:1021396422190

Marshall, G. N., Wortman, C. B., Kusulas, J. W., Hervig, L. K., \& Vickers, R. R. (1992). Distinguishing optimism from pessimism: Relations to fundamental dimensions of mood and personality. Journal of Personality and Social Psychology, 62(6), 1067-1074. http://doi.org/10.1037/0022-3514.62.6.1067

Martínez, A., Reyes, G., García, A. y Gonzáles, M. (2006). Optimismo/pesimismo disposicional y estrategias de afrontamiento del estrés. Psicothema, 18(1), 66-72.

Martínez, M. (2008, Octubre). Engagement. Ponencia presentada en el V Simposio Internacional sobre Clima Organizacional, Agentes Facilitadores y Diferenciadores organizado por el Centro de Investigación en Comportamiento Organizacional - Cincel. Medellín, Colombia.

Martínez-Correa, A., Reyes, G. A., García-León, A., \& Isabel, M. (2006). Optimismo / pesimismo disposicional y estrategias de afrontamiento del estrés. Psicothema, 18(1), 6672. http://doi.org/10.2307/3537281

McGraw K.O. y Wong S.P. (1996) Forming inferences about some intraclass correlation coefficients. Psychological Methods 1, 30-46.

Mendoza, M. y Gómez, B. (20111) Felicidad: análisis de drivers entre Chile y Canadá Miguel. Estudios de Administración. 18(1). 1-21.

Meneghel, I., Borgogni, L., Miraglia, M., Salanova, M., \& Martínez, I. M. (2016). From social context and resilience to performance through job satisfaction: A multilevel study over time. Human Relations, 69 (11). Doi: 10.1177/0018726716631808

Meyers, C. M., van Woerkom, M., \& Bakker, A. B. (2013). The added value of the positive: A literature review of positive psychology interventions in organizations. European Journal of Work and Organizational Psychology, 22(5), 618-632. http://doi.org/10.1080/1359432X.2012.694689

Meyers, M. C., \& van Woerkom, M. (2016). Effects of a Strengths Intervention on General and Work-Related Well-Being: The Mediating Role of Positive Affect. Journal of Happiness Studies, 1-19. article. http://doi.org/10.1007/s10902-016-9745-x 
Ministerio de la Protección Social (2006). Ley 1090. Bogota: Congreso de la República de Colombia.

Moghnie, L., \& Kazarian, S. S. (2012). Subjective Happiness of Lebanese College Youth in Lebanon: Factorial Structure and Invariance of the Arabic Subjective Happiness Scale. Social Indicators Research, 109(2), 203-210. http://doi.org/10.1007/s11205-011-9895-5

Morales, N. (2008). La libertad para crecer y preferencias de liderazgo. Revista Interamericana de Psicología Ocupacional, 27(2), 87-102.

Moyano, D. E., Flores, M.E. y Soromaa, H. (2011). Fiabilidad y validez de constructo del test MUNSH para medir felicidad, en población de adultos mayores chilenos. Universitas Psychologica, 10 (2), 567-580.

Muchinsky, P. (2002). Psicología Aplicada al Trabajo. México: Thompson Editores.

Newton, N., Khanna, C. y Thompson, J. (2008). Workplace Failure: Mastering the Last Taboo. Consulting Psychology Journal: Practice and Research, 60(3), 227-245.

Norrish, J. M., \& Vella-Brodrick, D. A. (2008). Is the study of happiness a worthy scientific pursuit? Social Indicators Research, 87(3), 393-407. http://doi.org/10.1007/s11205-0079147-x

Novick (2000). La transformación de la organización del trabajo. En E de la Garza (Coord.). Tratado latinoamericano de sociología del trabajo (p.123-146). México: el Colegio de México-Facultad Latinoamericana de Ciencias Sociales (Universidad Autónoma Metropolitana). Fondo de Cultura Económica.

Nunnally, J., \& Berstein, I. (1999). Teoría Psicométrica. (McGraw-Hill, Ed.). México.

OIT (2013). http://www.ilo.org/public/spanish/dialogue/themes/ce.htm consultado el 9 de septiembre de 2015.

Omar, A. y Uribe, H. (2005). Las Dimensiones de Personalidad como Predictores de los Comportamientos de Ciudadanía Organizacional. Estudios de Psicología. 10 (2).

Organización Mundial de la Salud. Constitución de la Organización Mundial de la Salud. Documentos Básicos, Pub. L. No. 45 (2006).

Ortega, A., \& Salanova, M. (2016). Evolución de los modelos sobre el afrontamiento del estrés: hacia el coping positivo. Ágora de Salut, 3, 285-293. http://doi.org/http://dx.doi.org/10.6035/AgoraSalut.2016.3.30

Otake, K., Shimai, S., Tanaka-Matsumi, J., Otsui, K., \& Fredrickson, B. (2006). Happy people become happier through kindness: A counting kindnesses intervention. Journal of Happiness Studies, 7(3), 361-375. Doi: 10.1007/s1002-005-3650-z 
Otero, J. M., Luengo, A., Romero, E., Gómez, J. A., \& Castro, C. (1998). Psicología de la personalidad. Manual de prácticas. (Ariel Practicum, Ed.). Barcelona.

Ouweneel, E., Le Blanc, P. M., \& Schaufeli, W. B. (2013). Do-it-yourself. Career Development International, 18(2), 173-195. http://doi.org/10.1108/CDI-10-2012-0102

Pavot, W. y Diener, Ed. (1993). Review of the Satisfaction With Life Scale. Psychological Assessment, 5(2), 164-172. doi: 10.1037/1040-3590.5.2.164

Pedrosa, I., Celis-Atenas, K., Suárez-Álvarez, J., García-Cueto, E., \& Muñiz, J. (2015). Cuestionario para la evaluación del optimismo: Fiabilidad y evidencias de validez. Terapia Psicológica, 33(2), 127-138. http://doi.org/10.4067/S0718-48082015000200007

Pei-shan, L. (2014). More Happy or Less Unhappy? Comparison of the Balanced and Unbalanced Designs for the Response Scale of General Happiness. Journal of Happiness Studies, 15(6), 1407-1423. http://doi.org/10.1007/s10902-013-9484-1

Pérez, C. L. (2009). Optimism and positive health as predictors of adjustment to university life. Acta Colombiana de Psicología, 12(1), 95-107.

Peterson, C., Park, N. \& Seligman, M. (2005). Orientations to happiness and life satisfaction: the full life versus the empty life. Journal of Happiness Studies, 6(1), 25-41. Doi: $10.1007 /$ s10902-004-1278-z

Piqueras, J., Kuhne, W., Vera-Villarroel, P., van Straten, A. \& Cuijpers, P. (2011). Happiness and health behaviours in Chilean college students: A cross-sectional survey. BMC Public Health, 11(1), p.443.Doi: 10.1186/1471-2458-11-443

Podsakoff P.M., Mackenzie S.B., Lee J. y Podsakoff N.P. (2003) Common Method Biases in Behavioural Research: A critical review of the literature and recommended remedies. Journal of Applied Psychology, 5, 879-903.

Podsakoff, P. M., MacKenzie, S. B., \& Podsakoff, N. P. (2011). Sources of Method Bias in Social Science Research and Recommendations on How to Control It. Annual Review of Psychology, 63(1), 539-569. http://doi.org/10.1146/annurev-psych-120710-100452

Polivy, J. y Herman, P. (2002). If at First You Don't Succeed False Hopes of Self-Change. American Psychologist, 57(9) 677-689.

Positive Psychology Center. (2015). Authentic Happiness Website. Disponible en www.authentichappiness.sas.upenn.edu . Consultado el 16 de marzo de 2015.

Preacher, K. J., \& Hayes, A. F. (2004). SPSS and SAS procedures for estimating indirect effects in simple mediation models. Behavior research methods, instruments, \& computers, 36(4), 717-731. Doi: 10.3758/bf03206553 
Questionnaire Center | Authentic Happiness. (2016). Retrieved October 25, 2016, from https://www.authentichappiness.sas.upenn.edu/es/testcenter

Quick, J. C., \& Quick, J. D. (2004). Healthy, happy, productive work: A leadership challenge. Organizational Dynamics, 33(4), 329-337. http://doi.org/10.1016/j.orgdyn.2004.09.001

Raaijmakers, Q. a W., Hoof, A. Van, Hart, H. 'T, Verbogt, T. F. M. a, \& Vollebergh, W. a M. (2000). Adolescents' midpoint responses on Likert-type scale items : neutral or missing values? International Journal of Public Opinion Research, 12(2), 208-216.

Rauch, W. A., Schweizer, K., \& Moosbrugger, H. (2007). Method effects due to social desirability as a parsimonious explanation of the deviation from unidimensionality in LOT-R scores. Personality and Individual Differences, 42(8), 1597-1607. JOUR. http://doi.org/10.1016/j.paid.2006.10.035

Rego, A., Ribeiro, N., \& Cunha, M. (2010). Perceptions of organizational virtuousness and happiness as predictors of organizational citizenship behaviors. Journal of Business Ethics, 93(2), 215-235. doi:10.1007/s10551-009-0197-7

Rentería, E. (2008). Nuevas realidades organizacionales y del mundo del trabajo: implicaciones para la construcción de la identidad o del sujeto. Informes Psicológicos, 10(10), 65-80.

Rifkin, J. (2014). La sociedad de coste marginal cero. El Internet de las cosas. El procomún colaborativo y el eclipse del capitalismo. Barcelona, España: Espasa Libros.

Rodriguez y Canal (2011). Is workers' effort sensitive to contract type and firm ownership. The spanish case. Economía laboral, 9, 1-27.

Rodríguez-Gutiérrez, C., \& Canal-Domínguez, J. F. (2012). Is Workers' Effort Sensitive to Contract Type and Firm Ownership? The Spanish Case. Revista de Economía Laboral, 9(1), 1-27. Retrieved from http://www.unioviedo.es/Revistas/REL/articulos/n9/n9art1.pdf

Rodríguez-Muñoz, A., \& Sanz-Vergel, A. I. (2013). Happiness and well-being at work: A special issue introduction. Revista de Psicología del Trabajo y de las Organizaciones, 29(3), 95-97. Doi: 10.5093/tr2013a14

Romero, O (1994). Crecimiento Psicológico y Motivaciones Sociales. Revista Interamericana de Psicología Ocupacional, 13 (2), 93-106.

Romero, O. (1999). Crecimiento Psicológico y Motivaciones Sociales (3 ed.). Mérida: Rogya.

Rondón-Bernard, J. E., \& Angelucci-Bastidas, L. T. (2016). Análisis psicométrico del Life Orientation Test (LOT-R) en población diabética venezolana. Ansiedad y Estrés, 22(1), 1118. http://doi.org/10.1016/J.ANYES.2016.02.002 
Rothwell, W., Hohne, C., \& King, S. (2000). Human Performance Improvement. Houston: Gulf Publishing Company.

Sakamoto, S., \& Tanaka, E. (2002). A study of the Japanese version of revised Life Orientation Test. Japanese Journal of Health Psychology, 15(1), 59-63. JOUR. http://doi.org/10.11560/jahp.15.1_59

Salamanca, R. M. V., \& Pérez, C. L. (2011). Calidad de vida objetiva, optimismo y variables socio-jurídicas, predictivos de la calidad de vida subjetiva en Colombianos desmovilizados. Avances En Psicología Latinoamericana, 29(1), 114-128.

Salanova, M., Llorens, S., Acosta, H., \& Torrente, P. (2013). Positive Interventions in Positive Organizations. Terapia Psicológica, 31(1), 101-113. http://doi.org/10.4067/S071848082013000100010

Salanova, M., Llorens, S., Cifre, E. \& Martinez, I. (2012). We Need a Hero! Toward a Validation of the Healthy and Resilient Organization (HERO) Model. Group \& Organization Management, 37(6), 785-822. Doi: 10.1177/1059601112470405

Salom, C., y Romero, O. (1994). Crecimiento Psicológico y Motivaciones Sociales en Trabajadores Industriales. Revista Interamericana de Psicología Ocupacional, 13 (2), 107116.

Sanín Posada, A. (2016). Personas y Organizaciones más Felices ¿Cómo Lograrlo? Conferencia presentada en el marco del evento Conferencias Trimestrales. Medellín: Cincel.

Sanín, A. \& Salanova, M. (2014). Satisfacción laboral: el camino entre el crecimiento psicológico y el desempeño laboral en empresas colombianas industriales y de servicios. Universitas Psychologica, 13(1). 95-107. Doi:10.11144/Javeriana.UPSY13-1.slcp

Sanín, A. \& Salanova, M. (2015). Adaptación del Authentic Happiness Inventory (AHI) para población trabajadora colombiana. Revista Interamericana de Psicología Ocupacional. 34 (2). 76-83

Sanín, A. \& Salanova, M. (n.d.). Verificación de las condiciones psicométricas del Test de Orientación en la Vida (LOT-R) aplicado en población trabajadora Colombiana. Sometido.

Sanín, A. (2007), Estudio de Diferencias en Apoyo del Jefe e Imagen Gerencial asociadas al Género, Nivel Educativo y Nivel Jerárquico. Revista Interamericana de Psicología Ocupacional. 26 (2), 38-62.

Sanín, A. (2010). Validación Psicométrica de un Conjunto de Instrumentos Que miden Factores Psicosociales Disposicionales. Revista Interamericana de Psicología Ocupacional, 29(2), 146-173. 
Sanín, A. (2015). Felicidad en el Trabajo. Ponencia presentada en el Seminario Organizaciones Saludables: Visión para el desarrollo humano y la competitividad en el siglo XXI. Editorial Universidad Pontificia Bolivariana: Medellín.

Sanín, A. y Restrepo, M (2009). Vinculación Laboral, Motivación y Desempeño de Empleados de Carrera y Supernumerarios en una Universidad del Estado. Revista Interamericana de Psicología Ocupacional, 28(2), 149-183.

Sanín, A., Salanova, M., \& Vera-Villaroel, P (s.f). Efectos de la Intervención de la felicidad y el optimismo sobre el desempeño. Sometido.

Santos, F., Guillén, C., \& Montalbán, F. M. (2012). Contrato de trabajo, compromisso y satisfacción: moderación de la empleabilidad. Revista de Administração de Empresas, 52(2), 345-359. http://doi.org/10.1590/S0034-75902012000300006

Scheier, M. Carver, C. \& Bridges, M. (1994). Distinguishing optimism from neuroticism (and trait anxiety, self-mastery, and self-esteem): A reevaluation of the Life Orientation Test. Journal of Personality and Social Psychology. 67(6). 1063-1078. Doi: 10.1037/00223514.67.6.1063

Scheier, M. F., \& Carver, C. S. (1985). Optimism, coping, and health: assessment and implications of generalized outcome expectancies. Health Psychology, 4(3), 219-247. http://doi.org/10.1037/0278-6133.4.3.219

Schiffrin, H. H., \& Nelson, S. K. (2010). Stressed and happy? Investigating the relationship between happiness and perceived stress. Journal of Happiness Studies, 11(1), 33-39. http://doi.org/10.1007/s10902-008-9104-7

Schiffrin, H.H., Rezendes, H.H., y Nelson, S.K. (2008). Stressed and happy? Investigating the relationship between happiness and perceived stress. Journal of Happiness Studies. doi:10.1007/s10902-008-9104-7.

Segerstrom, S. C., Evans, D. R., \& Eisenlohr-Moul, T. A. (2011). Optimism and pessimism dimensions in the Life Orientation Test-Revised: Method and meaning. Journal of Research in Personality, 45(1), 126-129. JOUR. http://doi.org/10.1016/j.jrp.2010.11.007

Seidlitz, L., Wyer, R. S., \& Diener, E. (1997). Cognitive correlates of subjective well-being: The processing of valenced life events by happy and unhappy persons. Journal of Research in Personality, 31, 240-256.

Seligman M., Steen, T., Park, N. y Peterson, C. (2005). Positive Psychology Progress. Empirical Validation of Interventions. American Psychologist, 60(5), 410-421. DOI: 10.1037/0003-066X.60.5.410

Seligman, M. (2004). Aprenda optimismo. Haga de la vida una experiencia maravillosa. Barcelona: Debolsillo. 
Seligman, M. (2011). La Auténtica Felicidad. Barcelona: ZETA

Seligman, M. (2016). Florecer: La nueva psicología positiva y la búsqueda del bienestar. Editorial Oceano.

Seligman, M., \& Csikszentmihalyi, M. (2000). Positive psychology: An introduction. American Psychologist, 55(1), 5-14. http://doi.org/10.1037//0003-066X.55.1.5

Seligman, M., \& Csikszentmihalyi, M. (2006). Flow and the Foundations of Positive Psychology: The Collected Works of Mihaly Csikszentmihalyi. Learned optimistm: How to change your mind. http://doi.org/10.1007/978-94-017-9088-8_18

Sheldon, K. M., \& Lyubomirsky, S. (2006). Achieving sustainable gains in happiness: Change your actions, not your circumstances. Journal of Happiness Studies, 7(1), 55-86. http://doi.org/10.1007/s10902-005-0868-8

Sheldon, K. M., y Lyubomirsky, S. (2007). Is It Possible to Become Happier? (And If So, How?). Social and Personality Psychology Compass, 1(1), 129-145.

Sheldon, K., \& Lyubomirsky, S. (2006). Achieving sustainable gains in happiness: Change your actions, not your circumstances. Journal of Happiness Studies, 7(1), 55-86. Doi: 10.1007/s10902-005-0868-8

Sheldon, K., Abad, N., Ferguson, Y., Gunz, A., Houser-marko, L., Nichols, C., y Lyubomirsky, S. (2010). Persistent pursuit of need-satisfying goals leads to increased happiness: A 6month experimental longitudinal study. Motivation and Emotion, 34(1), 39-48. doi:10.1007/s11031-009-9153-1

Shelley, T. \& Silvia, P. (2002). Self-Awareness, Probability of Improvement, and the SelfServing Bias. Journal of Personality and Social Psychology, 82(1), 49-61.

Shepherd, J., Oliver, M., \& Schofield, G. (2014). Convergent Validity and Test-Retest Reliability of the Authentic Happiness Inventory in Working Adults. Social Indicators Research, 124(3), 1049-1058. http://doi.org/10.1007/s11205-014-0812-6

Smyer, M., \& Pitt-Catsouphes, M. (2007). The meanings of work for older workers. Generations, 31(1), 23-30.

Solanes, Á., \& Zaragoza, B. (2010). ¿Trabajo de Preferencia o Contrato Indefinido? Un análisis de su impacto sobre el estado del contrato psicológico. Acciones e Investigaciones Sociales, 28(julio 2010), 57-77.

Sonnentag, S. (2003). Recovery, work engagement, and proactive behavior: a new look at the interface between nonwork and work. Journal of applied psychology, 88(3), 518-528. Doi: 10.1037/0021-9010.88.3.518 
Spagnoli, P., Caetano, A., \& Silva, A. (2012). Psychometric Properties of a Portuguese Version of the Subjective Happiness Scale. Social Indicators Research, 105(1), 137-143. http://doi.org/10.1007/s11205-010-9769-2

Spencer, L., McClelland D. y Spencer, S. (1990). Competency Assessment Methods. History and State of Art. USA: Hay/MCber Researh Press.

Steca, P., Monzani, D., Greco, A., Chiesi, F., \& Primi, C. (2015). Item response theory analysis of the Life Orientation Test-Revised: Age and gender differential item functioning analyses. Assessment. JOUR PMID - 25078402, Sage Publications. http://doi.org/10.1177/1073191114544471

Taborda, H. (2010). Modelos bayesianos de inferencia psicológica: ¿cómo predecir acciones en situaciones de incertidumbre? Universitas Psychologica, 9 (2), 495-507.

Taris, T., \& Schreurs, P. (2009). Well-being and organizational performance: An organizational-level test of the happy-productive worker hypothesis. Work \& Stress, 23(2), 120-136. Doi: 10.1080/02678370903072555

ten Klooster, P. M., Weekers, A. M., Eggelmeijer, F., van Woerkom, J. M., Drossaert, C. H. C., Taal, E., ... Rasker, J. J. (2010). Optimisme en/of pessimisme: Factorstructuur van de Nederlandse Life Orientation Test-Revised. [Optimism and/or pessimism: Factor structure of the Dutch Life Orientation Test-Revised.]. Psychologie \& Gezondheid, 38(2), 89-100. JOUR. http://doi.org/10.1007/BF03089356

Tkach, C., \& Lyubomirsky, S. (2006). How do people pursue happiness?: Relating personality, happiness-increasing strategies, and well-being. Journal of Happiness Studies, 7(2), 183225. Doi:10.1007/s10902-005-4754-1.

Toro F. (2005) Liderazgo Organizacional Objeciones y Quejas sobre el Apoyo del Jefe. Revista Interamericana de Psicología Ocupacional, 24 (1 y 2), 46-59.

Toro, F. (2002). Desempeño y Productividad. Medellín: Cincel.

Toro, F. (2010). Validación Psicométrica de un Conjunto de Instrumentos que Evalúan Efectos Individuales de Diversos Factores Psicosociales. Revista Interamericana de Psicología Ocupacional, 29(2), 193-225.

Toro, F. y Sanín, A. (comp.) (2013). Gestión del Clima Organizacional. Intervención basada en evidencias. Cincel: Medellín.

Toro, F., Londoño, M. E., Sanín, A., y Valencia, M. (2010). Modelo analítico de factores psicosociales en contextos laborales. Revista Interamericana de Psicología Ocupacional, 29(2), 95-137. 
Trottier, C., Trudel, P., Mageau, G., \& Halliwell, W. R. (2008). Validation de la version canadienne-française du Life Orientation Test-Revised. Canadian Journal of Behavioural Science, 40(4), 238-243. http://doi.org/10.1037/a0013244

Tsou, M.-W., \& Liu, J.-T. (2001). Happiness and Domain Satisfaction in Taiwan. Journal of Happiness Studies, 2(3), 269-288. http://doi.org/10.1023/A

Turkheimer, E., Haley, A., Waldron, M., D'Onofrio, B., \& Gottesman, I. (2003). Socioeconomic status modifies heritability of iq in young children. Psychological Science, 14(6), 623-628. Doi: 10.1046/j.0956-7976.2003.psci_1475.x

Uribe, R., Garrido, P., y Rodríguez (2011). Influencia del tipo de contratación en la calidad de vida laboral: manifestaciones del capitalismo organizacional. Revista Virtual Universidad Católica del Norte. 33, 1-17.

Uribe-Rodríguez, A. F., Garrido-Pinzón, J., \& Rodríguez, A. M. (2011). Influencia del tipo de contratación en la calidad de vida laboral: manifestaciones del capitalismo organizacional. Revista Virtual Universidad Católica del Norte, 33, 101 - 116.

Useche, M.C. (2002). La organización del trabajo en el marco de la globalización. Gaceta laboral. 1, 67-78.

Väänänen, A., Kevin, M. V., Ala-Mursula, L., Pentti, J., Kivimäki, M., \& Vahtera, J. (2005). The double burden of and negative spillover between paid and domestic work: associations with health among men and women. Women \& health, 40(3), 1-18. Doi:10.1300/J013v40n03_0

Valdunciel, L., Flórez, M., \& Davila, J.-A. (2007). Análisis de la calidad del servicio que prestan las entidades bancarias y su repercusión en la satisfacción del cliente y la lealtad hacia la entidad. Revista Asturiana De Economía, 38, 79-108.

Vautier, S., \& Raufaste, E. (2006). Configural instability of data from the Life Orientation Test-Revised. Personality and Individual Differences, 40(8), 1511-1518. JOUR. http://doi.org/10.1016/j.paid.2005.10.015

Vautier, S., Raufaste, E., \& Cariou, M. (2003). Dimensionality of the Revised Life Orientation Test and the status of filler items. International Journal of Psychology, 38(6), 390-400. JOUR. http://doi.org/10.1080/00207590344000222

Vázquez, S. (2012). La felicidad en el Trabajo y en la Vida. A coruña, España: Actualiza Editorial.

Velasco, R. y Londoño, C. (2011) Calidad de vida objetiva, optimismo y variables sociojurídicas, predictivos de la calidad de vida subjetiva en colombianos desmovilizados. Avances en Psicología Latinoamericana, 29(1), 114-128. 
Vera, P., Celis, K. y Cordova, N. (2011). Evaluación de la Felicidad: Análisis psicométrico de la escala de felicidad subjetiva en población chilena. Terapia Psicológica. 29(1). 127-133. doi: 10.4067/S0718-48082011000100013.

Vera-Villarroel, P., Contreras, D., Celis-Atenas, K., Lillo, S., Urzua, A., Silva, J. (2016). Los afectos como mediadores de la relación optimismo y bienestar. Revista Argentina Clínica Psicológica (en prensa).

Vera-Villarroel, P., Córdova-Rubio, N. \& Celis-Atenas, K. (2009). Evaluación del Optimismo: Un análisis preliminar del Life Orientation Test Versión Revisada (LOT-R) en población chilena. Universitas Psychologica, 8(1), 61-68.

Vera-Villarroel, P., Pávez, P., \& Silva, J. (2012). El rol predisponente del optimismo: hacia un modelo etiológico del bienestar. Terapia psicológica, 30(2), 77-84. Doi: 10.4067/S071848082012000200008

Vera-Villarroel, P., Piqueras, J., Kuhne, W., Cuijpers, P. \& van Straten, A. (2014). Differences between men and women in self-reported body mass index and its relation to drug use. Subst Abuse Treat Prev Policy, 9(1), 1. Doi: 10.1186/1747-597x-9-1

Vesga Rodríguez, J. J. (2011). Los tipos de contratación laboral y sus implicaciones en el contrato psicológico. Pensamiento Psicológico, 5(16), 171-182. Retrieved from http://dialnet.unirioja.es/descarga/articulo/3668776.pdf \nhttp://dialnet.unirioja.es/servl et/extart?codigo $=3668776$

Wanberg, C. R., \& Banas, J. T. (2000). Predictors and outcomes of openness to changes in a reorganizing workplace. The Journal of Applied Psychology, 85(1), 132-142. http://doi.org/10.1037/0021-9010.85.1.132

Watson, D., Clark, L. a, \& Tellegen, A. (1988). Development and validation of brief measures of positive and negative affect: the PANAS scales. Journal of Personality and Social Psychology, 54(6), 1063-70. http://doi.org/10.1037/0022-3514.54.6.1063

Whitman, D., Van Rooy, D., \& Viswesvaran, C. (2010). Satisfaction, citizenship behaviors, and performance in work units: A meta-analysis of collective construct relations. Personnel Psychology, 63(1), 41-81. Doi: 10.1111/j.1744-6570.2009.01162.x

Wilkin, C. (2012). I can't get no job satisfaction: Meta-analysis comparing permanent and contingent workers. Journal of Organizational Behavior. http://doi.org/10.1002/job.1790

Wiseman, R. (2010). 59 Segundos: Piensa un poco para cambiar mucho. Barcelona: RBA Libros.

Wright, T. \& Cropanzano, R. (2000). Psychological well-being and job satisfaction as predictors of job performance. Journal of Occupational Health Psychology, 5(1), 84-94. Doi: 10.1037/1076-8998.5.1.84 
Wright, T. A., Larwood, L., \& Denney, P. J. (2002). The different "faces" of happiness unhappiness in organizational research: Emotional exhaustion, positive affectivity, negative affectivity, and psychological well-being as correlates of job performance. Journal of Business and Management, 8, 109-126.

Wright, T., Larwood, L., \& Denney, P. (2002). The different 'faces' of happiness - unhappiness in organizational research: Emotional exhaustion, positive affectivity, negative affectivity, and psychological. Journal of Business and Management, 8(2), 109-126. Retrieved from http://search.proquest.com/docview/211508979? accountid=15297

Xia, J., Wu, D., Zhang, J., Xu, Y., \& Xu, Y. (2016). Chinese version of the Optimism and Pessimism Scale: Psychometric properties in mainland China and development of a short form. Journal of Health Psychology, 21(6), 983-993. http://doi.org/10.1177/1359105314544071

Youssef, C. M., \& Luthans, F. (2007). Positive Organizational Behavior in the Workplace: The Impact of Hope, Optimism, and Resilience. Journal of Management, 33(5), 774-800. http://doi.org/10.1177/0149206307305562

Zelenski, J. M., Murphy, S. A., \& Jenkins, D. A. (2008). The happy-productive worker thesis revisited. Journal of Happiness Studies, 9(4), 521-537. http://doi.org/10.1007/s10902-0089087-4

Zenger, M., Finck, C., Zanon, C., Jimenez, W., Singer, S., \& Hinz, A. (2013). Evaluation of the Latin American version of the Life Orientation Test-Revised. International Journal of Clinical and Health Psychology, 13(3), 243-252. http://doi.org/10.1016/S1697-2600(13)70029-2 
ANEXOS

A

\section{INTERVENCIÓN 1}

Salir de la Rutina

Bienvenido

A partir de este momento haces parte del grupo 1.

Durante este mes tu actividad será salir de la rutina. Lo primero que debes hacer es pensar que es lo que típicamente haces en los días de trabajo y luego qué es lo que haces los fines de semana.

Luego de eso debes pensar en hacer alguna actividad social, al menos una vez a la semana en los días laborales. Puede ser simplemente salir a almorzar con amigos o encontrarte con ellos en algún lugar después del trabajo. Si es algo que ya haces, la idea es que incrementes esta conducta o pienses en otras diferentes a las que usualmente haces. Por ejemplo si siempre sales a comer con ellos, intenta invitarlos a hacer algún deporte contigo. También puedes involucrar a tu familia en estas actividades.

Adicionalmente:

Ensaya otras rutas para ir a tu trabajo

Mira algún programa de televisión diferente a los que siempre vez.

Si nunca has ido a teatro: ve una vez

Si casi nunca, o nunca vas a cine, ve al menos una vez este mes. Si es en compañía de otros será mejor.

Empieza a leer algún libro si no es lo que acostumbras.

Piensa en algún proyecto de tu casa que llevas tiempo aplazando y comprométete a terminarlo este mes.

Recuerda hobbies que hacías cuando eras niño o adolescente e intenta hacer de nuevo algunos de ellos. Jugar juegos de video, practicar algún deporte, entre otros.

Si no acostumbras cocinar, hazlo al menos una vez durante este mes.

En fin, la lista podría ser mucho más largo. Pero ya tienes la clave. Sencillamente busca hacer cosas diferentes a las que siempre haces. Entre más, mejor y si es en compañía de otras personas más todavía.

Para facilitar el desarrollo de estas actividades te invito a hacer una lista de cosas que harás para salir de la rutina, prográmalas y adelante. Es importante que cuando termine el mes puedas tener claro qué fue lo que hiciste diferente.

POR ULTIMO EVITA AVERIGUAR QUÉ ESTÁN HACIENDO LOS OTROS COMPAÑEROS QUE ESTÁN PARTICIPANDO EN ESTA INVESTIGACIÓN 


\section{INTERVENCIÓN 2}

\section{Reformulación de Metas}

\section{Bienvenido}

A partir de este momento haces parte del grupo 2.

Durante este mes tu actividad será Cumplir Metas. Lo primero que debes hacer es pensar en dos metas que hayas pensado en alcanzar este año. Concéntrate por lo pronto en metas cuyo logro dependa de tus propios esfuerzos.

A continuación escribe tus metas en un lugar en el que puedas revisarlas constantemente. Cuando lo hagas asegúrate de que la meta tal y como la escribiste responde a las siguientes preguntas:

¿Qué quiero lograr?

¿Cuándo quiero que eso pase?

¿Para qué quiero que eso pase?

Luego de que tengas esto definido debes evaluar las cuatro condiciones que describimos a continuación con una escala de 1 a 5 , en la que 5 indica que esa condición es muy favorable y 1 que es poco favorable

- $\quad$ Especificidad o claridad: Qué tan bien definida está tu meta.

- $\quad$ Dificultad. Tu meta cuenta con un nivel de dificultad modera. No es ni muy fácil ni imposible de alcanzar.

- $\quad$ Relación: tu meta se relaciona con otras cosas que deseas y quieres en tu vida. No es algo aislado y sin sentido.

- $\quad$ Conflicto. Cumplir tu meta no entra en conflicto con otros intereses personales o laborables.

Luego de hacer esta calificación con la mayor honestidad posible, trabaja durante este mes por lograr una calificación de 5 en cada condición de las metas.

Adicionalmente deberás definir las etapas para el cumplimiento de cada meta. A cada etapa le pondrás una fecha límite. Procura cada semana cumplir, al menos, una de las etapas de cada meta. De forma tal que cuando termine el mes ya hayas cumplido con cuatro de estas etapas.

Adicionalmente: Deberás contarle a la mayor cantidad de personas posible las metas que tienes entre manos. Y qué es lo primero que harás.

POR ULTIMO EVITA AVERIGUAR QUÉ ESTÁN HACIENDO LOS OTROS COMPAÑEROS QUE ESTÁN PARTICIPANDO EN ESTA INVESTIGACIÓN 


\section{INTERVENCIÓN 3}

Resignificación del fracaso

\section{Bienvenido}

A partir de este momento haces parte del grupo 3.

Durante este mes tu actividad será Aprender. Lo primero que debes hacer es pensar en dos situaciones problemáticas que te hayan ocurrido recientemente y que consideres que fuiste el principal responsable de que sucedieran. Piensa en cosas del día a día y no en asuntos vitales o emocionalmente difíciles.

A continuación escribe estas dos situaciones asegurándote de mencionar solo lo que sucedió. Evita usar calificativos, juicios o conjeturas. Solo debes describir la situación. Luego responde estas preguntas para cada una

¿Qué pasó?

¿Qué pensé cuando eso pasó?

¿Qué sentí cuando eso pasó?

¿Qué hice cuando eso pasó?

Luego de que hayas hecho ese ejercicio para las dos situaciones vas a hacer una lista de los aprendizajes que te dejo cada una. Esfuérzate y escribe al menos 5 cosas que aprendiste derivadas de cada situación. Piensa en aprendizajes positivos.

Luego de que hagas eso, comparte las dos situaciones con alguien en quien confíes mucho y que juzgues como una persona con mentalidad positiva. Si quieres puedes decirle que estás participando en una investigación para que lo contextualices. A esa persona solo debes contarle lo que pasó y debes pedirle que te diga que hubiera pensado el/ella en la misma situación. Contrasta sus respuestas con las tuyas.

Todo esto debes hacerlo la primera semana. A partir de la segunda semana debes estar muy atento. Pues debes hacer una lista de las situaciones o momentos en los que utilizas lo que aprendiste. No es una lista extensa, Basta con que puedas cuantificar el número de veces que utilizas aquello que aprendiste.

POR ULTIMO EVITA AVERIGUAR QUÉ ESTÁN HACIENDO LOS OTROS COMPAÑEROS QUE ESTÁN PARTICIPANDO EN ESTA INVESTIGACIÓN

\section{INTERVENCIÓN 4}

\section{Gratitud}

Bienvenido

A partir de este momento haces parte del grupo 4. 
Durante este mes tu actividad será Dar Gracias. Lo primero que debes tener presente es que "gracias" será una palabra que usarás mucho durante este mes. Por pequeño que sea el detalle que alguna persona tenga contigo, debes agradecérselo. No dejes pasar por alto ninguna oportunidad de dar las gracias.

Adicionalmente deberás escribir dos cartas cada semana. Estas deben estar dirigidas a 8 personas a las que les quieras dar las gracias por algo que consideras importante. No es necesario que entregues las cartas, basta con que las escribas. Si las quieres entregar es decisión tuya. Lo que sí es importante es que le escribas las cartas a personas a las que efectivamente puedes entregárselas así no lo vayas a hacer.

Asegúrate que al menos una de las cartas está dirigida a un amigo, otra a un familiar y otra a un compañero de trabajo. Eso para las primeras 7 cartas. La última carta será dirigida a ti mism@.

Las cartas no tienen que ser largas, basta con que escribas qué agradeces, a quién agradeces y porqué eso es o ha sido importante para ti.

Al finalizar el mes debes contar con 8 cartas.

POR ULTIMO EVITA AVERIGUAR QUÉ ESTÁN HACIENDO LOS OTROS COMPAÑEROS QUE ESTÁN PARTICIPANDO EN ESTA INVESTIGACIÓN

\section{INTERVENCIÓN 5}

Amabilidad

Bienvenido

A partir de este momento haces parte del grupo 5.

Durante este mes tu actividad será Amabilidad. Lo primero que debes tener presente es que este mes vas a ser más amable que de costumbre. Por pequeño que sea el detalle, deberás tratar con amabilidad a conocidos y desconocidos. Seguro eso te caracteriza, pero este mes deberás resaltarlo más.

Adicionalmente deberás hacer, mínimo, dos actos de amabilidad cada semana. Estas deben estar dirigidas a 8 personas o grupos diferentes. Tú puedes definir como ejecutar esos actos. Si te resulta difícil he aquí una lista.

Cede: Si estás en una fila, vas en carro, o estás en el transporte público, permite que una persona que lo necesite pasé antes que tú. Cede el pasó o tu silla. Hazlo tantas veces como te resulte posible. 
Ayuda: Si ves que alguien requiere algún tipo de ayuda, asegúrate que eres tu el que la proporciona. No tiene por qué ser económica, basta con que le des una mano a alguien. Escucha: Es posible que el acto de amabilidad más grande sea escuchar a otro cuando lo necesita.

Seguramente la lista puede ser más larga, pero lo ideal es que uses tu creatividad. Entre más "Gracias" recibas de los demás durante cada semana, mejor estarás desarrollando el ejercicio.

POR ULTIMO EVITA AVERIGUAR QUÉ ESTÁN HACIENDO LOS OTROS COMPAÑEROS QUE ESTÁN PARTICIPANDO EN ESTA INVESTIGACIÓN

\section{INTERVENCIÓN 6}

\section{Lápiz en la boca}

Bienvenido

A partir de este momento haces parte del grupo 6.

Durante este mes tu actividad será Lápiz en Boca. Por extraño y descabellado que te pueda parecer lo que tendrás que hacer, es importante que lo hagas diariamente durante el tiempo recomendado.

Aquí va:

Busca o compra un lápiz. Debe ser el mismo lápiz todos los días.

Antes de lavarte los dientes en la mañana pon el lápiz de manera horizontal en tu boca como lo muestra la imagen

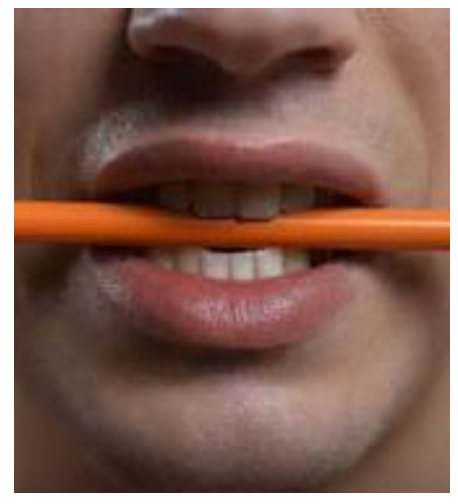

Apriétalo con los dientes NO con los labios. Hazlo con firmeza pero no con mucha fuerza. Mantenlo así durante 30 segundos.

Repite esto en tu hora de almuerzo y cuando llegues de trabajar. 
Recuerda, lo más importante es que ejecutes el ejercicio con la frecuencia definida. Será conveniente además que evites buscar en internet o preguntarle a alguien para qué sirve lo que estás haciendo. Nos comprometemos a explicarte luego cómo funciona. Por ahora es importante que no lo sepas. Ten presente que hacer este ejercicio no te hará daño.

POR ULTIMO EVITA AVERIGUAR QUÉ ESTÁN HACIENDO LOS OTROS COMPAÑEROS QUE ESTÁN PARTICIPANDO EN ESTA INVESTIGACIÓN

\section{INTERVENCIÓN 7}

\section{Placebo}

Bienvenido

A partir de este momento haces parte del grupo 7.

Durante este mes tu actividad será "escribir tus gustos". La idea es que dos veces cada semana escribas qué es lo que más te gusta hacer y por qué.

Tu actividad es sencilla. Así que no intentes hacerla toda en una semana o un día. Lo importante es que pienses en dos días de la semana en los que harás la actividad. Es decir que deberás programar 8 días durante este mes. Cuando se llegue el día definido debes tomar una hoja de papel y completar la frase "Una de las cosas que más me gusta hacer es...." Luego escribe de manera breve, porque te gusta.

Recuerda, lo más importante es que ejecutes el ejercicio con la frecuencia definida. Será conveniente además que evites buscar en internet o preguntarle a alguien para qué sirve lo que estás haciendo. Este servirá en la medida que no te des cuenta. Ten presente que hacerlo no te hará daño.

POR ULTIMO EVITA AVERIGUAR QUÉ ESTÁN HACIENDO LOS OTROS COMPAÑEROS QUE ESTÁN PARTICIPANDO EN ESTA INVESTIGACIÓN

\section{INTERVENCIÓN 8}

\section{Control}

\section{Bienvenido}

A partir de este momento haces parte del grupo 8.

Durante este mes tu actividad será "Seguir la rutina". Lo que tienes que hacer es diligenciar los cuestionarios cuando te corresponda y asegurarte de que tu jefe también lo haga. Intenta durante este mes hacer lo que siempre haces. Intenta no salir de tu rutina. Haz durante este mes lo que acostumbras. 
POR ULTIMO EVITA AVERIGUAR QUÉ ESTÁN HACIENDO LOS OTROS COMPAÑEROS QUE ESTÁN PARTICIPANDO EN ESTA INVESTIGACIÓN

\section{INTERVENCIÓN 9}

\section{Espera}

\section{Bienvenido}

A partir de este momento haces parte del grupo 9.

Durante este mes tu actividad será "Esperar". Tu grupo es un grupo especial. Ha sido seleccionado para esperar mientras conocemos cuál de todas las estrategias que estamos implementando para mejorar los estados afectivos es la más exitosa luego se te enviará la información.

Mientras eso sucede lo único que te pedimos es diligenciar los cuestionarios cuando te corresponda y asegurarte de que tu jefe también lo haga. Intenta mientras esperas seguir con tu vida normalmente.

POR ULTIMO EVITA AVERIGUAR QUÉ ESTÁN HACIENDO LOS OTROS COMPAÑEROS QUE ESTÁN PARTICIPANDO EN ESTA INVESTIGACIÓN

INTERVENCIÓN 10

Combina 1 y 6

INTERVENCIÓN 11

Combina 2 y 5

INTERVENCIÓN 10

Combina 3 y 4

B

\section{CUESTIONARIOS}

\section{AFECTOS POSITIVOS Y TRABAJO}

En esta investigación se quiere explorar algunas emociones positivas que experimentan las personas y su relación con el mundo del trabajo. Su aporte será fundamental para 
desarrollar teorías y modelos aplicables a nuestro país. Por ese motivo le agradecemos mucho su participación.

Recuerde que está en libertad de decidir si quiere o no participar en esta investigación. Tenga presente que sus datos serán tratados con total reserva y confidencialidad. Sus respuestas solo serán usadas para describir resultados de grupos y nunca de manera individual. También tiene derecho a pedir que sus resultados sean retirados de la base de datos en cualquier momento.

En ninguno de las encuestas hay respuestas buenas o malas. Todas ellas son válidas. Lo ideal es que conteste de acuerdo con lo que piensa o siente de verdad. Intente responder rápidamente, no se detenga mucho a analizar cada pregunta.

\section{INVENTARIO DE EMOCIONES POSITIVAS}

A continuación se presentan 13 ítems. Usted deberá responder cada uno pensando primero en su trabajo y después en su vida en general. Por favor, lea cada grupo de afirmaciones atentamente. Después, elija la afirmación de cada grupo que mejor describa la forma en la que se ha sentido durante la semana pasada, incluyendo hoy mismo (piense primero en su trabajo y luego en su vida). Después de haber decidido qué responder vaya a la hoja de respuestas y marque en la columna correspondiente la letra que eligió. Proceda como muestra el siguiente ejemplo.

\section{EJEMPLO}

\section{7}

A. Normalmente estoy aburrido.

B. Normalmente no estoy ni aburrido ni contento.

C. Normalmente me siento bien.

D. Normalmente estoy muy animado.

E. Siempre estoy contento

12

A. Cuando estoy alegre no logro concentrarme

B. Cuando estoy alegre, presto la misma atención a lo que sucede alrededor que a lo que estoy haciendo.

C. Cuando estoy alegre, presto más atención a lo que estoy haciendo que a lo que sucede a mi alrededor.

D. Cuando estoy alegre, casi no me doy cuenta de lo que sucede a mi alrededor.

E. Cuando estoy alegre, presto tanta atención a lo que estoy haciendo que el mundo exterior deja prácticamente de existir. 
Supongamos que en el ítem 7 usted se siente identificado con la opción "C" en el caso del trabajo y con la opción “D” en la vida en general. Entonces busca el ítem 7 en la hoja de respuestas y marca como se muestra en la figura.

Ahora supongamos que en el ítem 12 usted decide que las opciones que mejor lo describen son la " $A$ " cuando piensa en su trabajo y la "E" cuando piensa en su vida en general. Entonces marca como muestra la figura.

Asegúrese de haber leído todas las afirmaciones de cada grupo antes de realizar su elección. Recuerde que en la columna de la izquierda en la hoja de respuestas "Con el trabajo" responderá pensando en su trabajo. En la columna "Con la vida", lo hará pensando en su vida en general. Es importante que mantenga presente que no existen respuestas buenas o malas. Toda la información recopilada será muy valiosa para la investigación y será protegida bajo el principio de confidencialidad.

\section{1}

A. Normalmente estoy en un mal estado de ánimo.

B. Normalmente estoy en un estado de ánimo que no es bueno ni malo.

C. Normalmente tengo un buen estado de ánimo.

D. Normalmente tengo un muy buen estado de ánimo.

E. Normalmente tengo un estado de ánimo increíblemente bueno.

\section{2}

A. Lo que hago no tiene ningún propósito o sentido.

B. No sé cuál es el propósito o sentido de lo que hago.

C. Tengo una ligera idea sobre cuál es mi propósito de lo que hago.

D. Tengo una idea bastante buena sobre el propósito o sentido de lo que hago.

E. Tengo una idea muy clara sobre cuál es el propósito o de lo que hago.

\section{3}

A. Rara vez consigo lo que quiero.

B. Algunas veces, consigo lo que quiero, y otras veces no.

C. Conseguir lo que quiero es algo más frecuente que infrecuente.

D. Normalmente consigo lo que quiero.

E. Siempre consigo lo que quiero.

A. Tengo tristeza.

B. No tengo ni tristeza ni alegría.

C. Tengo más alegría que tristeza.

D. tengo mucha más alegría que tristeza.

E. Estoy lleno(a) de alegría.

A. La mayoría del tiempo estoy aburrido(a).

B. La mayoría del tiempo no estoy aburrido(a) ni interesado(a) en lo que estoy haciendo.

C. La mayoría del tiempo estoy interesado(a) en lo que estoy haciendo.

D. La mayoría del tiempo estoy muy interesado(a) en lo que estoy haciendo. 
E. La mayoría del tiempo me entusiasma lo que estoy haciendo.

6

A. Me siento aislado(a) de las demás personas.

B. No me siento unido(a) ni aislado(a) de las demás personas.

C. Me siento unido(a) a mis amigos y a mi familia.

D. Me siento unido(a) a la mayoría de la gente, incluso aunque no les conozca bien.

E. Me siento unido(a) a todas las personas del mundo.

\section{7}

A. El tiempo pasa lentamente en la mayoría de las cosas que hago.

B. El tiempo pasa rápidamente en algunas de las cosas que hago y lentamente en otras.

C. El tiempo pasa rápidamente en la mayoría de las cosas que hago.

D. El tiempo pasa rápidamente en todas las cosas que hago.

E. El tiempo pasa tan rápidamente durante todas las cosas que hago que incluso ni me doy cuenta de ello.

\section{8}

A. Tengo poco o ningún entusiasmo.

B. Mi nivel de entusiasmo no es ni alto ni bajo.

C. Tengo una buena cantidad de entusiasmo.

D. Me siento entusiasmado(a) al hacer casi todo.

E. Tengo tanto entusiasmo que siento que puedo hacer casi cualquier cosa.

\section{9}

A. No me gusta lo que hago (pagado o no pagado).

B. Lo que hago ni me gusta ni me disgusta.

C. En su mayor parte, me gusta lo que hago.

D. Realmente me gusta lo que hago.

E. Verdaderamente me encanta lo que hago.

\section{0}

A. Soy pesimista sobre el futuro.

B. No soy ni optimista ni pesimista sobre el futuro.

C. Soy algo optimista sobre el futuro.

D. Soy bastante optimista sobre el futuro.

E. Soy extraordinariamente optimista sobre el futuro.
A. He logrado poco.
B. No he logrado ni más ni menos que la mayoría de las personas.
C. He logrado algo más que la mayoría de la gente.
D. He logrado más que la mayoría de la gente.
E. He logrado muchísimo más que la mayoría de la gente.

A. Si existiera un marcador, iría perdiendo en comparación con la mayoría de la gente.

B. Si existiera un marcador, el resultado sería empate en comparación con la mayoría de la gente.

C. Si existiera un marcador, llevaría algo de ventaja en comparación con la mayoría de la gente.

D. Si existiera un marcador, iría ganando en comparación con la mayoría de la gente. 
E. Si existiera un marcador, iría ganando por mucha ventaja en comparación con la mayoría de la gente

A. Experimento más sufrimiento que placer.

B. Experimento placer y sufrimiento en la misma medida.

C. Experimento más placer que sufrimiento.

D. Experimento mucho más placer que sufrimiento.

E. Todo está lleno de placer.

\section{TEST DE ORIENTACIÓN EN LA VIDA}

En este caso se quiere explorar algunas creencias y actitudes que pueden tener las personas en relación con su empresa, con su propio trabajo y con la vida en general. Para cumplir con este propósito usted deberá responder 10 ítems que se presentan a continuación pensando primero en su empresa, después en su trabajo y finalmente en su vida en general. Esto lo hará con base en la siguiente escala:
4. Totalmente de acuerdo
3. En buena parte de acuerdo
2. En buena parte en desacuerdo
1. Totalmente en desacuerdo
0 . No estoy seguro del asunto

\section{EJEMPLO}

Supongamos el ítem: 1 . Siempre espero lo mejor

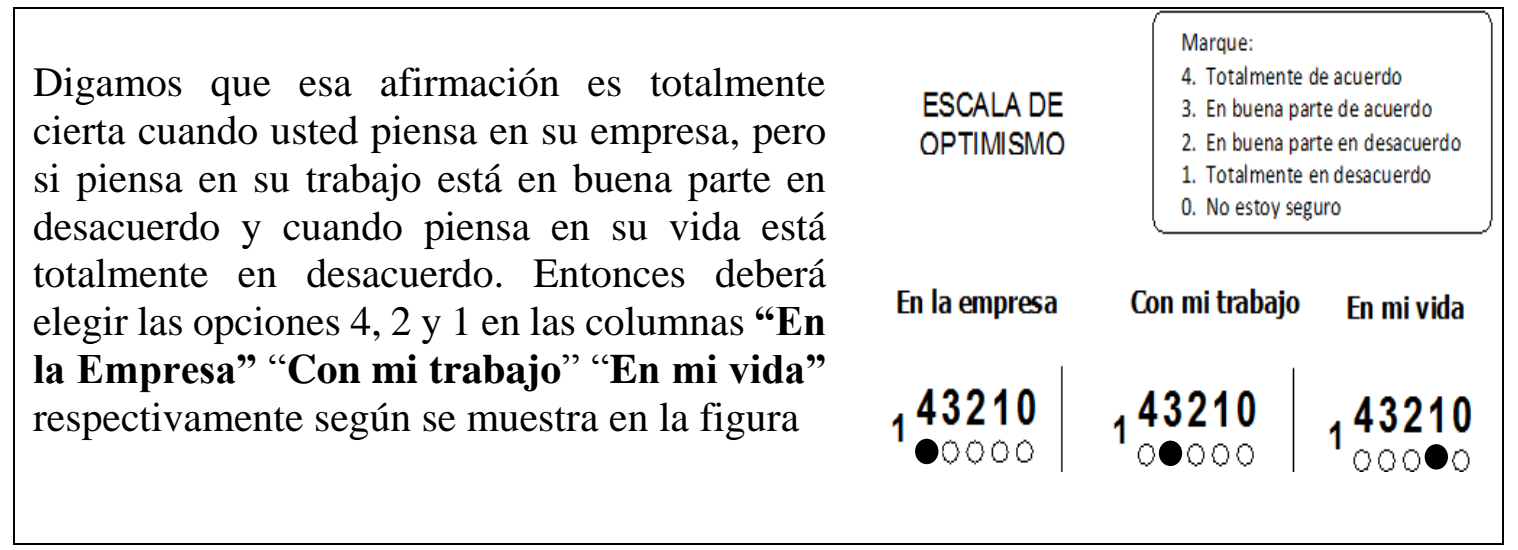

Recuerde, en la columna "En la Empresa” responda pensando en su empresa en general (si no trabaja en una empresa deje esa columna en blanco). En la Columna "Con mi trabajo" hágalo pensando en las actividades de trabajo que están bajo su control y en la columna "En mi vida" responda pensando en su vida en general. Recuerde que no existen respuestas buenas o malas y que toda la información recopilada será protegida bajo el principio de confidencialidad

1. En tiempos difíciles, suelo esperar lo mejor

2. Me resulta fácil relajarme

3. Si algo malo me tiene que pasar, estoy seguro de que me pasará 
4. Siempre soy optimista en cuanto al futuro

5. Disfruto un montón de mis amistades

6. Para mí es importante estar siempre ocupado

7. Rara vez espero que las cosas salgan a mi manera

8. No me disgusto fácilmente

9. Casi nunca cuento con que me sucedan cosas buenas

10. En general, espero que me ocurran más cosas buenas que malas

\section{ESCALA DE SATISFACCIÓN CON LA VIDA}

En este caso se presentan cinco afirmaciones con las que usted puede estar de acuerdo o en desacuerdo. Con base en la escala que se presenta a continuación indique su nivel de acuerdo con cada afirmación. Por favor sea abierto y honesto en su respuesta. Tenga en cuenta que el procedimiento de respuesta es similar a los anteriores.
6. totalmente de acuerdo
5. de acuerdo
4. un poco de acuerdo
3. ligeramente en desacuerdo
2. en desacuerdo
1. muy en desacuerdo

1. El tipo de vida que llevo se parece al tipo de vida que siempre soñé llevar

2. Las condiciones de mi vida son excelentes

3. Estoy satisfecho con mi vida

4. Hasta ahora he obtenido las cosas importantes que quiero en la vida

5. Si pudiera vivir mi vida de nuevo, me gustaría que todo volviese a ser igual 


\section{AGRADECIMIENTOS}

A los profesores de guitarra que no conocí, a los instructores de baile que debieron seguir su trabajo con una pareja menos, a los chefs que esperaban compartirme sus recetas pero no lo hicieron porque nunca estuve allí, a los productores de video juegos que se quedaron con una caja más en su inventario. A mi esposa, Carolina, por no pedirme que toque bien la guitarra, que baile mejor o que cocine algo diferente a lo de siempre. Sí. A ella en especial toda mi gratitud. Nunca se quejó y tuvo miles de razones para hacerlo.

Y también hay muchos otros a los que quiero gradecer y a todos por diversas razones.

A mis padres Olga y John y a mis hermanos (el viejo y los nuevos). Su apoyo y su credibilidad en mi hicieron que, aun cuando las cosas no salían como esperaba, siempre siguiera adelante.

A mis mejores amigos, que lo siguen siendo a pesar de mí.

A mis compañeros de trabajo que nunca me echaron en cara que los abandonara dos años y luego tres meses. Se encargaron de mi trabajo con tanto empeño y calidad que hasta he pensado que ya no me necesitan.

A Cincel, el hogar donde trabajo, que me apoyó, creyó en mí y me estímulo para sacar este reto adelante y allí, especialmente, a Fernando y Teresa. Sus vidas y obras me inspiraron.

A Marisa, mi tutora. Supo estar atenta a pesar de la distancia, me animo a seguir adelante, confió en mí y me sirvió de guía.

Y finalmente a la oportunidad de agradecer. iSoy feliz cuando lo hago! 